Pirineos. Revista de Ecología de Montaña

Vol. 172

Jaca, Enero-Diciembre, 2017, e032

ISSN-L: 0373-2568

doi: http://dx.doi.org/10.3989/pirineos.2017.172007

\title{
CONTRIBUCIÓN AL CONOCIMIENTO DE LA BIODIVERSIDAD FÚNGICA DEL PARQUE NACIONAL DE ORDESA Y MONTE PERDIDO II
}

\section{Contribution to the knowledge of the fungal biodiversity of Ordesa and Monte Perdido National Park II}

F. Pancorbo ${ }^{1 *}$, M.A. Ribes ${ }^{2}$, F. Esteve-Raventós ${ }^{3}, J$. Hernanz ${ }^{4}$, I. Olariaga ${ }^{5}$, P.P. Daniëls ${ }^{6}$, A. Hereza ${ }^{7}$, S. Sánchez ${ }^{8}$, J.F. Mateo ${ }^{9}$, F. Serrano ${ }^{10}$

\author{
${ }^{1}$ Pintores del Paular 25, 28740 Rascafría, Madrid. \\ ${ }^{2}$ Avenida Pablo Neruda 120, 28018 Madrid. \\ ${ }^{3}$ Departamento de Ciencias de la Vida (Botánica), Universidad de Alcalá, 28805 Alcalá de Henares, Madrid. \\ ${ }^{4}$ San José de Calasanz 7 b, $2^{\circ}$ I, 22700 Jaca, Huesca.
}

${ }^{5}$ Departamento de Biología Vegetal y Ecología (Botánica), Universidad del País Vasco (UPV/EHU), Apartado 644, 48080 Bilbao.

${ }^{6}$ Dpto. de Botánica, Ecología y Fisiología Vegetal, Ed. Celestino Mutis, $3{ }^{a}$ pta., Campus de Rabanales, Universidad de Córdoba, 14071 Córdoba. ${ }^{7}$ Pilar Lorengar 5, 3B, 22004 Huesca.

${ }^{8}$ Unidad de Recursos Forestales, Centro de Investigación y Tecnología Agroalimentaria de Aragón (CITA), Instituto Agroalimentario de Aragón - IA2 (CITAUniversidad de Zaragoza), Avda. Montañana 930, 50059, Zaragoza.

${ }^{9}$ Francisco Suay, $110,1^{\circ} \mathrm{C}, 16004$ Cuenca.

${ }^{10}$ Cno. Puente Virrey 6, 4 ${ }^{\text {a }}, 50008$ Zaragoza.

Identificador ORCID de los autores y e-mail:

F. Pancorbo: http://orcid.org/0000-0002-2397-177X E-mail: fpmaza@gmail.com

M. A. Ribes: http://orcid.org/0000-0003-2994-442X Email: miguelangel.ribes@gmail.com

F. Esteve-Raventós: http://orcid.org/0000-0001-8265-5067 E-mail: fernando.esteve@uah.es

J. Hernanz: http://orcid.org/0000-0001-5005-9279 E-mail: jorgehu@gmail.com

I. Olariaga: http://orcid.org/0000-0002-0334-7750 E-mail: ibai.olariaga@ehu.eus

P. P. Daniëls: http://orcid.org/0000-0002-8125-5341 E-mail: ppdaniels@hotmail.com

A. Hereza: http://orcid.org/0000-0003-2045-503X E-mail: adrian_hereza@hotmail.com

S. Sánchez: http://orcid.org/0000-0003-4331-9794 E-mail: ssanchezd@aragon.es

J. F. Mateo: http://orcid.org/0000-0001-5780-1624 E-mail: jfelixmateo@gmail.com

F. Serrano: http://orcid.org/0000-0002-8952-0656 E-mail: francisco@setasysitios.com

* Autor corresponsal

Recibido: 10-07-2017. Aceptado: 18-09-2017. Fecha de publicación on-line: 10-11-2017

Citation / Cómo citar este artículo: Pancorbo, F., Ribes, M.A., Esteve-Raventós, F., Hernanz, J., Olariaga, I., Daniëls, P.P., Hereza, A., Sánchez, S., Mateo, J.F., Serrano, F. (2017). Contribución al conocimiento de la biodiversidad fúngica del Parque Nacional de Ordesa y Monte Perdido II. Pirineos, 172, e032. doi: http://dx.doi.org/10.3989/pirineos.2017.172007

RESUMEN: En este trabajo se continúa con la revisión taxonómica de las especies recolectadas durante la campaña de 2015 en el Parque Nacional de Ordesa y Monte Perdido. Se añaden al catálogo previo 409 taxones, algunos de ellos de ecología alpina-subalpina, de los cuales el 76\% corresponde al phylum Basidiomycota y el 22,2\% al Ascomycota. Se presentan en forma de listado, y a continuación una selección de 20 descripciones taxonómicas com- 


\title{
• F. PANCORBO ET AL.
}

pletas, que corresponden con especies interesantes, poco frecuentes y posiblemente nuevas en el territorio peninsular. De las especies estudiadas se han encontrado seis que han sido propuestas para el inventario de especies protegidas de la península ibérica y/o Aragón.

Se presenta en este trabajo una primera aproximación, a modo de punta de lanza para evaluaciones posteriores, del grado de conservación de algunos hayedos del Parque a través de la ocurrencia de especies indicadoras.

PALABRAS CLAVE: Catálogo; corología; diversidad; ecología alpina; especies indicadoras; hongos; taxonomía; Huesca; Pirineos.

\begin{abstract}
This paper continues the taxonomic revision of the species collected during the campaign of 2015 in the National Park of Ordesa and Monte Perdido. 409 taxa are added to the previous inventory, some of them from alpine-subalpine ecology, of which $76 \%$ correspond to phylum Basidiomycota and $22.2 \%$ to Ascomycota. They are presented in the form of a check-list, followed by 20 selected taxonomic descriptions of interesting, infrequent species, and those though to be new in the peninsular territory. Among the species determined, six species were included in the proposals for the inventory of protected species of the Iberian Peninsula and/or Aragon.

This paper presents a first approximation, as a platform for later evaluations, of the beech conservation degree in some forests from the Park through the occurrence of indicator species.
\end{abstract}

KEYWORDS: Alpine-ecology; check list; chorology; diversity; fungi; indicator species; taxonomy; Huesca; Pyrenees.

\section{Introducción}

Este trabajo es continuación del iniciado en Ribes et al. (2016), con el objetivo de ampliar el conocimiento de la diversidad fúngica del Parque Nacional de Ordesa y Monte Perdido. Los taxones presentados aquí suponen una adición al catálogo iniciado en el trabajo anterior, bien porque no figuraban en él, bien porque aparecen en nuevas localizaciones.

Durante la campaña del año 2015, se han prospectado algunas zonas de ecología alpina-subalpina que ha permitido recolectar especies ligadas estrictamente a estos hábitats, no muy conocidas, y comprobar la gran adaptabilidad de algunas otras, enormemente ubicuas y que las encontramos tanto en zonas de fondo de valle y hábitat boscoso, como en zonas en el entorno de los $2.000 \mathrm{~m}$ de altitud con una gran exposición solar, nieve, viento y vegetación de pastos de montaña, mezcladas con plantas arbustivas de pequeño porte como Salix pyrenaica, Dryas octopetala, etc. (Fig. 1).

Durante el año 2015 se ha visitado el Parque durante un total de 54 días, bien en grupos o individualmente, con lo que siendo 11 los participantes que lo han visitado, representa un total de 97 visitas individuales. En este trabajo también se incluyen recolectas que quedaron pendientes de determinación en la campaña de 2014, así como alguna de 2016 que se ha considerado conveniente su publicación por ser primera cita para España. Las zonas de actuación son las definidas en la Tabla 1 en la que se ha marcado en color verde las zonas nuevas no definidas en el trabajo anterior.

\section{Materiales y métodos}

La mayor parte de la metodología empleada se ha definido previamente en Ribes et al. (2016). En el caso de las observaciones de Ramaria spp. se ha utilizado un mi- croscopio Nikon Labophot 2 con una cámara clara acoplada para la ilustración de microscopía. Las anotaciones del color se han tomado siguiendo los patrones normalizados de la tabla ISCC-NBS (1964). Las fotografías de microscopía electrónica se han tomado con el microscopio electrónico de barrido del servicio de microscopía de la Universidad de Alcalá de Henares.

Las muestras recolectadas se han deshidratado y se han depositado en el Herbario del Instituto Pirenaico de Ecología (JACA-MICO) y, siempre que ha sido posible, se ha guardado un duplicado, bien en los herbarios personales de los miembros del equipo: Ita Paz (IC), Gonzalo Sánchez Dueñas (GSD), Miguel Ángel Ribes (MAR), o bien en algún herbario oficial: Universidad de Alcalá (AH), Aranzadi, Sociedad de Ciencias (ARANFungi). Asimismo, se han estudiado colecciones de algunos tipos con objeto de compararlos con los taxones del presente estudio; estas colecciones fueron solicitadas y amablemente enviadas por los Herbarios de Génova (G) y Leiden (L).

\subsection{Abreviaturas y símbolos}

CB: Azul de lactofenol.

CR: Rojo Congo.

CRB: Azul de cresilo brillante.

IKI: solución de ioduro potásico 3\% - iodo $1 \%$ en agua.

KOH: Hidróxido potásico.

LBs: Gútulas lipídicas.

Me: Media biométrica.

$\mathrm{N}$ : Número de medidas.

$\mathrm{NH}_{4} \mathrm{OH}$ : Hidróxido amónico (10-15)\%.

Q: Coeficiente longitud/anchura.

Qe: Valor medio de Q.

VBs: Cuerpos vacuolares.

*: estructuras vivas en Ascomycetes.

$\dagger$ : estructuras muertas en Ascomycetes. 


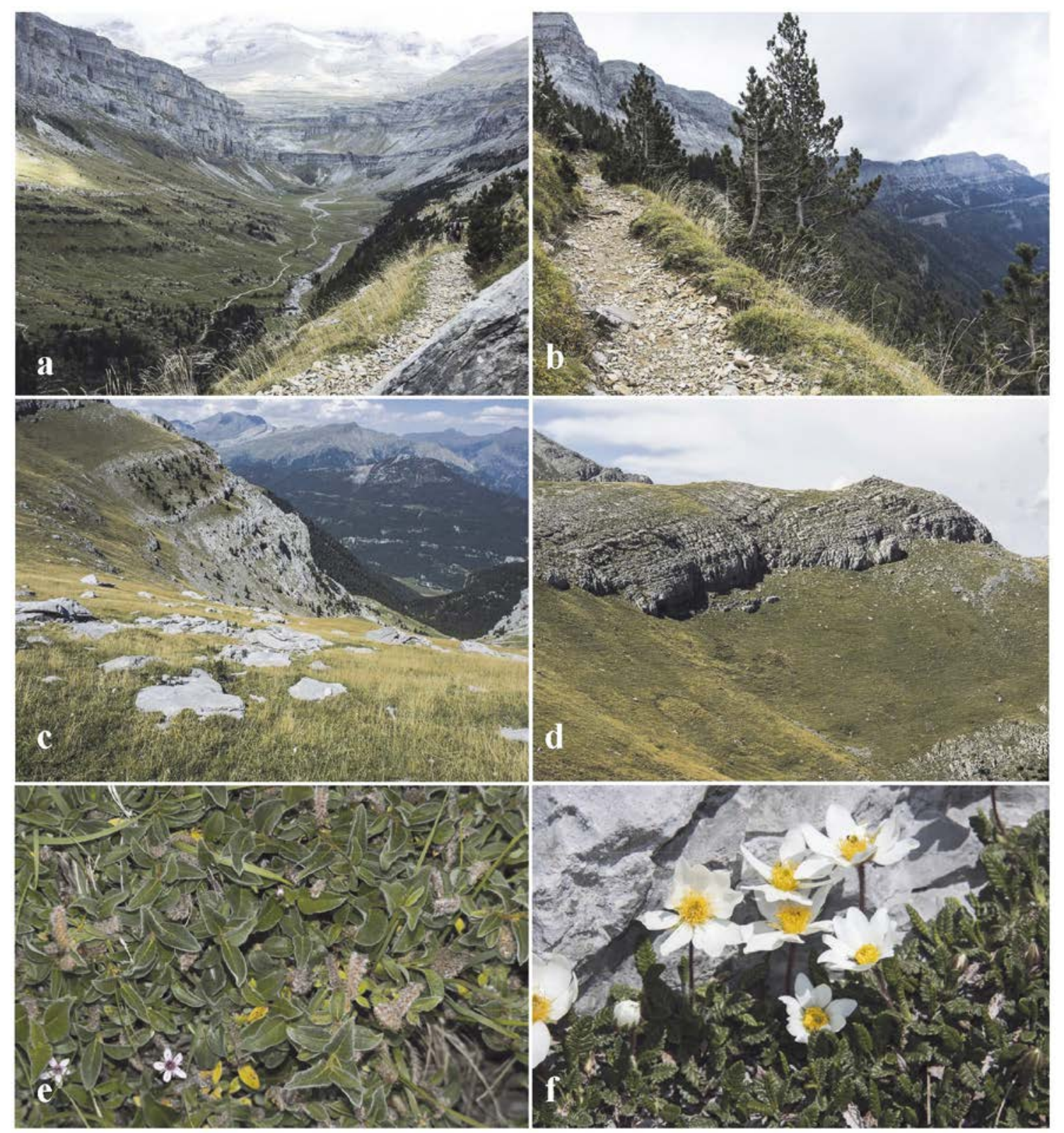

Figura 1: Hábitats alpinos-subalpinos a. Pastos supraforestales en el Circo de Soaso. b. Pinus uncinata en Faja de Pelay. c, d. Prados subalpinos en Portiello de Tella. e. Salix pirenaica. f. Dryas octopetala. Fotos: a-d. F. Pancorbo, e, f. J. Hernanz. Figure 1: Alpine-subalpine habitats a. Circo de Soaso grasslands. b. Pinus uncinata at Faja de Pelay. c, d. Subalpine meadows at Portiello de Tella. e. Salix pirenaica. f. Dryas octopetala. Photos: a-d. F. Pancorbo, e, f. J. Hernanz.

\subsection{Estudios moleculares}

Se han seleccionado siete especímenes en los que la secuenciación tenía especial interés para enriquecer los datos ofrecidos por las recolectas (Tabla 2). Las extracciones de $\mathrm{ADN}$ se realizaron en todos los casos a partir de material seco, empleando el PrepMan® Ultra Sample Preparation Reagent (Applied biosystems ${ }^{\mathrm{TM}}$ ) siguiendo el protocolo descrito por el fabricante. El resultado de la extracción se cuantificó con el espectrofotómetro Thermo Scientific Nanodrop ${ }^{\text {TM }} 2000$ para, posteriormente, diluir las muestras hasta unos 20-100 ng/ $\mu \mathrm{l}$ de ADN. Se seleccionó la región ITS del ADN nuclear comprendida entre los genes $18 \mathrm{~S}$ y $28 \mathrm{~S}$. Para la amplificación por PCR de esta región se emplearon los siguientes reactivos (para cada reacción de $25 \mu$ l totales): $5 \mu \mathrm{l}$ de $5 \mathrm{xMyTaq}^{\mathrm{TM}}$ buffer (Bioline), $1 \mu \mathrm{l}$ de albúmina de suero bovino (SigmaAldrich $\left.{ }^{\circledR}\right)$ preparada a $10 \mathrm{mg} / \mathrm{ml}, 1 \mu \mathrm{l}$ de cada cebador -ITS1F (Gardes \& Bruns, 1993) e ITS4 (White et al., 1990)—, $14 \mu \mathrm{l}$ de agua ultrapura, 0,5 $\mu \mathrm{l}$ de MyTaq $^{\mathrm{TM}}$ DNA Polimerase (Bioline) y 2,5 $\mu \mathrm{l}$ del ADN molde. Las condiciones de la PCR fueron las siguientes: 5 min a $94{ }^{\circ} \mathrm{C}$; 


\section{$4 \cdot$ F. PANCORBO ET AL}

Tabla 1: Localidades prospectadas.

Table 1: Areas of activity.

\begin{tabular}{|c|c|c|c|c|c|c|}
\hline Espacio & Zona & Lugar & Hábitat predominante & $\begin{array}{l}\text { Coordenadas (MGRS, } \\
\text { Datum: ETRS89) }\end{array}$ & Altitud (m) & Municipio \\
\hline \multirow[t]{5}{*}{1} & & Bujaruelo (río Ara) & & & & \\
\hline & 1.1 & $\begin{array}{l}\text { Bujaruelo, San } \\
\text { Nicolás }\end{array}$ & $\begin{array}{l}\text { Pradera, Abies alba, Buxus } \\
\text { sempervirens }\end{array}$ & 30TYN3731 & $1.350-1.400$ & Torla \\
\hline & 1.2 & $\begin{array}{l}\text { Bujaruelo, camino a } \\
\text { San Nicolás }\end{array}$ & $\begin{array}{l}\text { Pradera, Abies alba, Pinus } \\
\text { sylvestris, Buxus sempervirens }\end{array}$ & 30TYN3629, 30TYN3630 & $1.300-1.350$ & Torla \\
\hline & 1.3 & $\begin{array}{l}\text { Bujaruelo, senda } \\
\text { subida al puerto }\end{array}$ & Pradera y Pinus uncinata & 30TYN3731 & $1.600-1.800$ & Torla \\
\hline & 1.4 & $\begin{array}{l}\text { Bujaruelo, Collado } \\
\text { de Otal }\end{array}$ & $\begin{array}{l}\text { Prados supraforestales } \\
\text { salpicados de Pinus uncinata }\end{array}$ & 30TYN3531 & $1.500-1.600$ & Torla \\
\hline \multirow[t]{21}{*}{2} & & Ordesa (río Arazas) & & & & \\
\hline & 2.1 & Ordesa, La Pradera & $\begin{array}{l}\text { Pradera, bosque mixto y bosque } \\
\text { de ribera }\end{array}$ & 30TYN4026, 30TYN4126 & $1.295-1.330$ & Torla \\
\hline & 2.2 & Ordesa, Cotatuero & Bosque de Abies alba & 30TYN4126, 30TYN4226 & $1.295-1.800$ & Torla \\
\hline & 2.3 & Ordesa, Salarons & Bosque mixto & $\begin{array}{l}\text { 30TYN4025, 30TYN4026, } \\
\text { 30TYN4027 } \\
\end{array}$ & $1.250-1.900$ & Torla \\
\hline & 2.4 & Ordesa, Turieto alto & $\begin{array}{l}\text { Bosque de Fagus sylvatica, } \\
\text { Abies alba y Pinus sylvestris }\end{array}$ & $\begin{array}{l}\text { 30TYN3926, 30TYN4025, } \\
\text { 30TYN4026 }\end{array}$ & $1.300-1.400$ & Torla \\
\hline & 2.5 & Ordesa, Turieto bajo & $\begin{array}{l}\text { Bosque de Fagus sylvatica y } \\
\text { bosque mixto }\end{array}$ & 30TYN4026 & 1.300 & Torla \\
\hline & 2.6 & Ordesa, Laña caballo & $\begin{array}{l}\text { Bosque mixto de Fagus } \\
\text { sylvatica y Abies alba }\end{array}$ & $\begin{array}{l}\text { 30TYN4025, 30TYN4125, } \\
\text { 30TYN4026, 30TYN4126 }\end{array}$ & $1.295-1.390$ & Torla \\
\hline & 2.7 & Ordesa, La Vaqueriza & Bosque de Fagus sylvatica & 30TYN4126, 30TYN4125 & 1.295 & Torla \\
\hline & 2.8 & $\begin{array}{l}\text { Ordesa, Cubilar de } \\
\text { las vacas }\end{array}$ & Bosque de Fagus sylvatica & 30TYN4125, 30TYN4225 & $1.295-1.350$ & Torla \\
\hline & 2.9 & $\begin{array}{l}\text { Ordesa, Circo de } \\
\text { Soaso }\end{array}$ & Prados supraforestales & \begin{tabular}{|l}
$31 \mathrm{TBH} 5425,31 \mathrm{TBH} 5426$ \\
$31 \mathrm{TBH} 5525,31 \mathrm{TBH} 5526$ \\
\end{tabular} & $1.700-1.870$ & Torla \\
\hline & 2.10 & $\begin{array}{l}\text { Ordesa, Gradas de } \\
\text { Soaso }\end{array}$ & $\begin{array}{l}\text { Bosque mixto y prados. } \\
\text { Comundades de megaforbios }\end{array}$ & $31 \mathrm{TBH} 5425$ & $1.700-1.750$ & Torla \\
\hline & 2.11 & Ordesa, Faja de Pelay & $\begin{array}{l}\text { Pinar subalpino de Pinus } \\
\text { uncinata con Rhododendron } \\
\text { ferrugineum sobre areniscas } \\
\text { acidificadas }\end{array}$ & $\begin{array}{l}\text { 30TYN4125, 30TYN4225, } \\
\text { 30TYN4224, 30TYN4324, } \\
\text { 30TYN4424, 30TYN4524, } \\
\text { 31TBH5424, 31TBH5425, } \\
\text { 31TBH5426 }\end{array}$ & $1.800-1.950$ & Torla \\
\hline & 2.12 & $\begin{array}{l}\text { Ordesa, Laña } \\
\text { Sarratiello }\end{array}$ & Bosque mixto y de ribera & 30TYN4226 & 1.295 & Torla \\
\hline & 2.13 & $\begin{array}{l}\text { Ordesa, Circo de } \\
\text { Góriz }\end{array}$ & Prados subalpinos & 31TBH5528 & $2.050-2.350$ & Torla \\
\hline & 2.14 & Ordesa, Arripas & Bosque de Fagus sylvatica & 30TYN4225, 30TYN4325 & 1.400 & Torla \\
\hline & 2.15 & $\begin{array}{l}\text { Ordesa, Sierra de las } \\
\text { Cutas }\end{array}$ & $\begin{array}{l}\text { Pinar subalpino ralo de Pinus } \\
\text { uncinata sobre calizas, pastos } \\
\text { pedregosos de umbría caliza y } \\
\text { gleras subalpinas }\end{array}$ & $\begin{array}{l}\text { 30TYN3925, 30TYN4025, } \\
\text { 30TYN4125 }\end{array}$ & $1.900-2.245$ & Torla \\
\hline & 2.16 & $\begin{array}{l}\text { Ordesa, Senda de los } \\
\text { Cazadores }\end{array}$ & Bosque mixto & 30TYN4125 & $1.300-2.000$ & Torla \\
\hline & 2.17 & $\begin{array}{l}\text { Ordesa, Bosque de } \\
\text { las Hayas }\end{array}$ & Bosque de Fagus sylvatica & 30TYN4324, 30TYN4424 & $1.450-1.700$ & Torla \\
\hline & 2.18 & $\begin{array}{l}\text { Ordesa, Los } \\
\text { Chigüerres }\end{array}$ & $\begin{array}{l}\text { Bosque de ribera, matorral } \\
\text { subalpino y comunidades de } \\
\text { megaforbios }\end{array}$ & 30TYN4524, 30TYN4525 & $1.650-1.750$ & Torla \\
\hline & 2.19 & Ordesa, Faja Luenga & Humedales alpinos & 30 TYN4528 & 2.340 & Torla \\
\hline & 2.20 & $\begin{array}{l}\text { Ordesa, Llanos de } \\
\text { Millaris }\end{array}$ & Humedales alpinos & 30TYN4229 & 2.410 & Torla \\
\hline
\end{tabular}


(Cont.)

\begin{tabular}{|c|c|c|c|c|c|c|}
\hline Espacio & Zona & Lugar & Hábitat predominante & $\begin{array}{l}\text { Coordenadas (MGRS, } \\
\text { Datum: ETRS89) }\end{array}$ & Altitud (m) & Municipio \\
\hline 3 & & Añisclo (río Bellós) & & & & \\
\hline & 3.1 & $\begin{array}{l}\text { Añisclo, Molino de } \\
\text { Aso }\end{array}$ & Bosque de ribera & $\begin{array}{l}\text { 31TBH5716, 31TBH5816, } \\
\text { 31TBH5817 }\end{array}$ & $930-960$ & Fanlo \\
\hline & 3.2 & Añisclo, San Úrbez & $\begin{array}{l}\text { Bosque mixto de Quercus } \\
\text { subpyrenaica y Pinus sylvestris }\end{array}$ & 31TBH5716 & $930-960$ & Fanlo \\
\hline & 3.3 & $\begin{array}{l}\text { Añisclo, loma Ermita } \\
\text { de la Magdalena }\end{array}$ & Echinospartum horridum & 30TYN4419 & 1.370 & Fanlo \\
\hline & 3.4 & $\begin{array}{l}\text { Añisclo, Monte de } \\
\text { Nerín }\end{array}$ & Echinospartum horridum & 31TBH5518 & $1.300-2.000$ & Fanlo \\
\hline & 3.5 & $\begin{array}{l}\text { Añisclo, De Cuello } \\
\text { Arenas a Cuello } \\
\text { Gordo }\end{array}$ & Prados subalpinos & $\begin{array}{l}\text { 31TBH5521, 31TBH5522, } \\
\text { 31TBH5422, 31TBH5423, } \\
\text { 31TBH5424 }\end{array}$ & $1.900-2.180$ & Fanlo \\
\hline 4 & & Escuaín (río Yaga) & & & & \\
\hline \multirow{7}{*}{4} & 4.1 & $\begin{array}{l}\text { Escuaín, entorno de } \\
\text { pueblo }\end{array}$ & Corylus avellana, Salix sp. & 31TBH6419, 31TBH6420 & 1.200 & Puértolas \\
\hline & 4.2 & $\begin{array}{l}\text { Escuaín, La Valle - } \\
\text { Barranco de Forca } \\
\text { Martín }\end{array}$ & $\begin{array}{l}\text { Pinus sylvestris, Buxus } \\
\text { sempervirens y prados de } \\
\text { montaña }\end{array}$ & 31TBH6221, 31TBH6222 & $1.460-1.560$ & Puértolas \\
\hline & 4.3 & $\begin{array}{l}\text { Escuaín, San } \\
\text { Salvador }\end{array}$ & $\begin{array}{l}\text { Pinus sylvestris, Buxus } \\
\text { sempervirens y prados de } \\
\text { montaña }\end{array}$ & 31TBH6221, 31TBH6321 & $1.350-1.430$ & Puértolas \\
\hline & 4.4 & Escuaín, La Cruz & Prados con Pinus sylvestris & 31 TBH6320 & 1.300 & Puértolas \\
\hline & 4.5 & $\begin{array}{l}\text { Escuaín, Puente de } \\
\text { los Mallos }\end{array}$ & $\begin{array}{l}\text { Fagus sylvatica y Populus } \\
\text { tremula }\end{array}$ & $31 \mathrm{TBH} 6222$ & 1.400 & Puértolas \\
\hline & 4.6 & $\begin{array}{l}\text { Escuaín, Barranco de } \\
\text { la Fuente }\end{array}$ & $\begin{array}{l}\text { Bosque mixto con Corylus } \\
\text { avellana }\end{array}$ & 31TBH6419 & 1.200 & Puértolas \\
\hline & 4.7 & $\begin{array}{l}\text { Escuaín, Revilla, } \\
\text { Miradores de } \\
\text { Angonés } \\
\end{array}$ & $\begin{array}{l}\text { Quercus subpyrenaica, Pinus } \\
\text { sylvestris y Echinospartum } \\
\text { horridum }\end{array}$ & 31TBH6420, 31TBH6520 & $1.200-1.375$ & Tella-Sin \\
\hline \multirow[t]{9}{*}{5} & & Pineta (río Cinca) & & & & \\
\hline & 5.1 & Pineta, El Cornato & $\begin{array}{l}\text { Bosque de Abies alba con algún } \\
\text { Pinus sylvestris, Fagus sylvatica } \\
\text { y bosque de ribera }\end{array}$ & $\begin{array}{l}\text { 31TBH6824, 31TBH6923, } \\
\text { 31TBH6924 }\end{array}$ & $1.160-1.170$ & Bielsa \\
\hline & 5.2 & Pineta, fondo de circo & $\begin{array}{l}\text { Fagus sylvatica, prados y } \\
\text { bosque de ribera }\end{array}$ & $\begin{array}{l}\text { 31TBH6029, 31TBH6129, } \\
\text { 31TBH6128 }\end{array}$ & $1.280-1.430$ & Bielsa \\
\hline & 5.3 & $\begin{array}{l}\text { Pineta, senda de } \\
\text { subida a Lalarri }\end{array}$ & $\begin{array}{l}\text { Bosque mixto de Fagus } \\
\text { sylvatica y Abies alba }\end{array}$ & 31TBH6029, 31ТВH6129 & $1.300-1.570$ & Bielsa \\
\hline & 5.4 & $\begin{array}{l}\text { Pineta, Circo de } \\
\text { Lalarri }\end{array}$ & Prado fresco supraforestal & 31 TBH6129 & $1.550-1.620$ & Bielsa \\
\hline & 5.5 & Pineta, La Estiva & Humedales sobre pizarras & 31TBH6229, 31ТВH6329 & $2.050-2.100$ & Bielsa \\
\hline & 5.6 & Pineta, Plana Fonda & $\begin{array}{l}\text { Prados con Dryas octopetala, } \\
\text { Salix pyrenaica y Pinus uncinata }\end{array}$ & $\begin{array}{l}\text { 31TBH6328, 31TBH6329, } \\
\text { 31TBH6428 }\end{array}$ & $2.070-2.113$ & Bielsa \\
\hline & 5.7 & $\begin{array}{l}\text { Pineta, Portiello de } \\
\text { Tella }\end{array}$ & $\begin{array}{l}\text { Pradera subalpina con Dryas } \\
\text { octopetala, Salix pyrenaica }\end{array}$ & 31TBH6821, 31TBH6921 & $1.900-2.100$ & Bielsa \\
\hline & 5.8 & $\begin{array}{l}\text { Pineta, Forato La } \\
\text { Peña }\end{array}$ & $\begin{array}{l}\text { Prados subalpinos ácidos con } \\
\text { Rhododendron ferrugineum }\end{array}$ & $31 \mathrm{TBH} 6921$ & $1.700-1.900$ & Bielsa \\
\hline
\end{tabular}

35 ciclos de $30 \mathrm{~s}$ a $94{ }^{\circ} \mathrm{C}, 30 \mathrm{~s}$ a $53{ }^{\circ} \mathrm{C}, 1 \mathrm{~min}$ a $72{ }^{\circ} \mathrm{C} ; 7$ min a $72{ }^{\circ} \mathrm{C}$. Los fragmentos amplificados se separaron por electroforesis en gel de agarosa al 1,8\%, teñido con Midori Green (Nippon Genetics) y se visualizaron con un transiluminador de luz utravioleta. Las muestras en las que se detectó una sola banda se purificaron empleando el
QIAquick ${ }^{\circledR}$ PCR Purification Kit (Qiagen) y se enviaron a secuenciar (Stab vida, Portugal).

Adicionalmente, en el caso de Tricholoma ilkkae Mort. Chr., Heilm.-Claus., Ryman \& Niclas Bergius y Pholiota squarrosoides (Peck.) Sacc. se han incluido análisis filogenéticos junto a otros taxones cercanos 
para definir su posición entre ellos y complementar así la información de las recolectas. Por ese motivo se ha formado una matriz de datos con una secuencia propia de Tricholoma ilkkae y catorce procedentes de Genbank (Benson et al., 2013) con el fin de situarla dentro del árbol de Tricholoma sect. Caligata Bon publicado en el trabajo de Heilmann-Clausen et al. (2017). Del mismo modo se ha formado otra matriz conteniendo veinte secuencias de Pholiota squarrosoides (Peck.) Sacc., Pholiota jahnii Tjall.-Beuk. \& Bas y Pholiota squarrosa (Vahl) P.Kumm., de las cuales cuatro son propias y el resto proceden de GenBank (Benson et al., 2013). Además se ha comparado una secuencia propia de Cupulina montana Dougoud, Van Vooren \& M. Vega con la secuencia del holotipo de la especie cedida por los autores. Y por último se ha utilizado una secuencia propia de Plicariella scabrosa (Cooke) Spooner para proporcionar datos adicionales a la descripción de nuestra recolecta.

\subsection{Alineamiento de secuencias y análisis filogenético}

La edición de las secuencias y la obtención de secuencias consenso fueron realizadas con Geneious 10.0.9 (Kearse et al., 2012). Las secuencias fueron primeramente alineadas utilizando MAFFT v.7 (Katoh et al., 2002) a través de su servidor en línea, utilizando la estrategia LINS-i (Berger \& Munson, 1991) y posteriormente revisadas y corregidas manualmente con Geneious 10.0.9 (Kearse et al., 2012). Las secuencias resultantes fueron depositadas en GenBank (Benson et al., 2013), con los siguientes números de acceso: MF345957 a MF345963 (ver Tabla 2).

Las secuencias se han agrupado en una única matriz para cada análisis, incluyendo en un único bloque la región ITS1-5,8S-ITS2.
Los análisis filogenéticos fueron realizados utilizando dos diferentes estrategias, máxima verosimilitud (ML) e inferencia Bayesiana (BI). El análisis ML fue realizado mediante Garli v.2.0 (Zwickl, 2006), utilizando el modelo GTR $+\mathrm{I}+\Gamma$. El análisis para obtener el mejor árbol se repitió diez veces comenzando en árboles aleatorios (searchreps $=10$ ). El apoyo de las ramas (MLbs) se ha determinado mediante 1.000 réplicas de non-parametric bootstrapping (BS) con una sola repetición y reduciendo el umbral de rechazo de árbol (tree rejection threshold) a un valor de 20. El post-procesamiento de los resultados de la inferencia filogenética se realizó utilizando DendroPy (Sukumaran \& Holder, 2010). El análisis de inferencia Bayesiana fue realizado a través de CIPRES Science Gateway v3.3 (Miller et al., 2010), utilizando la estrategia Metropolis Coupled Markov Chain Monte Carlo $\left(\mathrm{MC}^{3}\right)$ implementada en MrBayes on XSEDE v.3.2.6 (Ronquist et al., 2012). El modelo elegido fue GTR $+\mathrm{I}+\Gamma$. El análisis consistió en tres tareas paralelas de búsqueda, ejecutándose 5 millones de generaciones y comenzando cada tarea con un árbol aleatorio. Cada tarea utilizó cuatro cadenas, tres de las cuales fueron calentadas incrementalmente con una temperatura de 0,15 , con la cual los resultados de convergencia resultaron un $5-10 \%$ superiores a los obtenidos con el valor por defecto temp $=0,20$. La frecuencia de muestreo fue configurada cada 1.000 árboles. El primer $25 \%$ del análisis fue despreciado como burn-in. La convergencia de MC3 fue adicionalmente evaluada con Tracer v.1.6 (Rambaut et al., 2014) para chequear los valores indicadores de convergencia, obteniendo valores de tamaño efectivo de muestra (ESS) por encima de 3.000 en todas las cadenas. Los árboles filogenéticos fueron dibujados con FigTree v.1.4.3 (Rambaut, 2007). La interpretación de los valores de soporte de las ramas sigue el criterio y escala definidos en Lutzoni et al. (2004).

Tabla 2: Especímenes y números de acceso de GenBank para las secuencias utilizadas en el presente estudio. Los especímenes tipo están indicados con $(\mathrm{T})$ y los utilizados como outgroup con $(\mathrm{O})$. Las secuencias generadas en el presente estudio aparecen en verde. Table 2: Specimen and GenBank accession numbers for sequences included in this study. Typus specimens are indicated by $(T)$ and those used as outgroup by $(O)$. Sequences obtained in this study are highlighted in green.

\begin{tabular}{|l|l|l|l|}
\hline \multicolumn{1}{|c|}{ Especie } & \multicolumn{1}{|c|}{ Datos especimen } & Orig. Secuencias & N. $^{{ }^{*}}$ acc. GenBank ITS \\
\hline Tricholoma ilkkae & España, Pirineos & GenBank & AB738881 \\
\hline Tricholoma ilkkae & España, Pirineos & GenBank & AB738882 \\
\hline Tricholoma ilkkae & Suecia, Gotland & GenBank & LT000172 \\
\hline Tricholoma ilkkae & Suecia, Uppland & GenBank & LT222028 \\
\hline Tricholoma ilkkae & Suecia, Gotland & GenBank & LT222029 (T) \\
\hline Tricholoma ilkkae & España, Pirineos (JACA-MICO-00219) & Este estudio & MF345963 \\
\hline Tricholoma dulciolens & Suecia & GenBank & AB738883 (T) \\
\hline Tricholoma dulciolens & USA, California & GenBank & AF309523 \\
\hline Tricholoma dulciolens & Italia & GenBank & JF908732 \\
\hline Tricholoma bakamatsutake & Japón & GenBank & AB856037 \\
\hline Tricholoma bakamatsutake & Japón & GenBank & AB036898 \\
\hline Tricholoma caligatum & España, Valencia & GenBank & LT000152 \\
\hline Tricholoma caligatum & Argelia & GenBank & KC565866 \\
\hline
\end{tabular}


(Cont.)

\begin{tabular}{|l|l|l|l|}
\hline \multicolumn{1}{|c|}{ Especie } & \multicolumn{1}{|c|}{ Datos especimen } & Orig. Secuencias & N. acc. GenBank ITS \\
\hline Tricholoma caligatum & Francia, Provenza & GenBank & TMU62964 \\
\hline Tricholoma matsutake (O) & Corea del Sur & GenBank & TMU62964 (O) \\
\hline Pholiota squarrosoides & USA & GenBank & FJ596860 \\
\hline Pholiota squarrosoides & USA & GenBank & FJ596876 \\
\hline Pholiota squarrosoides & USA & GenBank & FJ596877 \\
\hline Pholiota squarrosoides & USA & GenBank & FJ596859 \\
\hline Pholiota squarrosoides & Finlandia & GenBank & JF908591 \\
\hline Pholiota squarrosoides & España, Pirineos (JACA-MICO-00132) & Este estudio & MF345957 \\
\hline Pholiota squarrosoides & Francia, Pirineos (AH48186) & Este estudio & MF345958 \\
\hline Pholiota squarrosoides & Corea del Sur & GenBank & KX773887 \\
\hline Pholiota squarrosa & Corea del Sur & GenBank & KX773886 \\
\hline Pholiota squarrosa & USA & GenBank & DQ494683 \\
\hline Pholiota squarrosa & Alemania & GenBank & FR686575 \\
\hline Pholiota squarrosa & España, Somosierra (AH48188) & Este estudio & MF345959 \\
\hline Pholiota squarrosa & China & GenBank & JN230706 \\
\hline Pholiota squarrosa & China & GenBank & JQ283959 \\
\hline Pholiota squarrosa & Suecia & GenBank & JQ765683 \\
\hline Pholiota squarrosa & Suiza & GenBank & KM044069 \\
\hline Pholiota squarrosa & Suiza & GenBank & KM044075 \\
\hline Pholiota jahnii & Italia & GenBank & JF908590 \\
\hline Pholiota jahnii & España, Pirineos (AH48189) & Este estudio & MF345960 \\
\hline Pholiota mixta $(O) ~$ & República Checa & GenBank & HG007978 (O) \\
\hline Cupulina montana & España, Pirineos (JACA-MICO-01072) & Este estudio & MF345961 \\
\hline Plicariella scabrosa & Espana, Pirineos (JACA-MICO-01117) & Este estudio & MF3 45962 \\
\hline
\end{tabular}

\section{Resultados}

Se relacionan a continuación las especies recolectadas y determinadas durante la campaña de 2015 y algunas que quedaron pendientes del 2014 (Tabla 3). En la relación se citan aquellas especies que no se habían indicado en el trabajo anterior o que siendo citadas, se han encon- trado en otra localización, indicando con un asterisco $(*)$ aquellas que suponen una primera cita para España según nuestra búsqueda bibliográfica. En este trabajo, hemos seleccionado 20 especies de especial interés que describimos completamente con iconografía macro y microscópica, así como un comentario en Ramaria largentii Marr \& D.E. Stuntz ss. auct. eur.

Tabla 3: Catálogo de especies.

Table 3: Species check list.

\begin{tabular}{|r|l|l|}
\hline N. $^{\mathbf{}}$ & \multicolumn{1}{|c|}{ Especie } & \multicolumn{1}{|c|}{ Zona } \\
\hline 1 & Agaricus sylvicola (Vittad.) Peck & 4.4 \\
\hline 2 & Aleurodiscus amorphus (Pers.) J. Schröt. & $2.4 ; 5.1$ \\
\hline 3 & Amanita coryli Neville \& Poumarat & 4.2 \\
\hline 4 & Amanita franchetii (Boud.) Fayod & 5.2 \\
\hline 5 & Amanita muscaria (L.) Lam. & 5.7 \\
\hline 6 & Amanita pantherina (DC.) Krombh. & 5.2 \\
\hline 7 & Amanita phalloides (Vaill. ex Fr.) Link & 4.1 \\
\hline 8 & $\begin{array}{l}\text { Annulohypoxylon cohaerens (Pers.) Y.M. Ju, } \\
\text { J.D. Rogers \& H.M. Hsieh }\end{array}$ & $2.6 ; 2.17$ \\
\hline 9 & *Artomyces cristatus (Kauffman) Jülich & 2.4 \\
\hline 10 & Artomyces pyxidatus (Pers.) Jülich & 5.1 \\
\hline
\end{tabular}

\begin{tabular}{|c|c|c|}
\hline N. ${ }^{\mathbf{2}}$ & Especie & Zona \\
\hline 11 & Ascocoryne cylichnium (Tul.) Korf & $\begin{array}{l}2.7 ; 2.8 ; \\
2.16\end{array}$ \\
\hline 12 & Ascotremella faginea (Peck) Seaver & 2.4 \\
\hline 13 & Auricularia mesenterica (Dicks.) Pers. & 2.17 \\
\hline 14 & Auriscalpium vulgare Gray & $\begin{array}{l}2.4 ; 4.3 \\
5.1\end{array}$ \\
\hline 15 & Bactridium flavum Kunze & 2.8 \\
\hline 16 & Baeospora myosura (Fr.) Singer & 4.3 \\
\hline 17 & Bertia moriformis (Tode) De Not. & 2.4 \\
\hline 18 & Biscogniauxia repanda (Fr.) Kuntze & 5.2 \\
\hline 19 & $\begin{array}{l}\text { Bisporella citrina (Batsch) Korf \& S.E. } \\
\text { Carp. }\end{array}$ & $2.16 ; 3.1$ \\
\hline
\end{tabular}




\begin{tabular}{|c|c|c|}
\hline N. ${ }^{\circ}$ & Especie & Zona \\
\hline 20 & Bjerkandera adusta (Willd.) P. Karst. & $2.4 ; 2.17$ \\
\hline 21 & Boletus edulis Bull. & 5.1 \\
\hline 22 & Boletus pinophilus Pilát \& Dermek & 5.2 \\
\hline 23 & Botryobasidium aureum Parmasto & 2.4 \\
\hline 24 & $\begin{array}{l}\text { Botryobasidium robustius Pouzar \& Hol.- } \\
\text { Jech. }\end{array}$ & 2.4 \\
\hline 25 & $\begin{array}{l}\text { Boudiera tracheia (Rehm ex Gamundí) } \\
\text { Dissing \& T. Schumach. }\end{array}$ & 5.5 \\
\hline 26 & $\begin{array}{l}\text { Bryocentria metzgeriae (Ade \& Höhn.) } \\
\text { Döbbeler }\end{array}$ & 3.1 \\
\hline 27 & Bulgaria inquinans (Pers.) Fr. & 2.7 \\
\hline 28 & Byssomerulius corium (Pers.) Parmasto & 3.1 \\
\hline 29 & $\begin{array}{l}\text { Calathella eruciformis (P. Micheli ex } \\
\text { Batsch) D.A. Reid }\end{array}$ & 2.18 \\
\hline 30 & Calocera viscosa (Pers.) Fr. & 2.4 \\
\hline 31 & Calocybe graveolens (Pers.) Singer & 5.1 \\
\hline 32 & Caloscypha fulgens (Pers.) Boud. & 2.4 \\
\hline 33 & *Calycellina chlorinella (Ces.) Dennis & 2.3 \\
\hline 34 & Cantharellus cibarius Fr. & 2.16 \\
\hline 35 & Cantharellus pallens Pilát & 3.1 \\
\hline 36 & Ceraceomyces sublaevis (. Bres) Jülich & 2.4 \\
\hline 37 & $\begin{array}{l}\text { Cerioporus varius (Pers.) Zmitr. \& } \\
\text { Kovalenko }\end{array}$ & 4.4 \\
\hline 38 & $\begin{array}{l}\text { Chaetosphaerella phaeostroma (Durieu \& } \\
\text { Mont.) E. Müll. \& C. Booth }\end{array}$ & 2.4 \\
\hline 39 & Chalciporus piperatus (Bull.) Bataille & $4.3 ; 4.4$ \\
\hline 40 & Chlorencoelia versiformis (Pers.) J.R. Dixon & $2.4 ; 2.7$ \\
\hline 41 & $\begin{array}{l}\text { Chlorociboria aeruginascens (Nyl.) } \\
\text { Kanouse ex C.S. Ramamurthi, Korf \& L.R. } \\
\text { Batra }\end{array}$ & $\begin{array}{l}2.17 \\
3.1 ; 5.2\end{array}$ \\
\hline 42 & Chondrostereum purpureum (Pers.) Pouzar & $2.4 ; 2.17$ \\
\hline 43 & Chroogomphus rutilus (Schaeff.) O.K. Mill. & $3.1 ; 5.1$ \\
\hline 44 & $\begin{array}{l}\text { Chrysomphalina chrysophylla (Fr.) } \\
\text { Clémençon }\end{array}$ & 5.1 \\
\hline 45 & Ciboria rufofusca (O. Weberb.) Sacc. & $2.4 ; 5.1$ \\
\hline 46 & Clavaria falcata Pers. & $1.1 ; 3.1$ \\
\hline 47 & Clavariadelphus pistillaris (L.) Donk & 2.7 \\
\hline 48 & Clavariadelphus truncatus Donk & $2.4 ; 4.4$ \\
\hline 49 & Clavicorona taxophila (Thom) Doty & 4.3 \\
\hline 50 & Clavulina rugosa (Bull.) J. Schröt. & $2.4 ; 5.7$ \\
\hline 51 & Clavulinopsis corniculata (Schaeff.) Corner & 3.1 \\
\hline 52 & Clavulinopsis helvola (Pers.) Corner & 3.1 \\
\hline 53 & Clavulinopsis umbrinella (Sacc.) Corner & 4.6 \\
\hline 54 & Clitocybe bresadolana Singer & 5.7 \\
\hline 55 & *Clitocybe houghtonii (W. Phillips) Dennis & $1.1 ; 2.4$ \\
\hline
\end{tabular}

\begin{tabular}{|c|c|c|}
\hline N. ${ }^{\circ}$ & Especie & Zona \\
\hline 56 & Clitocybe odora (Bull.) P. Kumm. & 5.1 \\
\hline 57 & Clitocybe phyllophila (Pers.) P. Kumm. & 1.1 \\
\hline 58 & Clitocybe rivulosa (Pers.) P. Kumm. & 2.16 \\
\hline 59 & Clitocybe vibecina (Fr.) Quél. & 1.1 \\
\hline 60 & Clitopilus prunulus (Scop.) P. Kumm. & $\begin{array}{l}1.1 ; 2.7 \\
2.8\end{array}$ \\
\hline 61 & Coniochaeta pulveracea (Ehrh.) Munk & 2.17 \\
\hline 62 & Coprinellus disseminatus (Pers.) J.E. Lange & 2.16 \\
\hline 63 & $\begin{array}{l}\text { Coprinellus micaceus (Bull.) Vilgalys, } \\
\text { Hopple \& Jacq. Johnson }\end{array}$ & 2.4 \\
\hline 64 & $\begin{array}{l}\text { Coprinopsis martinii (P.D. Orton) Redhead, } \\
\text { Vilgalys \& Moncalvo }\end{array}$ & 2.9 \\
\hline 65 & Cortinarius alpicola (Bon) Bon & 5.7 \\
\hline 66 & Cortinarius catharinae Consiglio & 3.1 \\
\hline 67 & Cortinarius cinnabarinus Fr. & 2.17 \\
\hline 68 & Cortinarius cotoneus Fr. & 3.1 \\
\hline 69 & Cortinarius croceus (Schaeff.) Gray & 3.1 \\
\hline 70 & Cortinarius humicola (Quél.) Maire & $2.8 ; 5.2$ \\
\hline 71 & Cortinarius infractus (Pers.) Fr. & 4.4 \\
\hline 72 & Cortinarius napus Fr. & 5.5 \\
\hline 73 & Cortinarius salor Fr. & 2.4 \\
\hline 74 & Cortinarius spilomeus (Fr.) Fr & 5.7 \\
\hline 75 & Cortinarius torvus (Fr.) Fr. & $2.16 ; 3.1$ \\
\hline 76 & Cortinarius trivialis J.E. Lange & 5.7 \\
\hline 77 & $\begin{array}{l}\text { Craterellus melanoxeros (Desm.) Pérez-De- } \\
\text { Greg. }\end{array}$ & 2.7 \\
\hline 78 & Craterellus tubaeformis (Fr.) Quél. & $2.4 ; 2.8$ \\
\hline 79 & Crepidotus applanatus (Pers.) P. Kumm. & 5.2 \\
\hline 80 & Crepidotus ehrendorferi Hauskn. \& Krisai & 2.17 \\
\hline 81 & Crepidotus subverrucisporus Pilát & 3.3 \\
\hline 82 & Crucibulum laeve (Huds.) Kambly & 5.2 \\
\hline 83 & Cuphophyllus cinerellus (Kühner) Bon & 1.1 \\
\hline 84 & $\begin{array}{l}\text { Cuphophyllus colemannianus (A. Bloxam) } \\
\text { Bon }\end{array}$ & 2.11 \\
\hline 85 & $\begin{array}{l}\text { Cuphophyllus virgineus (Wulfen) } \\
\text { Kovalenko }\end{array}$ & 1.1 \\
\hline 86 & $\begin{array}{l}\text { *Cupulina montana Dougoud, Van Vooren } \\
\text { \& M. Vega }\end{array}$ & 2.9 \\
\hline 87 & Cyathus striatus (Huds.) Willd. & $2.7 ; 3.1$ \\
\hline 88 & Cyclocybe erebia (Fr.) Vizzini \& Matheny & $2.4 ; 5.2$ \\
\hline 89 & Cylindrobasidium evolvens (Fr.) Jülich & 2.17 \\
\hline 90 & Cystoderma carcharias (Pers.) Fayod & 2.4 \\
\hline 91 & $\begin{array}{l}\text { Cystolepiota sistrata (Fr.) Singer ex Bon \& } \\
\text { Bellù }\end{array}$ & 2.17 \\
\hline 92 & Dacrymyces stillatus Nees & 2.4 \\
\hline
\end{tabular}




\begin{tabular}{|c|c|c|}
\hline N. ${ }^{\circ}$ & Especie & Zona \\
\hline 93 & Dacrymyces variisporus $\mathrm{McNabb}$ & 2.4 \\
\hline 94 & $\begin{array}{l}\text { Dacryobolus karstenii (Bres.) Oberw. ex } \\
\text { Parmastro }\end{array}$ & 2.4 \\
\hline 95 & $\begin{array}{l}\text { Daedaleopsis tricolor (Bull.) Bondartsev \& } \\
\text { Singer }\end{array}$ & $2.4 ; 2.14$ \\
\hline 96 & Dentipellis fragilis (Pers.) Donk & 2.4 \\
\hline 97 & Diatrype disciformis (Hoffm.) Fr. & 2.4 \\
\hline 98 & Diderma alpinum var. alpinum Meyl. & 1.3 \\
\hline 99 & Diderma globosum var. europaeum Buyck & 1.3 \\
\hline 100 & Discina ancilis (Pers.) Sacc. & 2.4 \\
\hline 101 & Echinoderma asperum (Pers.) Bon & 5.1 \\
\hline 102 & Echinoderma calcicola (Knudsen) Bon & 3.1 \\
\hline 103 & Echinoderma perplexum (Knudsen) Bon & 2.4 \\
\hline 104 & $\begin{array}{l}\text { Eichleriella deglubens (Berk. \& Broome) } \\
\text { Lloyd }\end{array}$ & $2.4 ; 2.17$ \\
\hline 105 & Elaphomyces barrioi A. Paz \& C. Lavoise & 2.4 \\
\hline 106 & Elaphomyces muricatus Fr. & $2.4 ; 2.7$ \\
\hline 107 & Encoeliopsis rhododendri (Ces.) Nannf. & 2.15 \\
\hline 108 & Entoloma catalaunicum (Singer) Noordel. & $4.2 ; 5.3$ \\
\hline 109 & Entoloma griseocyaneum (Fr.) P. Kumm. & 2.15 \\
\hline 110 & Entoloma pluteoides E. Horak & 2.4 \\
\hline 111 & Entoloma rhodopolium (Fr.) P. Kumm. & 2.8 \\
\hline 112 & Entoloma tjallingiorum Noordel. & 2.7 \\
\hline 113 & Eutypa spinosa (Pers.) Tul. \& C. Tul. & 2.4 \\
\hline 114 & Exidia recisa (Ditmar) Fr. & 2.4 \\
\hline 115 & Exidia thuretiana (Lév.) Fr. & 5.2 \\
\hline 116 & Exidiopsis effusa Bref. & 2.6 \\
\hline 117 & Flagelloscypha kavinae (Pilát) W.B. Cooke & 3.1 \\
\hline 118 & Flammulaster limulatus (Fr.) Watling & $2.16 ; 3.3$ \\
\hline 119 & Flammulina velutipes (Curtis) Singer & 5.2 \\
\hline 120 & Funalia trogii (Berk.) Bondartsev \& Singer & 2.7 \\
\hline 121 & $\begin{array}{l}\text { Galerina vittiformis f. bispora AH Sm. \& } \\
\text { Singer }\end{array}$ & 2.4 \\
\hline 122 & Ganoderma applanatum (Pers.) Pat. & 2.4 \\
\hline 123 & Gautieria retirugosa Th. Fr. & 2.4 \\
\hline 124 & Gautieria villosa Quél. & 2.4 \\
\hline 125 & $\begin{array}{l}\text { Geastrum melanocephalum (Czern.) } \\
\text { V.J.Staněk }\end{array}$ & 3.4 \\
\hline 126 & Geastrum michelianum (Sacc.) W.G. Sm. & 2.4 \\
\hline 127 & Gibberella baccata (Wallr.) Sacc. & 2.2 \\
\hline 128 & Gloeophyllum abietinum (Bull). P. Karst. & 1.1 \\
\hline 129 & Gomphus clavatus (Pers.) Gray & 5.1 \\
\hline 130 & Gymnopilus picreus (Pers.) P. Karst. & 2.4 \\
\hline
\end{tabular}

\begin{tabular}{|c|c|c|}
\hline N. ${ }^{\mathbf{D}}$ & Especie & Zona \\
\hline 131 & $\begin{array}{l}\text { Gymnopus confluens (Pers.) Antonín, } \\
\text { Halling \& Noordel. }\end{array}$ & $\begin{array}{l}2.4 ; 4.4 \\
5.2\end{array}$ \\
\hline 132 & Gymnopus peronatus (Bolton) Gray & 2.4 \\
\hline 133 & Gyromitra esculenta (Pers.) Fr. & 5.1 \\
\hline 134 & Gyromitra infula (Schaeff.) Quél. & 2.4 \\
\hline 135 & $\begin{array}{l}\text { Hebeloma geminatum Beker, Versterh. \& } \\
\text { U.Eberh }\end{array}$ & 5.7 \\
\hline 136 & Hebeloma sinapizans (Paulet) Gillets & 2.8 \\
\hline 137 & Helvella acetabulum (L.) Quél. & 2.2 \\
\hline 138 & Helvella crispa (Scop.) Fr. & 1.1 \\
\hline 139 & Helvella dovrensis T. Schumach. & 2.9 \\
\hline 140 & Helvella elastica Bull. & $\begin{array}{l}2.4 ; 3.1 \\
4.1\end{array}$ \\
\hline 141 & Helvella ephippium Lév. & 3.1 \\
\hline 142 & Helvella lacunosa Afzel. & $\begin{array}{l}2.4 ; 2.8 \\
2.17 ; 3.1\end{array}$ \\
\hline 143 & Helvella leucomelaena (Pers.) Nannf. & 3.2 \\
\hline 144 & Helvella villosa (Hedw.) Dissing \& Nannf. & 3.1 \\
\hline 145 & Hemimycena hirsuta (Tode) Singer & 2.18 \\
\hline 146 & Hemimycena lactea (Pers.) Singer & 3.1 \\
\hline 147 & Hericium alpestre Pers. & $\begin{array}{l}2.14 \\
2.17\end{array}$ \\
\hline 148 & $\begin{array}{l}\text { Humaria hemisphaerica (F.H. Wigg.) } \\
\text { Fuckel }\end{array}$ & $\begin{array}{l}2.4 ; 2.16 ; \\
3.1 ; 4.2 ; \\
4.4\end{array}$ \\
\hline 149 & Hydnellum caeruleum (Hornem.) P. Karst. & 4.3 \\
\hline 150 & Hydnellum ferrugineum (Fr.) P. Karst. & $4.3 ; 5.1$ \\
\hline 151 & $\begin{array}{l}\text { Hydnocristella himantia (Schwein.) R.H. } \\
\text { Petersen }\end{array}$ & 3.1 \\
\hline 152 & Hydnum repandum $\mathrm{L}$. & 2.16 \\
\hline 153 & Hygrocybe chlorophana (Fr.) Wünsche & 4.2 \\
\hline 154 & Hygrocybe coccinea (Schaeff.) P. Kumm. & 1.1 \\
\hline 155 & Hygrocybe conica (Schaeff.) P.Kumm. & $\begin{array}{l}1.1 ; 2.11 \\
3.1 ; 5.7\end{array}$ \\
\hline 156 & $\begin{array}{l}\text { Hygrocybe insipida (J.E. Lange) M.M. } \\
\text { Moser }\end{array}$ & 3.1 \\
\hline 157 & Hygrocybe mucronella (Fr.) P. Karst. & 3.1 \\
\hline 158 & Hygrocybe punicea (Fr.) P. Kumm. & 1.1 \\
\hline 159 & Hygrophorus agathosmus (Fr.) Fr. & 4.4 \\
\hline 160 & Hygrophorus chrysodon (Batsch.) Fr. & 2.4 \\
\hline 161 & Hygrophorus cossus (Soweby) Fr. & 2.16 \\
\hline 162 & Hygrophorus discoxanthus (Fr.) Rea & $2.4 ; 3.1$ \\
\hline 163 & Hygrophorus eburneus (Bull.) Fr. & 5.2 \\
\hline 164 & Hygrophorus erubescens (Fr.) Fr. & 5.2 \\
\hline 165 & Hygrophorus pudorinus (Fr.) Fr. & 2.4 \\
\hline
\end{tabular}




\begin{tabular}{|c|c|c|}
\hline N. ${ }^{\circ}$ & Especie & Zona \\
\hline 166 & Hygrophorus unicolor Gröger & 2.7 \\
\hline 167 & Hymenochaete cruenta (Pers.) Donk & 2.4 \\
\hline 168 & Hymenoscyphus serotinus (Pers.) W. Phillips & 2.17 \\
\hline 169 & Hyphoderma mutatum (Peck) Donk & $2.4 ; 2.17$ \\
\hline 170 & Hypholoma fasciculare (Huds.) P. Kumm. & 5.1 \\
\hline 171 & Hypochnicium wakefieldiae (Bres.) J. Erikss & 2.4 \\
\hline 172 & Hypocrea pulvinata Fuckel & 2.4 \\
\hline 173 & Hypoderma commune (Fr.) Duby & 3.1 \\
\hline 174 & Hypomyces aurantius (Pers.) Fuckl & 2.4 \\
\hline 175 & $\begin{array}{l}\text { Hypomyces rosellus (Alb. \& Schwein.) Tul. } \\
\text { \& C. Tul. }\end{array}$ & 2.8 \\
\hline 176 & Hypoxylon fragiforme (Pers.) J. Kichx f. & 2.4 \\
\hline 177 & Inocybe bongardii (Weinm.) Quél. & $\begin{array}{l}2.4 ; 2.8 \\
5.1\end{array}$ \\
\hline 178 & Inocybe cf. amethystina Kuyper & 2.15 \\
\hline 179 & *Inocybe coelestium Kuyper & 2.7 \\
\hline 180 & Inocybe fraudans (Britzelm.) Sacc. & 2.7 \\
\hline 181 & Inocybe gymnocarpa Kühner & 2.4 \\
\hline 182 & Inocybe leucoblema Kühner & 2.4 \\
\hline 183 & Inocybe lilacina (Peck) Kauffman & 2.4 \\
\hline 184 & $\begin{array}{l}\text { *Inocybe nitidiuscula f. epixantha (Kühner) } \\
\text { Stangl }\end{array}$ & 2.11 \\
\hline 185 & $\begin{array}{l}\text { *Inocybe occulta Esteve-Rav., Bandini, B. } \\
\text { Oertel \& G. Moreno }\end{array}$ & 2.15 \\
\hline 186 & *Inocybe tricolor Kühner & 5.7 \\
\hline 187 & Inocybe xanthomelas Boursier \& Kühner & 5.2 \\
\hline 188 & Inonotus radiatus (Sowerby) P. Karst. & 2.17 \\
\hline 189 & Ischnoderma resinosum (Schrad.) P. Karst. & 2.7 \\
\hline 190 & $\begin{array}{l}\text { Kretzschmaria deusta (Hoffm.) P.M.D. } \\
\text { Martin }\end{array}$ & 2.7 \\
\hline 191 & Laccaria amethystina Cooke & 5.1 \\
\hline 192 & Laccaria bicolor (Maire) P.D. Orton & $4.2 ; 4.3$ \\
\hline 193 & Lachnellula calycina (Schumach.) Sacc. & 3.1 \\
\hline 194 & Lachnellula subtilissima (Cooke) Dennis & 5.1 \\
\hline 195 & Lachnum virgineum (Batsch) P. Karst. & 2.4 \\
\hline 196 & Lactarius azonites (Bull.) Fr. & 5.2 \\
\hline 197 & Lactarius blennius (Fr.) Fr. & 3.1 \\
\hline 198 & Lactarius citriolens Pouzar & $3.2 ; 5.2$ \\
\hline 199 & Lactarius deliciosus (L.) Gray & 5.1 \\
\hline 200 & Lactarius evosmus Kühner \& Romagn. & 5.7 \\
\hline 201 & Lactarius fraxineus Romagn. & 4.2 \\
\hline 202 & Lactarius fuliginosus (Fr.) Fr. & 2.4 \\
\hline 203 & $\begin{array}{l}\text { Lactarius intermedius Krombh. ex Berk. \& } \\
\text { Broome }\end{array}$ & 2.16 \\
\hline
\end{tabular}

\begin{tabular}{|c|c|c|}
\hline N. ${ }^{\mathbf{T}}$ & Especie & Zona \\
\hline 204 & Lactarius salmonicolor $\mathrm{R}$. Heim \& Leclair & $2.7 ; 5.1$ \\
\hline 205 & Lactarius sanguifluus (Paulet) Fr. & 4.2 \\
\hline 206 & $\begin{array}{l}\text { Lactarius semisanguifluus R. Heim \& } \\
\text { Leclair }\end{array}$ & 4.2 \\
\hline 207 & Lactarius torminosus (Schaeff.) Gray & 5.1 \\
\hline 208 & Lactarius uvidus (Fr.) Fr. & 3.1 \\
\hline 209 & $\begin{array}{l}\text { Lasiobelonium barbatum (Kunze : Fr.) } \\
\text { Raitv. }\end{array}$ & 3.1 \\
\hline 210 & $\begin{array}{l}\text { Lasiosphaeria spermoides (Hoffm.) Ces. \& } \\
\text { De Not }\end{array}$ & 2.4 \\
\hline 211 & Leccinum scabrum (Bull.) Gray & 4.2 \\
\hline 212 & Lentinellus castoreus (Fr.) Kühner \& Maire & 2.4 \\
\hline 213 & Lentinellus cochleatus (Pers.) P. Karst. & 2.4 \\
\hline 214 & Lentinellus flabelliformis (Bolton) S. Ito & 2.4 \\
\hline 215 & $\begin{array}{l}\text { Lentinellus micheneri (Berk. \& M.A. Curtis) } \\
\text { Pegler }\end{array}$ & 5.2 \\
\hline 216 & Lentinellus ursinus (Fr.) Kühner & $1.1 ; 2.4$ \\
\hline 217 & Leotia lubrica (Scop.) Pers. & 5.2 \\
\hline 218 & Lepidoderma carestianum (Rabenh.) Rostaf. & 1.3 \\
\hline 219 & Lepidoderma chailletii Rostaf. & 1.3 \\
\hline 220 & Lepiota clypeolaria (Bull.) P. Kumm & $2.4 ; 5.1$ \\
\hline 221 & Lepiota erminea (Fr.) P. Kumm. & 2.15 \\
\hline 222 & Lepiota magnispora Murrill & 5.7 \\
\hline 223 & Lepista glaucocana (Bres.) Singer & 4.4 \\
\hline 224 & Lepista irina var. montana Bon & $2.9 ; 5.7$ \\
\hline 225 & $\begin{array}{l}\text { Leptosporomyces septentrionalis (J. Erikss) } \\
\text { Krieglst. }\end{array}$ & 2.4 \\
\hline 226 & $\begin{array}{l}\text { Leucoglossum leucosporum (Benkert \& } \\
\text { Hardtke) S. Arauzo }\end{array}$ & 5.2 \\
\hline 227 & Leucostoma persoonii (Nitschke) Höhn. & 2.18 \\
\hline 228 & $\begin{array}{l}\text { Lichenomphalia velutina (Quél.) Redhead, } \\
\text { Lutzoni, Moncalvo \& Vilgalys }\end{array}$ & 3.1 \\
\hline 229 & Lycogala epidendrum (J.C. Buxb. ex L.) Fr. & $\begin{array}{l}2.2 ; 3.1 ; \\
5.2\end{array}$ \\
\hline 230 & Lycoperdon molle Pers. & 2.4 \\
\hline 231 & Lyophyllum rhopalopodium Clémençon & $2.17 ; 4.4$ \\
\hline 232 & Macrocystidia cucumis (Pers.) Joss. & 2.4 \\
\hline 233 & $\begin{array}{l}\text { Macrotyphula fistulosa (Holmsk.) R.H. } \\
\text { Petersen }\end{array}$ & 4.3 \\
\hline 234 & $\begin{array}{l}\text { Macrotyphula juncea (Alb. \& Schwin.) } \\
\text { Berthier }\end{array}$ & 2.4 \\
\hline 235 & Marasmiellus ramealis (Bull.) Singer & 3.1 \\
\hline 236 & $\begin{array}{l}\text { Marasmius epiphyllloides (Rea) Sacc. \& } \\
\text { Trotter }\end{array}$ & 3.1 \\
\hline 237 & Marasmius hudsonii (Pers.) Fr. & 4.3 \\
\hline 238 & Marasmius rotula (Scop.) Fr. & 2.8 \\
\hline
\end{tabular}




\begin{tabular}{|c|c|c|}
\hline N. ${ }^{\mathbf{H}}$ & Especie & Zona \\
\hline 239 & Marcelleina rickii (Rehm) Graddon & 2.9 \\
\hline 240 & Melanoleuca pseudoluscina Bon & 2.9 \\
\hline 241 & Melogramma pulvis-pyrius (Pers.) Fuckel & 2.17 \\
\hline 242 & Melogramma spiniferum (Wallr.) De Not. & 2.17 \\
\hline 243 & $\begin{array}{l}\text { Mensularia nodulosa (Fr.) T. Wagner \& M. } \\
\text { Fisch. }\end{array}$ & 2.4 \\
\hline 244 & Merulius tremellosus Schrad. & 2.8 \\
\hline 245 & $\begin{array}{l}\text { Microglossum griseoviride V. Kucera, } \\
\text { Lizon, M. Tomsovsky }\end{array}$ & 5.2 \\
\hline 246 & Microglossum nudipes Boud. & 3.1 \\
\hline 247 & Microglossum viride (Pers.) Gillet & 5.2 \\
\hline 248 & Morchella deliciosa Fr. & 5.1 \\
\hline 249 & Morchella tridentina Bres. & 5.2 \\
\hline 250 & Mycena amicta (Fr.) Quél. & $2.7 ; 3.1$ \\
\hline 251 & Mycena capillaris (Schumach.) P. Kumm. & 3.1 \\
\hline 252 & Mycena crocata (Schrad.) P. Kumm & 2.4 \\
\hline 253 & Mycena epipterygia (Scop.) Gray & $2.4 ; 2.11$ \\
\hline 254 & Mycena flavoalba (Fr.) Quél & 2.11 \\
\hline 255 & Mycena haematopus (Pers.) P. Kumm. & $2.4 ; 2.17$ \\
\hline 256 & Mycena maculata P. Karst. & 2.4 \\
\hline 257 & Mycena melliigena (Berk. \& Cooke) Sacc. & 3.1 \\
\hline 258 & Mycena pura (Pers.) P. Kumm. & $4.4 ; 5.7$ \\
\hline 259 & Mycena rosea Gramberg. & $2.4 ; 4.4$ \\
\hline 260 & $\begin{array}{l}\text { Mycena sanguinolenta (Alb. \& Schwein.) P. } \\
\text { Kumm }\end{array}$ & 2.4 \\
\hline 261 & $\begin{array}{l}\text { Mycetinis alliaceus (Jacq.) Earle ex A.W. } \\
\text { Wilson \& Desjardin }\end{array}$ & 5.2 \\
\hline 262 & Mycoacia nothofagi (G. Cunn) Ryvarden & 2.4 \\
\hline 263 & Mycoacia uda (Fr.) Donk & 3.1 \\
\hline 264 & $\begin{array}{l}\text { Myochromella boudieri (Kühner \& } \\
\text { Romagn.) V. Hofst., Clémençon, Moncalvo } \\
\text { \& Redhead }\end{array}$ & 2.4 \\
\hline 265 & Nectria cinnabarina (Tode) Fr. & 2.18 \\
\hline 266 & Nemania serpens (Pers.) Gray & 2.7 \\
\hline 267 & Neobulgaria pura (Pers.) Petr. & 2.4 \\
\hline 268 & $\begin{array}{l}\text { Neonectria coccinea (Pers.) Rossman \& } \\
\text { Samuels }\end{array}$ & $5.1 ; 5.2$ \\
\hline 269 & Onnia tomentosa (Fr.) P. Karst. & 2.4 \\
\hline 270 & $\begin{array}{l}\text { Ophiostoma polyporicola Constant. \& } \\
\text { Ryman }\end{array}$ & 2.4 \\
\hline 271 & Orbilia delicatula (P. Karst.) P. Karst. & 2.8 \\
\hline 272 & Otidea cf. cochleata (L.) Fuckel & 4.4 \\
\hline 273 & Otidea concinna (Pers.) Sacc. & 2.17 \\
\hline 274 & $\begin{array}{l}\text { Oudemansiella melanotricha (Dörfelt) M.M. } \\
\text { Moser }\end{array}$ & 4.4 \\
\hline
\end{tabular}

\begin{tabular}{|c|c|c|}
\hline N. ${ }^{\circ}$ & Especie & Zona \\
\hline 275 & Panaeolus acuminatus Quél. & 1.1 \\
\hline 276 & Panellus stipticus (Bull.) P. Karst. & $1.1 ; 5.1$ \\
\hline 277 & Peniophora proxima Bres. & 3.1 \\
\hline 278 & Peziza gerardii Cooke & 5.3 \\
\hline 279 & Peziza saniosa Schrad. & $2.4 ; 5.2$ \\
\hline 280 & $\begin{array}{l}\text { Peziza succosella (Le Gal \& Romagn.) } \\
\text { M.M. Moser ex Aviz.-Hersh. \& Nemlich }\end{array}$ & 3.1 \\
\hline 281 & Phaeolus schweinitzii (Fr.) Pat. & 5.1 \\
\hline 282 & $\begin{array}{l}\text { Phaeomarasmius rimulincola (Rabenh.) } \\
\text { Scherff. }\end{array}$ & 3.1 \\
\hline 283 & Phellodon niger (Fr.) P. Karst. & 4.3 \\
\hline 284 & Phlebia albida Fr. & 2.8 \\
\hline 285 & Phlebia centrifuga P. Karst. & 2.8 \\
\hline 286 & Phlebia nothofagi (G. Cunn.) Nakasone & 2.8 \\
\hline 287 & Phlebia radiata $\mathrm{Fr}$. & $2.4 ; 2.17$ \\
\hline 288 & $\begin{array}{l}\text { Phlebia tremellosa (Schrad.) Nakasone y } \\
\text { Burds }\end{array}$ & 2.4 \\
\hline 289 & Phloeomana clavata (Peck) Redhead & 3.1 \\
\hline 290 & Phloeomana speirea (Fr.) Redhead & $2.4 ; 3.1$ \\
\hline 291 & Pholiota astragalina (Fr.) Singer & 5.1 \\
\hline 292 & Pholiota flammans (Batsch) P. Kumm. & 2.4 \\
\hline 293 & Pholiota gummosa (Lasch) Singer & 4.3 \\
\hline 294 & Pholiota squarrosa (Vahl) P. Kumm. & $\begin{array}{l}2.8 ; 2.17 \\
5.2\end{array}$ \\
\hline 295 & *Pholiota squarrosoides (Peck) Sacc. & 2.8 \\
\hline 296 & Phyllotopsis nidulans (Pers.) Singer & $\begin{array}{l}2.4 ; 2.6 ; \\
4.1\end{array}$ \\
\hline 297 & Pithya vulgaris Fuckel & $2.4 ; 5.1$ \\
\hline 298 & *Plicariella scabrosa (Cooke) Spooner & 5.2 \\
\hline 299 & Plicaturopsis crispa (Pers.) D.A. Reid & 2.17 \\
\hline 300 & Pluteus cervinus (Schaeff.) P. Kumm. & 5.1 \\
\hline 301 & Pluteus salicinus (Pers.) P.Kumm & 2.4 \\
\hline 302 & Pluteus satur Kühner \& Romagn. & 2.16 \\
\hline 303 & Polyporus brumalis (Pers.) Fr. & 2.3 \\
\hline 304 & Polyporus ciliatus Fr. & 2.4 \\
\hline 305 & $\begin{array}{l}\text { Porostereum spadiceum (Pers.) Hjortstam \& } \\
\text { Ryvarden }\end{array}$ & 2.17 \\
\hline 306 & Postia caesia (Schrad.) P. Karst. & 2.4 \\
\hline 307 & Postia fragilis (Fr.) Jülich & $2.4 ; 3.1$ \\
\hline 308 & Proliferodiscus tricolor (Sowerby) Baral & 3.3 \\
\hline 309 & Propolis leonis (Tul. \& C. Tul.) Rehm & 3.1 \\
\hline 310 & Pseudoclitocybe cyathiformis (Bull.) Singer & 3.1 \\
\hline 311 & $\begin{array}{l}\text { Pseudohydnum gelatinosum (Scop.) P. } \\
\text { Karst. }\end{array}$ & $2.4 ; 5.1$ \\
\hline
\end{tabular}




\begin{tabular}{|c|c|c|}
\hline N. ${ }^{\circ}$ & Especie & Zona \\
\hline 312 & Pulvinula convexella (P. Karst.) Pfister & 5.3 \\
\hline 313 & Pycnoporellus fulgens (Fr.) Donk & 2.4 \\
\hline 314 & Ramaria botrytis (Pers.) Ricken & 2.17 \\
\hline 315 & $\begin{array}{l}\text { Ramaria broomei (Cotton \& Wakef.) R.H. } \\
\text { Petersen }\end{array}$ & 4.2 \\
\hline 316 & Ramaria flava (Schaeff.) Quél. & 1.1 \\
\hline 317 & Ramaria ignicolor Corner & 5.1 \\
\hline 318 & $\begin{array}{l}\text { Ramaria largentii Marr \& D.E. Stuntz ss. } \\
\text { auct. eur }\end{array}$ & 2.1 \\
\hline 319 & Ramaria mairei Donk & $2.8 ; 5.1$ \\
\hline 320 & $\begin{array}{l}\text { *Ramaria ochrochlora Furrer-Ziogas \& } \\
\text { Schild }\end{array}$ & 1.1 \\
\hline 321 & Ramaria subbotrytis (Coker) Corner & 2.8 \\
\hline 322 & Ramaria suecica (Fr.) Donk & 4.2 \\
\hline 323 & Ramariopsis crocea (Pers.) Corner & 3.1 \\
\hline 324 & Resupinatus applicatus (Batsch) Gray & $1.1 ; 2.4$ \\
\hline 325 & Reticularia lycoperdon Bull. & 2.4 \\
\hline 326 & $\begin{array}{l}\text { Rhizomarasmius epidryas (Kühner ex A. } \\
\text { Ronikier) A. Ronikier \& Ronikier }\end{array}$ & 5.7 \\
\hline 327 & $\begin{array}{l}\text { Rhodocollybia maculata (Alb. \& Schwein.) } \\
\text { Singer }\end{array}$ & 4.3 \\
\hline 328 & Rimbachia neckerae (Fr.) Redhead & $2.4 ; 3.1$ \\
\hline 329 & $\begin{array}{l}\text { Rosellinia mammiformis (Pers.) Ces. \& De } \\
\text { Not. }\end{array}$ & 3.1 \\
\hline 330 & Rugosomyces ionides (Bull.) Bon & 5.1 \\
\hline 331 & Russula aurea Pers. & $2.8 ; 5.1$ \\
\hline 332 & Russula badia Quélet & 1.1 \\
\hline 333 & Russula chloroides (Krombh.) Bres. & 2.4 \\
\hline 334 & Russula cyanoxantha (Schaeff.) Fr. & 2.8 \\
\hline 335 & Russula exalbicans (Pers.) Melzer \& Zvára & 4.2 \\
\hline 336 & Russula fellea (Fr.) Fr. & $2.4 ; 2.16$ \\
\hline 337 & Russula foetens Pers. & 4.2 \\
\hline 338 & Russula fragilis (Pers.: Fr.) Fries & 1.1 \\
\hline 339 & Russula luteotacta Rea & 4.2 \\
\hline 340 & Russula sanguinea Fr. & $\begin{array}{l}4.2,4.4 \\
5.7\end{array}$ \\
\hline 341 & Russula torulosa Bresadola & 4.4 \\
\hline 342 & Russula turci Bresadola & 5.1 \\
\hline 343 & Russula xerampelina (Schaeff.) Fr. & 4.4 \\
\hline 344 & Rutstroemia firma (Pers.) P. Karst. & 4.3 \\
\hline 345 & Sarcomyxa serotina (Pers.) P. Karst. & $2.17 ; 5.2$ \\
\hline 346 & $\begin{array}{l}\text { Scutellinia citrina (Massee y Crossl.) Y.J. } \\
\text { Yao y Spooner }\end{array}$ & 2.9 \\
\hline 347 & Scutellinia crinita (Bull.) Lambotte & 2.7 \\
\hline
\end{tabular}

\begin{tabular}{|c|c|c|}
\hline N. ${ }^{\circ}$ & Especie & Zona \\
\hline 348 & Scutellinia hyperborea T. Schumach. & 5.5 \\
\hline 349 & Scutellinia minor (Velen.) Svrcek. & 5.5 \\
\hline 350 & $\begin{array}{l}\text { Scutellinia trechispora (Berk. \& Broome) } \\
\text { Lambotte }\end{array}$ & $\begin{array}{l}1.2 ; 5.2 \\
5.5\end{array}$ \\
\hline 351 & Sistotrema brinkmannii (Bres.) J. Erikss. & 2.8 \\
\hline 352 & Sowerbyella imperialis (Peck) Korf & $\begin{array}{l}2.7 ; 2.17 \\
5.2\end{array}$ \\
\hline 353 & Sparassis crispa (Wulfen) Fr. & $2.4 ; 5.2$ \\
\hline 354 & Steccherinum ochraceum (Pers.) Gray & $2.4 ; 3.1$ \\
\hline 355 & Steccherinum oreophilum Lindsey \& Gilb. & 2.2 \\
\hline 356 & $\begin{array}{l}\text { Steccherinum robustius (J. Erikss. \& S. } \\
\text { Lundell) J. Erikss. }\end{array}$ & 2.17 \\
\hline 357 & Stereum hirsutum (Willd.) Pers. & $2.3 ; 3.1$ \\
\hline 358 & Stereum ochraceoflavum (Schwein.) Sacc. & 3.1 \\
\hline 359 & Stereum rugosum Pers. & 2.4 \\
\hline 360 & $\begin{array}{l}\text { Stereum sanguinolentum (Alb. \& Schwein.) } \\
\text { Fr. }\end{array}$ & 2.4 \\
\hline 361 & Stereum subtomentosum Pouzar & $2.2 ; 2.4$ \\
\hline 362 & $\begin{array}{l}\text { Strobilurus stephanocystis (Kühner \& } \\
\text { Romagn. ex Hora) Singer }\end{array}$ & 5.1 \\
\hline 363 & Stromatoscypha fimbriata (Pers.) Donk & 2.8 \\
\hline 364 & Stropharia aeruginosa (Curtis) Quél. & $2.4 ; 2.8$ \\
\hline 365 & Stropharia caerulea Kreisel & 3.1 \\
\hline 366 & $\begin{array}{l}\text { Stylodothis puccinioides (DC.) Arx \& E. } \\
\text { Müll }\end{array}$ & 2.4 \\
\hline 367 & Suillellus luridus (Schaeff.) Murrill & $2.4 ; 5.2$ \\
\hline 368 & Suillus variegatus (Sw.) Richon \& Roze & 5.1 \\
\hline 369 & $\begin{array}{l}\text { Tarzetta catinus (Holmsk.) Korf \& J.K. } \\
\text { Rogers }\end{array}$ & 2.6 \\
\hline 370 & Tarzetta cupularis (L.) Svrček & 2.2 \\
\hline 371 & Terana coerulea (Lam.) Kuntze & 3.1 \\
\hline 372 & Thelephora palmata (Scop.) Fr. & 4.4 \\
\hline 373 & $\begin{array}{l}\text { Tolypocladium capitatum (Holmsk.) Quandt, } \\
\text { Kepler \& Spatafora }\end{array}$ & 2.7 \\
\hline 374 & Trametes versicolor (L.) Lloyd & $2.3 ; 3.1$ \\
\hline 375 & Tremella simplex H.S. Jacks. \& G.W. Martin & $2.4 ; 5.1$ \\
\hline 376 & $\begin{array}{l}\text { Tremellodendropsis tuberosa (Grev.) D.A. } \\
\text { Crawford }\end{array}$ & 1.1 \\
\hline 377 & Trichaptum abietinum (Dicks.) Ryvarden & $2.4 ; 5.1$ \\
\hline 378 & Trichoderma viride Pers. & 2.7 \\
\hline 379 & Tricholoma atrosquamosum Sacc. & 3.1 \\
\hline 380 & Tricholoma aurantium (Schaeff.) Ricken & $2.4 ; 5.1$ \\
\hline 381 & Tricholoma bufonium (Pers.) Gillet & $\begin{array}{l}1.1 ; 2.4 \\
2.8 ; 5.1\end{array}$ \\
\hline
\end{tabular}




\begin{tabular}{|c|l|l|}
\hline N. $^{\circ}$ & \multicolumn{1}{|c|}{ Especie } & \multicolumn{1}{|c|}{ Zona } \\
\hline 382 & $\begin{array}{l}\text { Tricholoma cingulatum (Almfelt ex Fr.) } \\
\text { Jacobasch }\end{array}$ & 3.1 \\
\hline 383 & $\begin{array}{l}\text { Tricholoma fulvum (DC.) Bigeard \& H. } \\
\text { Guill. }\end{array}$ & 4.2 \\
\hline 384 & $\begin{array}{l}\text { *Tricholoma ilkkae Mort. Chr., Heilm.- } \\
\text { Claus., Ryman \& Niclas Bergius }\end{array}$ & 2.4 \\
\hline 385 & Tricholoma imbricatum (Fr.) P. Kumm. & 2.11 \\
\hline 386 & Tricholoma lascivum (Fr.) Gillet & 2.4 \\
\hline 387 & Tricholoma pardinum (Pers.) Quél. & 2.4 \\
\hline 388 & Tricholoma portentosum (Fr.) Quél. & 1.1 \\
\hline 389 & Tricholoma saponaceum (Fr.) P. Kumm. & 4.3 \\
\hline 390 & Tricholoma sejunctum (Sowerby) Quél. & 4.3 \\
\hline 391 & Tricholoma sulphureum (Bull.) P. Kumm. & 3.1 \\
\hline 392 & Tricholoma terreum (Schaeff.) P. Kumm. & 4.2 \\
\hline 393 & Tricholoma ustale (Fr.) P. Kumm. & 2.4 \\
\hline 394 & Tricholomopsis decora (Fr.) Singer & 5.1 \\
\hline 395 & Tricholomopsis rutilans (Schaeff.) Singer & $2.4 ; 5.1$ \\
\hline & \multicolumn{2}{|c|}{} \\
\hline
\end{tabular}

\subsection{Descripción taxonómica comentada de las especies de interés}

Phylum Ascomycota

Boudiera tracheia (Rehm ex Gamundí) Dissing \& T. Schumach. (Fig. 2).

$\equiv$ Plicaria tracheia Rehm ex Gamundí.

Material estudiado: Zona 5.5, en talud arenoso y muy húmedo de un riachuelo de montaña, 28-VIII-2015, leg. J. Hernanz, F. Pancorbo, F. Esteve-Raventós, M.A. Ribes, JACA-MICO-01016. Zona 2.19, en el borde de un humedal, 26-VIII-2016, leg. J. Hernanz, M.A. Ribes, JACAMICO-01031. Zona 2.20, en el borde de un humedal, 6-IX-2016, leg. A. Lorenzo, J. Hernanz, JACA-MICO-01024. Zona 2.9, en el borde de un humedal, 8-IX2016, leg. J. Hernanz, M.A. Ribes, JACA-MICO-01023. Ibidem, 29-VIII-2016, leg. J. Hernanz, S. Tello, M.A. Ribes, JACA-MICO-01187, JACA-MICO-01188.

Apotecios de 1-3 mm de anchura, gregarios o dispersos, subglobosos a pulvinados, sésiles, superficie convexa, desde prácticamente lisa a irregular por la presencia de numerosas protuberancias. Himenio de color marrón violeta, aunque en ocasiones se encuentran ejemplares descoloridos, casi blancos. Margen indiferenciado, más o menos ondulado, del mismo color que el himenio o ligeramente más oscuro. Exterior del mismo color y textura que el himenio, que posteriormente se aclara.

Ascas cilíndricas, operculadas, octospóricas, bi-triseriadas cuando las esporas están inmaduras y uniseriadas cuando están maduras, ápice redondeado, euamiloides a lo

\begin{tabular}{|c|l|l|}
\hline N. $^{\circ}$ & \multicolumn{1}{|c|}{ Especie } & \multicolumn{1}{|c|}{ Zona } \\
\hline 396 & $\begin{array}{l}\text { Trichophaea woolhopeia (Cooke \& W. } \\
\text { Phillips) Boud. }\end{array}$ & $2.4 ; 2.8$ \\
\hline 397 & Tubaria dispersa (L.) Singer & 3.1 \\
\hline 398 & Tubaria furfuracea (Pers.) Gillet & 2.7 \\
\hline 399 & $\begin{array}{l}\text { Tuber excavatum fo. monticellianum } \\
\text { (Vittadini) Ceruti }\end{array}$ & 2.4 \\
\hline 400 & Tulasnella violea (Quél.) Bourdot \& Galzin & 2.8 \\
\hline 401 & Typhula erythropus (Pers.) Fr. & 3.1 \\
\hline 402 & Typhula hollandii D.A. Reid & 3.1 \\
\hline 403 & Typhula uncialis (Grev.) Berthier & 3.1 \\
\hline 404 & Volvariella taylorii (Berk. \& Broome) Singer & 5.2 \\
\hline 405 & Xerula melanotricha Dörfelt & $2.8 ; 5.1$ \\
\hline 406 & Xylaria carpophila (Pers.) Fr. & 2.4 \\
\hline 407 & Xylaria hypoxylon L. & 3.1 \\
\hline 408 & $\begin{array}{l}\text { Xylodon asperus (Fr.) Hjortstam \& } \\
\text { Ryvarden }\end{array}$ & 2.8 \\
\hline 409 & Youngiomyces multiplex (Thaxt.) Y.J. Yao & 2.4 \\
\hline
\end{tabular}

largo de toda su longitud, sin uncínulo basal, de (350-)355$442(-460) \times(30,1-) 32,4-46,5(-48,5) \mu \mathrm{m}, \mathrm{N}=32, \mathrm{Me}=402$ $\times 40,1 \mu \mathrm{m}$. Ascosporas globosas, hialinas, en la juventud con varios LBs, ligeramente amarillentas y con varios LBs más grandes cuando están maduras, de (22-)23,8-25,2($26,1) \times(21,9-) 23,7-25,2(-25,7) \mu \mathrm{m}, \mathrm{Q}=1, \mathrm{~N}=40, \mathrm{Me}=$ $24,5 \times 24,3 \mu \mathrm{m}, \mathrm{Qe}=1$, sin contar la ornamentación, que consiste en grandes espinas cónicas, rectas, cianófilas, con el ápice obtuso a plano y en ocasiones ligeramente engrosado o bifurcado, de (4,4-)4,8-5,9(-6,5) $\mu \mathrm{m}, \mathrm{N}=69, \mathrm{Me}=5,4$ $\mu \mathrm{m}$ de altura, con la base estrecha, de (1-)1,1-1,8(-2) $\mu \mathrm{m}, \mathrm{N}$ $=50, \mathrm{Me}=1,5 \mu \mathrm{m}$. Paráfisis cilíndricas, septadas, muy rectas y alineadas pero con la superficie ligeramente sinuosa, ensanchándose progresivamente hacia el ápice, que excede en (27-)37,7-75,7(-93,2) $\mu \mathrm{m}, \mathrm{N}=52, \mathrm{Me}=58,2 \mu \mathrm{m}$, la altura de las ascas, con la base más o menos hialina y progresivamente rellenas de pigmento de color marrón violeta, uniforme o bien en forma de gútulas de tamaño medianogrande, sobre todo en las paráfisis cercanas al margen, con la última célula de $(54,6-) 58-84,9(-89,3) \times(8,2-) 9,3-10,6(-$ $11,1) \mu \mathrm{m}, \mathrm{N}=23, \mathrm{Me}=70,2 \times 9,9 \mu \mathrm{m}$. Excípulo medular con textura intricata, con hifas de $(6,6-) 7,6-11,4(-12,8) \mu \mathrm{m}$, $\mathrm{N}=43, \mathrm{Me}=9,2 \mu \mathrm{m}$ de anchura, con presencia de algunas células globosas y pequeñas, intercaladas, que son mucho más abundantes y de mayor tamaño en el subhimenio. Excípulo ectal con textura globulosa, sobre todo en la base del apotecio, con células de $(26,2-) 28,1-42,3(-48,6) \times(18,2-$ )21,6-31,2(-34,8) $\mu \mathrm{m}, \mathrm{N}=36, \mathrm{Me}=34,8 \times 26,1 \mu \mathrm{m}$, haciéndose más cilíndrico-claviformes hacia la parte superior, terminando en el margen en pelos hifoides claviformes y netamente engrosados en el ápice, con la última célula de $(29,6-) 35,1-72,3(-96,9) \times(14,1-) 15,9-26,1(-27,9) \mu \mathrm{m}, \mathrm{N}$ $=50, \mathrm{Me}=54,2 \times 21,1 \mu \mathrm{m}$. 


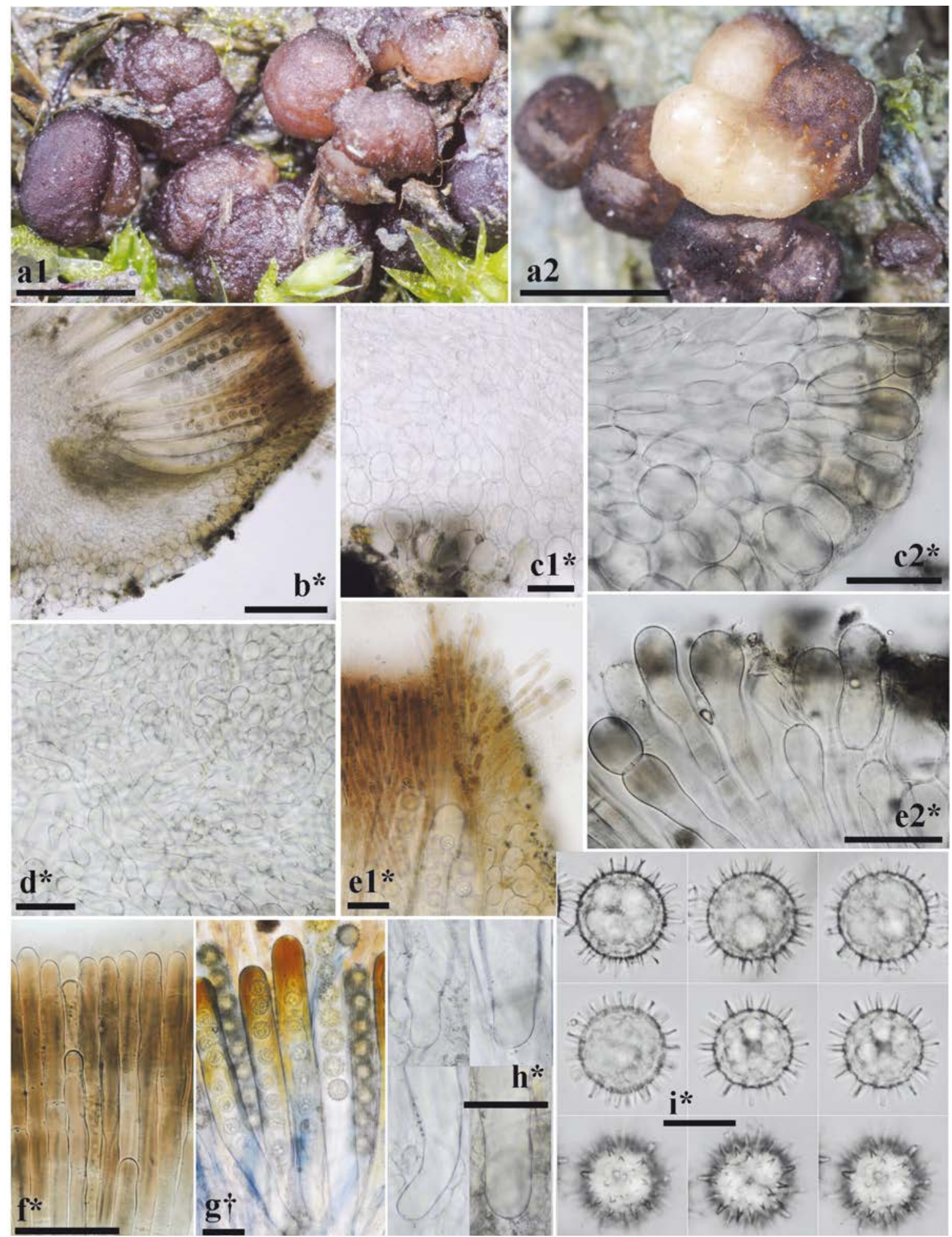

Figura 2: Caracteres morfológicos de Boudiera tracheia. a. Apotecios en fresco. b. Sección transversal del apotecio. c. Excípulo ectal en sección transversal. c1. Excípulo ectal en la base. c2. Excípulo ectal en el flanco. d. Excípulo medular en sección transversal. e. Células marginales en sección transversal. f. Paráfisis. g. Ascas. h. Base de las ascas. i. Ascosporas. Escala: $2 \mathrm{~mm}=\mathrm{a} ; 200 \mu \mathrm{m}=\mathrm{b}$; $50 \mu \mathrm{m}=\mathrm{c}-\mathrm{h} ; 20 \mu \mathrm{m}=\mathrm{i}$. Medio de montaje: $\mathrm{H}_{2} \mathrm{O}=\mathrm{b}-\mathrm{f}$, h-i; IKI = g. Fotos: todas a partir de JACA-MICO-01016.

Figure 2: Morphological characters of Boudiera tracheia. a. Fresh apothecia. b. Apothecial cross section. $\boldsymbol{c}$. Cross section of the ectal excipulum. c1. Ectal excipulum at the base. c2. Ectal excipulum at the flank. d. Cross section of the medullary excipulum. e. Cross section of the marginal cells. f. Paraphyses. g. Asci. h. Ascus base. i. Ascospores. Bar: $2 \mathrm{~mm}=a ; 200 \mu \mathrm{m}=b ; 50 \mu \mathrm{m}=c$-h; $20 \mu \mathrm{m}=i$. Mounting medium: $\mathrm{H}_{2} \mathrm{O}=b-f, h-i ; I K I=g$. Photos: all from JACA-MICO-01016. 
Observaciones: Siguiendo las claves de Dissing \& Schumacher (1979), por sus esporas sin retículo, con espinas de 3-6 $\mu \mathrm{m}$ de altura y menos de $2 \mu \mathrm{m}$ de anchura en la base, con el ápice obtuso o ligeramente ensanchado o bifurcado, llegamos claramente a la especie descrita. Muy similares son otras dos especies que presentan espinas con la base más ancha, de 2-3 $\mu \mathrm{m}$ : Boudiera acanthospo$r a$ Dissing \& T. Schumach., con esporas de menor tamaño, de 18,5-22,8 $\mu \mathrm{m}$ y espinas acabadas en punta, y $B$. echinulata (Seaver) Seaver (三 Sphaerosoma echinulatum Seaver), con esporas de tamaño muy similar, de 21,5-26,5 $\mu \mathrm{m}$, pero con pequeñas crestas en la base de las espinas, formando un retículo incompleto. Hay otras dos especies similares con espinas que no superan los $3 \mu \mathrm{m}$ de altura, que son $B$. dennisii Dissing \& Sivertsen y B. purpurea Eckbl.; la primera tiene un tamaño hasta de $8 \mathrm{~mm}$ y el excípulo ectal con textura prismatica y la segunda un tamaño hasta de $2 \mathrm{~mm}$ y un excípulo escasamente desarrollado (Medardi, 2007). En Europa se conoce al menos en Alemania, Dinamarca, Francia y Noruega (Hirsch, 1980; Dissing \& Schumacher, 1979; Chaillet et al., 2005; Dissing et al., 2000). Esta especie está citada en España al menos en Álava (Oleta, Aramaio, 7-VI-2006, 8-VI-2006, 15-VI-2006) (Arauzo et al., 2007), Asturias (Lena, hayedo de Valgrande, 31-VII-2009) (Rubio, 2009) y Vizcaya (Orozketa, Iurreta, 25-V-2006, 3-VI-2006) (Arauzo et al., 2007).

Calycellina chlorinella (Ces.) Dennis (Fig. 3).

$\equiv$ Hymenoscyphus chlorinellus (Ces.) Kuntze.

$\equiv$ Peziza chlorinella Ces.

$\equiv$ Pezizella chlorinella (Ces.) Sacc.

Material estudiado: Zona 2.3, sobre ramas de Echinospartum horridum, 2-X-2014, leg. J. Hernanz, JACA-MICO-01013.

Apotecios de 375-500 $\mu \mathrm{m}$ de anchura, gregarios o dispersos, poco confluentes, ligeramente cupuliformes a discoides, sésiles. Himenio de color blanco nacarado a cremoso, ligeramente traslúcido, cóncavo a casi plano en la madurez. Exterior y estípite del mismo color que el himenio. Margen con pequeños pelos blanquecinos.

Ascas cilíndricas, inoperculadas, octospóricas, biseriadas, con el ápice redondeado, ligeramente hemiamiloides o euamiloides (algunos ápices ascales toman una coloración rojo-marrón sucio y otros azul oscuro en presencia de IKI y todos presentan una coloración azul más claro pero débil en presencia de IKI tras su tratamiento con $\mathrm{KOH}$, estrechándose hace la base, con uncínulo basal, de (39,9-)42,9-50,0($52,7) \times(4,2-) 4,5-5,3(-5,5) \mu \mathrm{m}, \mathrm{N}=23, \mathrm{Me}=46,2 \times 4,9 \mu \mathrm{m}$. Ascosporas prácticamente cilíndricas, ligeramente más anchas en el centro que en los extremos, algunas algo alantoides, con los extremos redondeados, en ocasiones con un pequeño LB cercano a cada extremo, lisas, hialinas, de $(6,1-) 6,8-8,5(-8,9) \times(1,3-) 1,5-1,8(-2,0) \mu \mathrm{m}, \mathrm{Q}=(3,6-) 3,9-$ $5,3(-5,9), \mathrm{N}=48, \mathrm{Me}=7,6 \times 1,7 \mu \mathrm{m}, \mathrm{Qe}=4,6$. Paráfisis cilíndricas, septadas, con un gran VB cilíndrico, refringente, que ocupa prácticamente toda la célula terminal y ligera- mente engrosadas en el ápice, de (1,7-)2-2,8(-3,3) $\mu \mathrm{m}, \mathrm{N}=$ $51, \mathrm{Me}=2,4 \mu \mathrm{m}$. Excípulo medular no observado. Excípulo ectal, con textura prismatica, con células de (6,7-)7,2$11,6(-13,6) \times(2,2-) 2,8-4,9(-5,8) \mu \mathrm{m}, \mathrm{N}=46, \mathrm{Me}=9,4 \times 3,9$ $\mu \mathrm{m}$, haciéndose más cortas hacia el margen. Margen con pelos hifoides hialinos, cilíndricos, lisos, ligeramente flexuosos, con un VB similar al de las paráfisis y el ápice ligeramente ensanchado, de (2,5-)2,6-3,3(-4) $\mu \mathrm{m}, \mathrm{N}=69, \mathrm{Me}=3$ $\mu \mathrm{m}$, que se presentan entremezclados con paráfisis.

Observaciones: Es una especie descrita en 1854 como Peziza chlorinella Ces., que posteriormente ha pasado por numerosos géneros como Calloria Fr., Habrostictis Fuckel, Pezizella Fuckel, Mollisia (Fr.) P. Karst., Ocellaria Tul. \& C. Tul., Hymenoscyphus Gray, Hyalinia Boud. y Mollisiella Boud., lo que demuestra la controversia que ha suscitado su clasificación. Recientemente Helleman et al. (2013) discuten las diferencias entre los géneros Calloriella Höhnel, Calycellina Höhnel, Crustomollisia Svrček y Micropeziza Fuckel, señalando varias diferencias importantes entre Micropeziza y Calycellina: 1) las paráfisis de Micropeziza forman un pseudoepitecio que generalmente está ausente en Calycellina; aunque Calycellina en ocasiones presente un gel alrededor de los ápices de las paráfisis, no hay una capa granular cubriendo el gel, 2) los VBs refringentes en la parte apical de las paráfisis de Calycellina son distintos a los de Micropeziza, 3) las paráfisis de Micropeziza tienen un ápice claviforme a globoso, mientras que las de Calycellina no están infladas, 4) las células del margen de Calycellina normalmente tienen paredes delgadas y terminan en pelos o pelos hifoides y contienen generalmente un VB refractivo en la célula basal, mientras que en Micropezi$z a$ tienen paredes gruesas, nunca forman pelos y generalmente carecen de VBs y 5) los apotecios de Calycellina son más delicados y tienen colores blanquecinos o amarillentos, en contraste con los de Micropeziza que son más robustos y de colores marrones. Siguiendo las claves de Lowen \& Dumont (1984) 1legamos claramente a esta especie por su hábitat en ramas, su color claro, ascas mayores de $33 \mu \mathrm{m}$ y menores de $65 \mu \mathrm{m}$, con 8 esporas no septadas, mayores de $8 \mu \mathrm{m}$ y paráfisis no ramificadas. La especie más próxima sería Calycellina pulviscula (Cooke) Dennis, con ascas de 33 x $4 \mu \mathrm{m}$ con el ápice cónico, que crece sobre ramas de Phytolacca, himenio de color amarillo limón, base con un anillo basal, margen finamente denticulado, esporas de 5-6 × 0,5 $\mu \mathrm{m}$ y paráfisis obtusas de 2-2,5 $\mu \mathrm{m}$ de anchura. Se conoce al menos en Inglaterra (Wiltshire, 4-X-1973, sobre tallos herbáceos y Yorkshire 4-XI-1973, sobre Arctium) (Dennis, 1974), Países Bajos (Oeffelt, 4-XI-2006, sobre Reynoutria japonica), Francia (Haute Garonne, otoño de 1880, sobre Cannabis sativa) (Baral \& Marson, 2005) y Dinamarca (12 recolectas en los años 1983, 1996, 2003, 2005, 2006, 2009, 2014 y 2015 sobre tallos de hierbas, césped, Urtica, Epilobium angustifolium y Cirsium) (Petersen, 2017). En la bibliografía consultada no hemos encontrado ninguna cita anterior en España. 

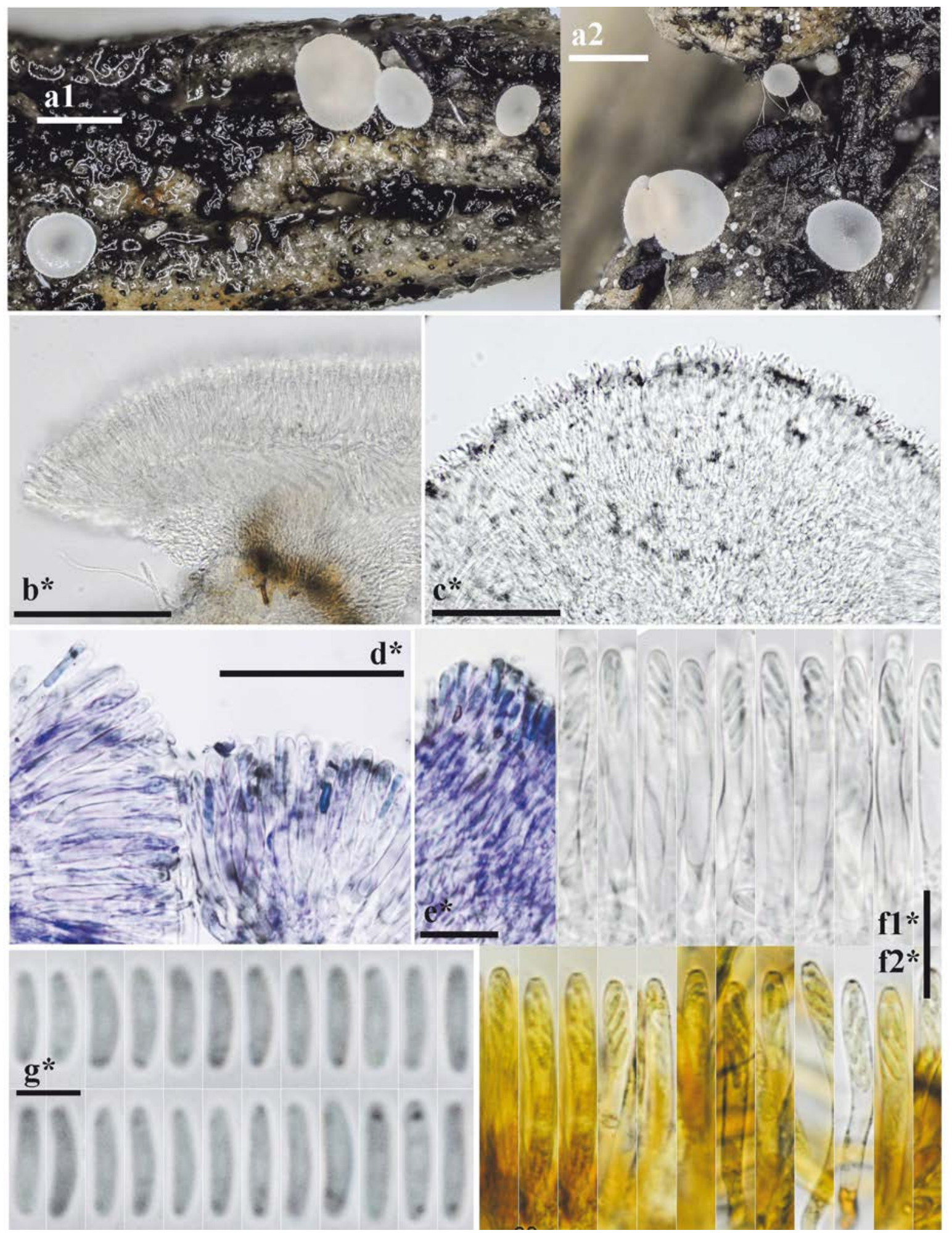

Figura 3: Caracteres morfológicos de Calycellina chlorinella. a. Apotecios en fresco. b. Sección transversal del apotecio. c. Vista exterior del apotecio. d. Paráfisis y ascas. e. Margen y pelos hifoides. f. Ascas. g. Ascosporas. Escala: $500 \mu \mathrm{m}=\mathrm{a} ; 100 \mu \mathrm{m}=\mathrm{b}-\mathrm{c}$; $50 \mu \mathrm{m}=\mathrm{d} ; 20 \mu \mathrm{m}=\mathrm{e}-\mathrm{f} ; 5 \mu \mathrm{m}=\mathrm{g}$. Medio de montaje: $\mathrm{H}_{2} \mathrm{O}=\mathrm{b}-\mathrm{c}, \mathrm{fl}, \mathrm{g} ; \mathrm{CRB}=\mathrm{d}-\mathrm{e}$; IKI = f2

Fotos: todas a partir de JACA-MICO-01013.

Figure 3: Morphological characters of Calycellina chlorinella. a. Fresh apothecia. b. Apothecial cross section. c. Apothecia, outer view. d. Paraphyses and asci. e. Margin and hyphoid hairs. f. Asci. g. Ascospores. Bar: $500 \mu m=a ; 100 \mu m=b-c ; 50 \mu m=d$;

$20 \mu \mathrm{m}=e-f ; 5 \mu m=g$. Mounting medium: $\mathrm{H}_{2} \mathrm{O}=b-c, f 1, g ; C R B=d-e$; IKI = f2. Photos: all from JACA-MICO-01013. 
Chlorencoelia versiformis (Pers.) J.R. Dixon (Fig. 4).

$\equiv$ Peziza versiformis Pers.

$\equiv$ Chlorociboria versiformis (Pers.) Seaver.

$\equiv$ Chlorosplenium versiforme (Pers.) De Not.

Material estudiado: Zona 2.7, sobre tronco en descomposición de Fagus sylvatica, 27-VIII-2015, leg. F. Serrano, S. Serrano, JACA-MICO-00731. Zona 2.4, sobre tronco en descomposición de Fagus sylvatica, 30-VIII2015, leg. G. Sánchez, F. Esteve-Raventós, F. Pancorbo, M.A. Ribes, JACA-MICO-01185.
Apotecios hasta de $20 \mathrm{~mm}$ de anchura, gregarios o solitarios, en ocasiones cespitosos, estipitados, cupuliformes a profundamente infundibuliformes en la juventud llegando a ser planos o convexos e incluso con el margen muy involuto y el borde frecuentemente ondulado en la madurez. Himenio de color variable, desde el amarillento pajizo al verde oliva claro en ejemplares frescos, que al ir secándose llega hasta verde oliva oscuro o marrón, con el centro siempre más oscuro y verdoso, con la superficie prácticamente lisa a irregular por la existencia de numerosas protuberancias, surcos o venosidades. Exterior y es-

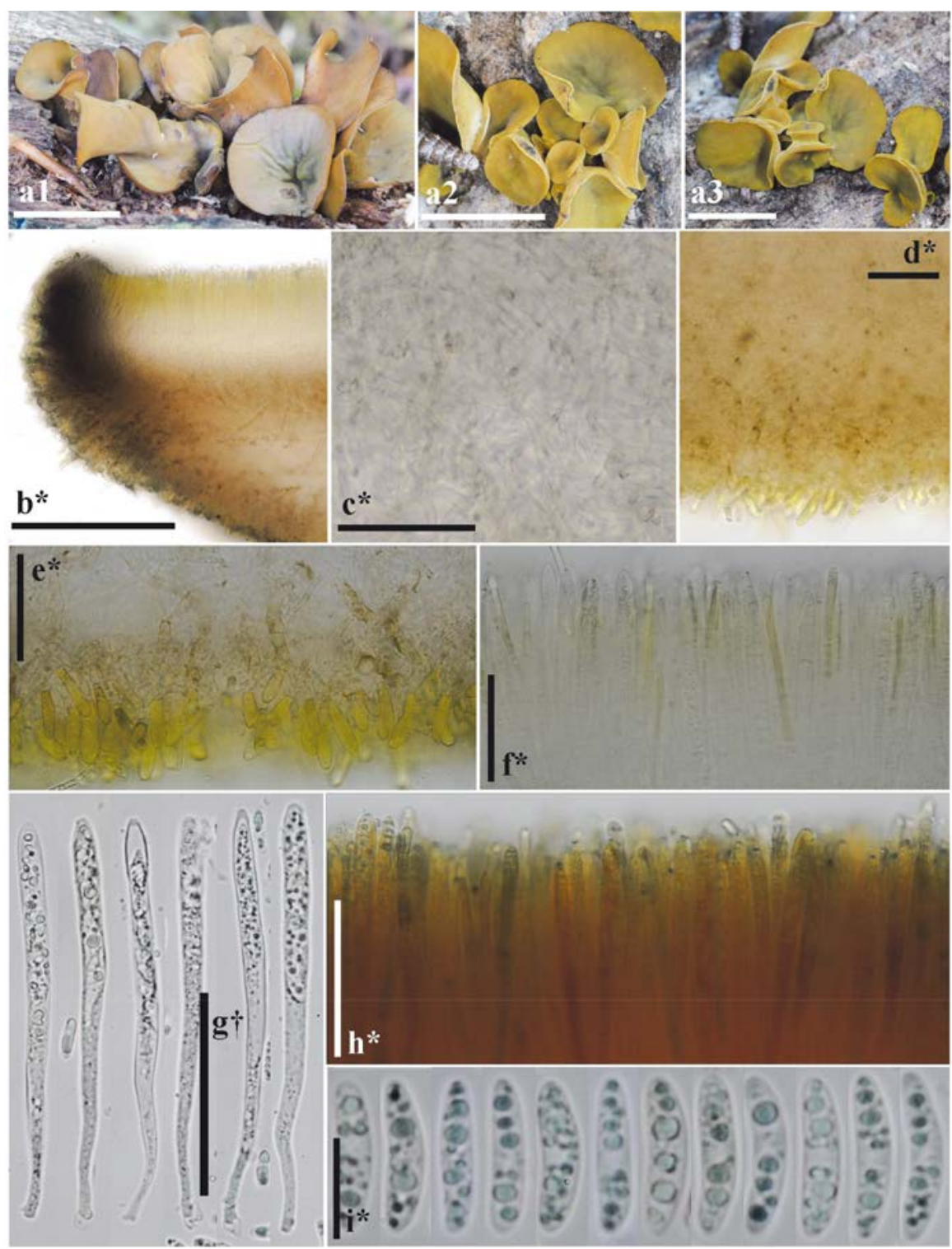

Figura 4: Caracteres morfológicos de Chlorencoelia versiformis. a. Apotecios en fresco. b. Sección transversal del apotecio. c. Excípulo medular. d. Excípulo ectal en la base del apotecio. e. Tomento del excípulo ectal. f. Paráfisis. g. Base de las ascas. h. Ascas. i. Ascosporas. Escala: $20 \mathrm{~mm}=\mathrm{a} 1-3 ; 200 \mu \mathrm{m}=\mathrm{b} ; 50 \mu \mathrm{m}=\mathrm{c}-\mathrm{h} ; 10 \mu \mathrm{m}=\mathrm{i}$. Medio de montaje: $\mathrm{H}_{2} \mathrm{O}=\mathrm{b}-\mathrm{g}$, i; IKI = h. Fotos: JACA-MICO-00731= a1, b-i; JACA-MICO-01185=a2-a3.

Figure 4: Morphological characters of Chlorencoelia versiformis. a. Fresh apothecia. b. Apothecial cross section. c. Medullary excipulum. d. Ectal excipulum at the apothecia base. e. Ectal excipulum tomentum. f. Paraphyses. g. Ascus base. h. Asci.

i. Ascospores. Bar: $20 \mathrm{~mm}=a 1-3 ; 200 \mu \mathrm{m}=b ; 50 \mu \mathrm{m}=c-h ; 10 \mu \mathrm{m}=i$. Mounting medium: $\mathrm{H}_{2} \mathrm{O}=b-g, i ; I K I=h$. Photos: JACA-MICO-00731=a1, b-i; JACA-MICO-01185=a2-a3. 
típite desde un color marrón pajizo más oscuro que el himenio a amarillo verdoso claro cubierto por una pruina amarillenta que le da un aspecto aterciopelado, en ocasiones con pliegues o surcos longitudinales.

Ascas cilíndrico-claviformes, inoperculadas, octospóricas, con las esporas biseriadas, ápice redondeado a ligeramente cónico, intensamente euamiloide, estrechándose hace la base, con uncínulo basal, de (116-)117-135(-137) $\times$ $(6,1-) 6,7-8,6(-8,9) \mu \mathrm{m}, \mathrm{N}=21, \mathrm{Me}=126 \times 7,8 \mu \mathrm{m}$ en vivo y de (97,7-)98,7-106(-119) × (5,4-)5,44-7,2(-8,6) $\mu \mathrm{m}, \mathrm{N}=$ $10, \mathrm{Me}=103 \times 6,4 \mu \mathrm{m}$ en material muerto. Ascosporas cilíndrico-alantoides, lisas, hialinas, ligeramente más anchas en el centro, con los extremos redondeados, con 3-4 grandes LBs y varios más pequeños, de (12,1-)13,5-16,0($17,0) \times(3,1-) 3,3-3,9(-4,1) \mu \mathrm{m}, \mathrm{Q}=(3,0-) 3,6-4,5(-4,7)$, $\mathrm{N}=50, \mathrm{Me}=14,6 \times 3,6 \mu \mathrm{m}, \mathrm{Qe}=4,0$. Paráfisis cilíndricas, septadas, con un gran VB cilíndrico, de color amarillo verdoso, que ocupa prácticamente toda la célula terminal y ligeramente engrosadas en el ápice, de $(2,9-) 3,2-4,6(-5,6)$ $\mu \mathrm{m}, \mathrm{N}=65, \mathrm{Me}=3,9 \mu \mathrm{m}$ de anchura. Subhimenio de color marrón y textura intricata. Excípulo medular muy ancho, con textura intricata, compuesto por células de color amarillo pardo claro, de $(2,4-) 2,8-4,3(-5,2) \mu \mathrm{m}, \mathrm{N}=39$, $\mathrm{Me}=3,5 \mu \mathrm{m}$ de anchura. Excípulo ectal estrecho, ligeramente más oscuro que el medular, con una estructura compleja: las células con textura intricata del excípulo medular se van haciendo ligeramente más gruesas y con pigmentación parietal aislada de color marrón; a continuación presenta una fina capa de células con textura globulosaangularis, con células de (15,5-)16,3-27,4(-34,1) $\times$ $(4,9-) 5,2-7(-9,2) \mu \mathrm{m}, \mathrm{N}=55, \mathrm{Me}=23 \times 6,1 \mu \mathrm{m}$, que finalmente dan origen a un tomento perpendicular compuesto por 2-3 células con textura prismatica, siendo la última siempre claviforme y completamente rellena con un VB refringente de color amarillo verdoso similar al de las paráfisis, con presencia ocasional de pequeños VBs globosos similares a las anteriores en las células basales, que son más prismáticas.

Observaciones: Es una especie descrita en 1798 como Peziza versiformis Pers., que posteriormente ha sido publicada en varios géneros, como Chlorosplenium Fr., Coryne Ness, Helotium Pers., Midotis Fr., Chlorociboria Seaver ex C.S. Ramamurthi, Korf \& L.R. Batra e incluso como Craterellus caespitosus Peck. Esta especie es muy parecida a Chlorencoelia torta (Schwein.) J.R. Dixon, que tiene las esporas irregularmente elipsoidales (no cilíndrico alantoides), casi siempre bigutuladas y bastante más pequeñas, de $(5,6-) 9-11(-12) \times 2-4 \mu \mathrm{m}$ y las células del excípulo medular más oscuras (Dixon, 1975). Los análisis moleculares (ITS), que incluyen secuencias de recolecciones recientes de Estonia y USA, también distinguen estas dos especies, además de que las ascosporas examinadas en ambas colecciones apoyan esta clara distinción: ascosporas subcilíndrico-alantoides con 2-6 gútulas en $C$. versiformis y subcilíndrico-elipsoides con 2 gútulas en $C$. torta. Por otra parte, la filogenia ITS no apoya la monofilia de $C$. torta: recolecciones etiquetadas como C. torta de Norte América, recolectadas cerca de la localidad del tipo, son distintas de recolecciones del Su- deste Asiático, lo que sugiere que representan distintas especies (Pärtel et al., 2017). C. versiformis está descrita sobre madera, tanto de angiospermas como de gimnospermas, en Betula, Nothofagus, Quercus, Tsuga y Fagus, sobre todo en otoño, pero también en primavera, y está presente fuera de Europa al menos en Argentina, Canadá (British Columbia, Ontario, Quebec), Corea, Estados Unidos (Michigan, Minesota, New Hampshire, Nueva York, Carolina del Norte, Ohio, Pensilvania, Virginia del Este), Japón (Hokkaido) y Nueva Zelanda. En Europa está citada en Austria, Dinamarca, Estonia, Finlandia, Francia, Noruega, Polonia, Reino Unido, Rusia, Suecia, Turquía, Ucrania y Yugoslavia (Dixon, 1975; Güngör et al., 2013; Morozova, 2014). En España está citada al menos en Asturias (Somiedo, Pola de Somiedo, La Trapa, 12-X-2001, 705 m, sobre madera de Corylus avellana) (Rubio et al., 2006), Cantabria (Mortera, 16-V-1998, 40 m, sobre rama de Eucalyptus globulus) (Alonso et al., 2001) y Navarra (Ochagavía, 20IX-2009) (Mikel Tapia, com. personal).

Cupulina montana Dougoud, Van Vooren \& M. Vega (Fig. 5).

Material estudiado: Zona 2.9, en talud de tierra, muy húmedo, de un riachuelo de montaña, 29-VIII-2016, leg. S. Tello, J. Hernanz, M.A. Ribes, JACA-MICO-01018, duplicado en MAR-290816 173. Ibidem, en taludes de la misma zona, 30-IX-2016, leg. A. Lorenzo, J. Hernanz, JACA-MICO-01072. Secuencia ITS GenBank MF345961.

Apotecios de 2-3 mm de anchura, gregarios o dispersos, ligeramente cupuliformes, hemisféricos por la parte inferior, sésiles, más o menos embebidos en el sustrato. Himenio de color naranja ocráceo claro, ligeramente cóncavo a casi plano en la madurez. Exterior rugoso, de color más claro que el himenio. Margen diferenciado, ligeramente excedente y curvado hacia el interior, crenulado, de color amarillo claro a casi blanco.

Ascas cilíndricas, operculadas, octospóricas, biseriadas, con el ápice redondeado, inamiloides, con uncínulo basal, de (242-)249-278(-292) × (17,5-)19,3-23,5(-24,5) $\mu \mathrm{m}$, $\mathrm{N}=24, \mathrm{Me}=264 \times 21,5 \mu \mathrm{m}$. Ascosporas fusiformes, con los extremos agudos y homopolares, de (28-)29,1$33,3(-38,9) \times(11,2-) 11,8-13,2(-14,4) \mu \mathrm{m}, \mathrm{Q}=(2,3-) 2,4-$ $2,6(-2,8), \mathrm{N}=100, \mathrm{Me}=31,2 \times 12,4 \mu \mathrm{m}, \mathrm{Qe}=2,5$, hialinas, lisas, completamente llenas de LBs, refringentes en la madurez, de $(2,2-) 2,8-3,8(-4,1) \mu \mathrm{m}, \mathrm{N}=50, \mathrm{Me}=3,3$ $\mu \mathrm{m}$ de anchura. Paráfisis cilíndricas, septadas, de la misma longitud que las ascas, bifurcadas en la base, con pigmentación amarillenta y el ápice ligeramente engrosado, de (3,7-)4-6,1(-6,6) $\mu \mathrm{m}, \mathrm{N}=61, \mathrm{Me}=5,1 \mu \mathrm{m}$. Excípulo medular con textura intricata, con hifas de $(3,3-) 4,5-$ $7,3(-9,3) \mu \mathrm{m}, \mathrm{N}=37, \mathrm{Me}=6 \mu \mathrm{m}$ de anchura. Excípulo ectal con textura globulosa-angularis, de células ligeramente comprimidas y perpendiculares a la superficie, de $(18,8-) 22,9-35,4(-40,4) \times(14,4-) 16,4-26,5(-29,3) \mu \mathrm{m}, \mathrm{N}$ $=50, \mathrm{Me}=28,3 \times 21,8 \mu \mathrm{m}$, haciéndose más pequeñas y globosas hacia el margen, prolongándose en pelos hifoides cilíndricos, ligeramente engrosados en el ápice, de 


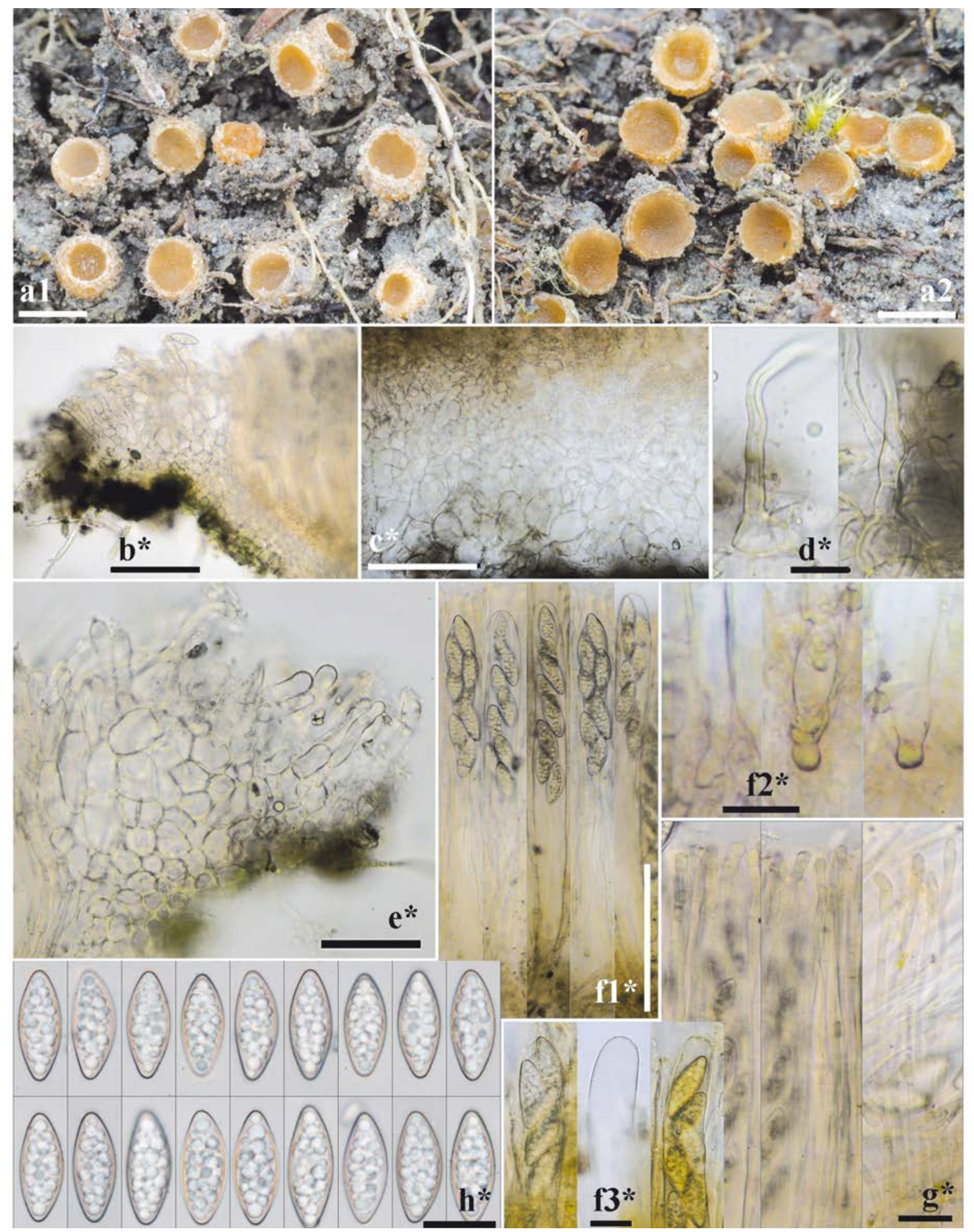

Figura 5: Caracteres morfológicos de Cupulina montana. a. Apotecios en fresco. b. Sección transversal del apotecio. c. Excípulo medular y ectal. d. Hifas de anclaje. e. Pelos del margen. f. Ascas. f1. Ascas enteras. f2. Base de las ascas. f3. Apice de las ascas. g. Paráfisis. h. Ascosporas. Escala: $3 \mathrm{~mm}=\mathrm{a} ; 100 \mu \mathrm{m}=\mathrm{b}, \mathrm{c}, \mathrm{f} 1 ; 50 \mu \mathrm{m}=\mathrm{e} ; 20 \mu \mathrm{m}=\mathrm{d}$, f2-h. Medio de montaje: $\mathrm{H}_{2} \mathrm{O}=\mathrm{b}-\mathrm{f} 2$, g-h; $\mathrm{IKI}=\mathrm{f} 3$. Fotos: todas a partir de JACA-MICO-01018.

Figure 5: Morphological characters of Cupulina montana. a. Fresh apothecia. b. Apothecial cross section. c. Medullary and ectal excipulum. d. Anchoring hyphae. e. Margin hairs. f. Asci. f1. Full asci. f2. Ascus base. f3. Ascus tip. g. Paraphyses. h. Ascospores. Bar: $3 \mathrm{~mm}=a ; 100 \mu \mathrm{m}=b, c, f 1 ; 50 \mu \mathrm{m}=e ; 20 \mu \mathrm{m}=d$, f2-h. Mounting medium: $\mathrm{H}_{2} \mathrm{O}=b$ - $f 2, \mathrm{~g}$ - $h$; IKI $=f 3$.

Photos: all from JACA-MICO-01018. 
$(38,1-) 45-53,5(-59) \times(6,3-) 6,5-10,4(-11,4) \mu \mathrm{m}, \mathrm{N}=14$, $\mathrm{Me}=49,6 \times 8,5 \mu \mathrm{m}$. Hifas de anclaje muy largas, septadas, de paredes gruesas refringentes, desarrollándose a partir de células globosas del excípulo ectal, más abundantes en la base del apotecio.

Observaciones: La primera impresión sobre el terreno fue la de haber encontrado alguna especie del género Leucoscypha Boud. emend. Rifai, bien Leucoscypha semiimmersa (P. Karst.) Svrček o L. patavina (Cooke \& Sacc.) Svrček, sin embargo los caracteres microscópicos la separan claramente por sus esporas mayores, multigutuladas y su hábitat montano. Se diferencia de las especies del género Leucoscypha en que estas últimas tienen esporas más pequeñas, con dos grandes gútulas y con una reacción carminófila de los núcleos de las paráfisis. Nuestras recolectas coinciden tanto en su hábitat como en los caracteres macro y microscópicos, así como en la secuencia obtenida de la región ITS, con la descripción original de Dougoud et al. (2015), única referencia publicada hasta el momento, quienes señalan que se trata de una especie exclusiva del ambiente montano, a partir de $1.600 \mathrm{~m}$, en suelo calcáreo, desnudo o cubierto de musgo. Nuestras recolectas están ambas realizadas en sendos taludes muy húmedos, arenosos y musgosos de un pequeño riachuelo de montaña. La distribución conocida de la especie está limitada a las recolectas de los autores de la especie y otros micólogos colaboradores, en Austria (Vorarlberg), Francia (Savoie, HauteSavoie, Hautes-Alpes y Hautes-Pyrénées) y Suiza (Tessin, Uri y Alpe du Piora), por lo que estas recolectas pirenaicas serían las primeras citas después de la descripción original, apreciándose claramente la localización exclusivamente alpina de la especie, tanto en los Alpes austríacos, franceses y suizos como en el Pirineo francés y español.

Peziza gerardii Cooke (Fig. 6).

= Peziza violacea W.R. Gerard.

= Peziza ionella Quél.

$\equiv$ Galactinia gerardii (Cooke) Bánhegyi.

$\equiv$ Humaria gerardii (Cooke) Sacc.

三Leucoloma gerardii (Cooke) Lamb.

三 Plicaria gerardii (Cooke) Bánhegyi.

Material estudiado: Zona 5.3, en un talud de tierra dentro de un bosque de Fagus sylvatica y Abies alba, 30-VIII2014, leg. J. Hernanz, JACA-MICO-00297. Ibidem 16-X2015, JACA-MICO-01015. Zona 2.1, sobre tierra desnuda, 27-VIII-2015, leg. S. Serrano, JACA-MICO-01044. Zona 5.3, en un talud de tierra dentro de un bosque viejo de $\mathrm{Fa}$ gus sylvatica y Abies alba, 16-X-2015, leg. J. Hernanz, M.A. Ribes, JACA-MICO-01054. Zona 2.9, en tierra desnuda y muy húmeda entre la hierba, 29-VIII-2016, leg. S. Tello, J. Hernanz, M.A. Ribes, JACA-MICO-01186.

Apotecios de 3-5,5 $\mathrm{mm}$ de anchura, discoides a poco profundamente cupuliformes, con el himenio cóncavo a casi plano, irregular, de color violeta oscuro, con el exterior algo más claro a prácticamente del mismo color, glabro y con numerosos granos de tierra adheridos, margen de ligera a notablemente festoneado o dentado.
Ascas cilíndricas, operculadas, octospóricas, uniseriadas, con el ápice redondeado, de euamiloide difuso a prácticamente nulo en algunas colecciones, estrechándose hacia la base, con uncínulo basal, de (299-)300-340(-343) $\times(12,4-) 13,1-16,4(-17) \mu \mathrm{m}, \mathrm{N}=12, \mathrm{Me}=315 \times 14,9 \mu \mathrm{m}$. Ascosporas fusiformes, con los extremos agudos, hialinas, con 2 grandes LBs y varios más pequeños, aparentemente lisas en agua, pero con finas estrías longitudinales difíciles de ver incluso en azul de algodón al lactofenol, de $(20,5-) 21,8-24,7(-28,4) \times(8,2-) 8,6-9,7(-10,3) \mu \mathrm{m}$, $\mathrm{Q}=(2,2-) 2,3-2,8(-3,3), \mathrm{N}=67, \mathrm{Me}=23,4 \times 9,2 \mu \mathrm{m}$, $\mathrm{Qe}=2,6$. Paráfisis cilíndricas, septadas y ligeramente engrosadas en el ápice, de (4-)4,4-5,9(-6,4) $\mu \mathrm{m}, \mathrm{N}=27$, $\mathrm{Me}=5,1 \mu \mathrm{m}$. Subhimenio de color violeta y textura intricata. Excípulo medular muy ancho, con textura globulosa, compuesto por células hialinas de (16,6-)20,7-30,2(-32,8) $\times(14,6-) 17,7-25,5(-32) \mu \mathrm{m}, \mathrm{N}=50, \mathrm{Me}=25,3 \times 21,6 \mu \mathrm{m}$, intercalado con hifas cilíndricas estrechas menos visibles, con textura intricata. Excípulo ectal estrecho, más oscuro que el medular, con textura globulosa-subangularis, de $(19-) 23,1-42,9(-50,5) \times(16,1-) 19,2-31,8(-35,8) \mu \mathrm{m}$, $\mathrm{N}=51, \mathrm{Me}=32,6 \times 24,3 \mu \mathrm{m}$, con células que van haciéndose más alargadas desde la base hacia la parte superior, terminando por formar en el margen pelos hifoides claviformes, septados, de $(50,6-) 66,6-92,2(-99,6) \times$ $(6,8-) 7,7-12,5(-12,9) \mu \mathrm{m}, \mathrm{N}=39, \mathrm{Me}=79,5 \times 10,2 \mu \mathrm{m}$.

Observaciones: Es una especie fácil de identificar al microscopio, fundamentalmente por las características de las esporas: con una morfología fusiforme y una ornamentación en forma de finas estrías longitudinales, aunque la ornamentación esporal es bastante difícil de poner de manifiesto, incluso empleando un colorante y el objetivo de inmersión. De hecho, numerosos autores, tanto antiguos como actuales, la han presentado como una especie de esporas lisas, tal y como comenta Van Vooren (2010). Este autor también señala que los trabajos de filogenia molecular de Hansen et al. (2001) confirman la pertenencia de esta especie a la familia Pezizaceae Dumont y la proximidad de especies del género Marcelleina Brumm. en un clado perfectamente aislado, resultado sorprendente porque, más allá de su parecido macroscópico, tradicionalmente Marcelleina se ha situado en la familia Pyronemataceae Corda por sus ascas inamiloides. Además, describe una colección francesa de agosto de 2005, que macroscópicamente no se distingue de las colecciones típicas, pero con esporas bastante más pequeñas, de (17-)18-21 × 8-10 $\mu \mathrm{m}, \mathrm{Me}=19 \times 8,8 \mu \mathrm{m}, \mathrm{Qe}=2,2$ y señala que el único autor que menciona algo parecido es Donadini (1980), que indica unas medidas esporales de $18-20 \times 9-10 \mu \mathrm{m}$, y que paradójicamente en otra publicación (Donadini, 1981) señala ascosporas de tamaño habitual, 25-28 × 8-10 $\mu$ m. Señala Van Vooren (op. cit.) que la especie está ampliamente distribuida en el hemisferio norte, tanto en EEUU como en Europa: Alemania, Dinamarca, España, Estonia, Finlandia, Francia, Hungría, Italia, Montenegro, Noruega, Países Bajos, Polonia, República Checa, Reino Unido y Suiza. También está citada en Israel. En España está citada al menos en Álava (Valdegobía) (Fernández Vicente et al., 2007), (P.N. Izki, 5-VII- 


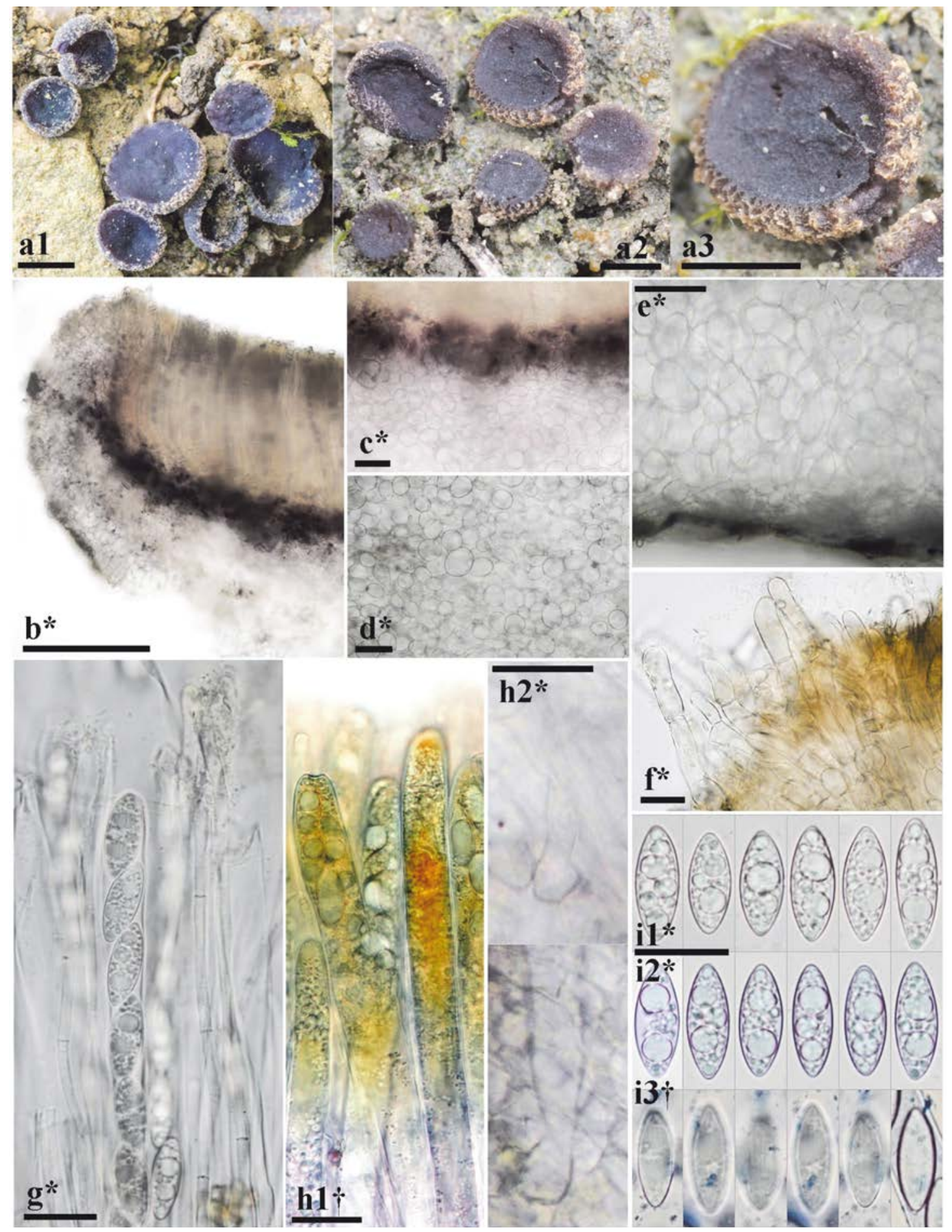

Figura 6: Caracteres morfológicos de Peziza gerardii. a. Apotecios en fresco. b. Sección transversal del apotecio. c. Subhimenio y excípulo medular en sección transversal. d. Excípulo medular en sección transversal. e. Excípulo ectal en sección transversal en la base. f. Pelos hifoides en el margen. g. Paráfisis y ascas. h. Ascas. h1. Parte superior de las ascas. h2. Base de las ascas.

i. Ascosporas. Escala: $3 \mathrm{~mm}=\mathrm{a} ; 500 \mu \mathrm{m}=\mathrm{b} ; 50 \mu \mathrm{m}=\mathrm{c}-\mathrm{e} ; 20 \mu \mathrm{m}=\mathrm{f}-\mathrm{i}$. Medio de montaje: $\mathrm{H}_{2} \mathrm{O}=\mathrm{b}$-g, h2, i1; Melzer $=\mathrm{h} 1$; $\mathrm{CRB}=\mathrm{i} 2 ; \mathrm{CB}=\mathrm{i} 3$. Fotos: JACA-MICO-01015 $=\mathrm{a} 1, \mathrm{~b}-\mathrm{i} 3 ; \mathrm{JACA}-\mathrm{MICO}-01186=\mathrm{a} 2-3$.

Figure 6: Morphological characters of Peziza gerardii. a. Fresh apothecia. b. Apothecial cross section. $\boldsymbol{c}$. Cross section of the himenium and medullary excipulum. $\boldsymbol{d}$. Medullary excipulum cross section. $\boldsymbol{e}$. Ectal excipulum cross section at the base. f. Hyphoid hairs at the margin. g. Paraphyses and asci. h. Asci. h1. Ascus tips. h2. Ascus base. i. Ascospores. Bar: $3 \mathrm{~mm}=a$; $500 \mu \mathrm{m}=b$; $50 \mu \mathrm{m}=c-e ; 20 \mu \mathrm{m}=f-i$. Mounting media: $\mathrm{H}_{2} \mathrm{O}=b-\mathrm{g}, \mathrm{h2}, \mathrm{i1}$; Melzer $=h 1 ; C R B=i 2 ; C B=i 3$. Photos: JACA-MICO-01015 =a1, b-i3; JACA-MICO-01186 = a2-3 
2007) (Errotari, 2007), (Albina, 17-VII-2008) (Errotari, 2008), Asturias (Somiedo, Pineda, 23-VI-2007) (Rubio, 2007), Barcelona (Ríells del Montseny, 10-IX-1999) (Rocabruna \& Tabarés, 2001), Burgos (Vilviestre del Pinar, 11V-2008) (Santamaría Rodríguez, 2009), Cáceres (Almaraz, 3-IV-2013) (Gelpi, 2016), Córdoba (Arroyo del Moral, 15III-2003) (Daniëls \& Moreno-Arroyo, 2006), Guipúzcoa (Aia, Sagastizabal, 27-VII-2013) (Aranzadi, 2013), Málaga (Parauta, P.N. Sierra de las Nieves, 22-V-2013) (Becerra, 2014), Navarra (Imoz, Zarrant, Ausano, 8-VII-1993) (Aranzadi, 1993), La Rioja (Las Ruedas de Ocón, 9-IX1989) (Caballero Moreno \& Palacios Remondo, 2003), Salamanca (La Orbada, 27-V-2000) (Calonge et al., 2003), Soria (Castroviejo, río Yalde, 30-VII-2013) (Carlos del Amo, com. personal), Tenerife (Beltrán Tejera, 2010) y Teruel (Pitarque y El Cuervo) (Raúl Tena, com. personal).

Plicariella scabrosa (Cooke) Spooner (Fig. 7).

$\equiv$ Peziza scabrosa Cooke.

$\equiv$ Phaeopezia scabrosa (Cooke) Sacc.

EScabropezia scabrosa (Cooke) Dissing \& Pfister.

Material estudiado: Zona 5.3, en un talud de tierra dentro de un bosque de Fagus sylvatica y Abies alba, 16-X2015, leg. J. Hernanz, JACA-MICO-01117. Secuencia ITS GenBank MF345962.

Apotecios de 10-15 mm de anchura, cupuliformes, sésiles, con el himenio cóncavo, liso, de color marrón oscuro a negruzco, exteriormente cubierto con grandes verrugas cónicas de color marrón, más claro que el himenio, margen con tendencia a mantenerse incurvado hacia el interior, crenulado, carne de color marrón, muy acuosa al corte.

Ascas cilíndricas, operculadas, octospóricas, uniseriadas cuando las esporas están maduras, pero irregularmente ordenadas cuando son jóvenes, con el ápice truncado, euamiloides a lo largo de toda su longitud, pero más intensamente en el ápice, estrechándose hacia la base, con uncínulo basal, de (350-)353-390(-400) $\times(14,4-) 17$ $25,3(-26,1) \mu \mathrm{m}, \mathrm{N}=24, \mathrm{Me}=378 \times 20,8 \mu \mathrm{m}$. Ascosporas esféricas, hialinas y lisas cuando son jóvenes, ornamentadas, monogutuladas (LB) y ligeramente marrones cuando están maduras, de (13,9-)14,5-15,7(-16) × (13,8) 14,3-15,6(-15,7) $\mu \mathrm{m}, \mathrm{Q}=1, \mathrm{~N}=77, \mathrm{Me}=15,1 \times 14,9 \mu \mathrm{m}$, $\mathrm{Qe}=1$, incluyendo la ornamentación, que consiste en verrugas más o menos rectangulares, truncadas, formando incluso un reborde superior ligeramente más ancho o una especie de plataforma, regularmente distribuidas, cianófilas, de $(1,1-) 1,3-1,8(-2,1) \times(0,7-) 0,9-1,3(-1,5) \mu \mathrm{m}, \mathrm{N}=53$, $\mathrm{Me}=1,5 \times 1,1 \mu \mathrm{m}$ (anchura $\times$ altura). Paráfisis cilíndricas, septadas, bifurcadas en la base, rectas, ligeramente engrosadas en el ápice, con la última célula de (34-)43,3-71,5($74,7) \times(6,3-) 7,4-14,1(-15,7) \mu \mathrm{m}, \mathrm{N}=42, \mathrm{Me}=59,8 \times 9,5$ $\mu \mathrm{m}$, en ocasiones con los ápices cubiertos y englobados por una sustancia amorfa de color pardo amarillento. Subhimenio con textura globulosa, con células redondeadas a ligeramente ampuliformes. Excípulo medular con textura intricata, compuesto por células de color pardo claro, de $(5,8-) 7-11,6(-14,1) \mu \mathrm{m}, \mathrm{N}=50, \mathrm{Me}=9 \mu \mathrm{m}$ de an- chura. Excípulo ectal más oscuro que el medular, con textura globulosa, con células de (37-)42,1-63,3(-70,8) × $(24,5-) 28,9-44,6(-50,6) \mu \mathrm{m}, \mathrm{N}=51, \mathrm{Me}=50,7 \times 36,7 \mu \mathrm{m}$, intercaladas con hifas similares a las del excípulo medular y cubierto de protuberancias triangulares, compuestas por células globosas del mismo tipo, mezcladas con una materia amorfa de color marrón muy oscuro.

Observaciones: Dougoud (2012) hace una interesante comparativa entre Plicariella scabrosa y otras dos especies muy próximas difíciles de separar: Plicariella flavovirens (Fuckel) Van Vooren \& Moyne [三 Scabropezia flavovirens (Fuckel) Dissing \& Pfister] y Scabropezia echinophora (Donadini) Donadini ( $\equiv$ Peziza echinophora Donadini), y llega a la conclusión de que $P$. flavovirens se distingue por su ornamentación esporal compuesta por verrugas más pequeñas y redondeadas, no truncadas, y por el subhimenio de textura intricata (en lugar de textura globulosa-angularis de $P$. scabrosa) y que $S$. echinophora se distingue por el color muy oscuro, negro con reflejos verdosos, el aspecto hialino de las esporas y por las ascas más estrechas, de 16-18 $\mu \mathrm{m}$. También señala que la presencia de látex hialino que pasa a color blanco tras unos minutos, abundante en ejemplares jóvenes y en buen estado de hidratación, no se detalla en la descripción original de P. scabrosa ni en la de Hansen et al. (1998), citándose por primera vez por Ribollet (2008). Nosotros no hemos observado claramente ese látex, pero sí una carne muy acuosa al preparar los cortes para la observación microscópica. Por otra parte, Van Vooren \& Moyne (2012) publican la nueva combinación Plicariella flavovirens (Fuckel) Van Vooren \& Moyne y rectifican un error de determinación de una anterior recolecta (Van Vooren, 2006), señalando también que las diferencias fundamentales con la especie que nos ocupa, son la ornamentación formada por verrugas bajas y aisladas y la estructura del subhimenio, compuesto por hifas más o menos intricadas, alargadas, mezcladas con otras más anchas, además de la presencia de un látex incoloro (hialino y después blanco en $P$. scabrosa). También señalan la curiosa afinidad filogenética de las especies del género Scabropezia, colocándose en un clado con el hongo hipogeo Pachyphloeus melanoxanthus (Berk.) Tul. \& C. Tul. especie tipo del género y que la Universidad de Minnesota está llevando a cabo un estudio completo del género Pachyphloeus que permitirá aclarar esta situación. Se conocen recolectas europeas de $P$. scabrosa, especie descrita de Norteamérica (Maine), al menos de Eslovaquia (Vel'ká Fatra, 8-IX-2015), Dinamarca (Mon, Store Klinteskov, Jydelejeslugten, 19-IX1994; Zealand, Leestrup Skov, 14-IX-1997 y Jutland, Vejle, Grund Skov, 12-X-1997), Francia (Saint-Amadin, Bois de Montagnac, 25-IX-2014) y Suiza (Vaud, Chabrey, Bois de Ville, 23-X-2011 y 7-XI-2011; Ermensee, Heidenrain, 31-X2011; Auw, Bergwald, 5-X-2008 y Emmenbrücke, Mittel Hüsle, 19-VIII-2009) según Dougoud (2012), Van Vooren (2015), Hansen et al. (1998) y Polhorský (2016). En la bibliografía consultada no hemos encontrado ninguna cita anterior en España, sin embargo tenemos constancia de un recolecta pendiente de publicar hecha un poco antes que la nuestra (29-VIII-2015) en La Rioja, Santa Coloma, a 625 m, bajo la hojarasca en la orilla de un riachuelo dentro de un hayedo, hecha por Rubén Martínez Gil (com. personal). 


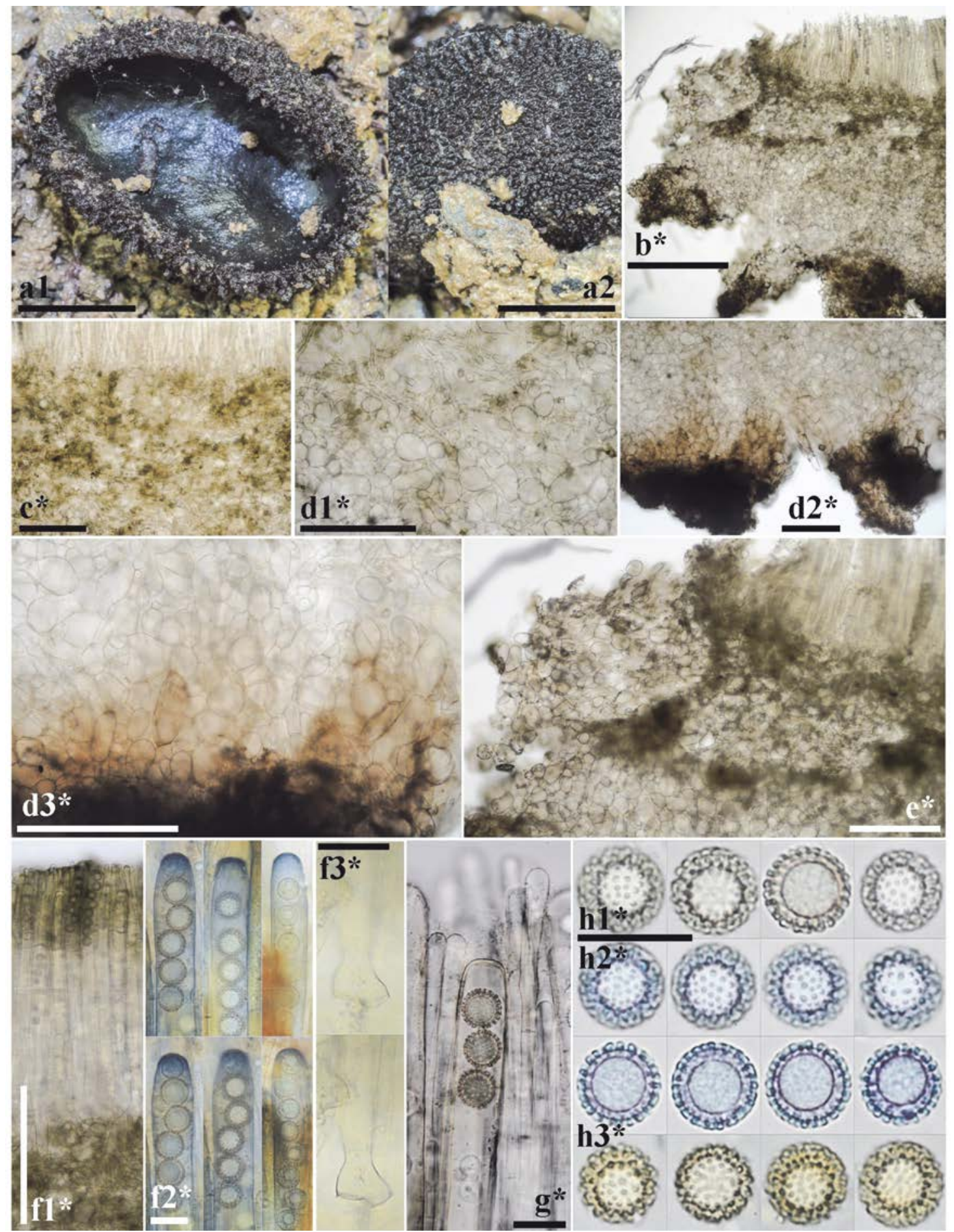

Figura 7: Caracteres morfológicos de Plicariella scabrosa. a. Apotecios en fresco. b. Sección transversal del apotecio. c. Subhimenio y excípulo medular en sección transversal. d. Excípulo ectal en sección transversal. d1. Transición del excípulo medular al ectal. d2. Protuberancias triangulares. d3. Última capa de células antes de las protuberancias triangulares. e. Margen. f. Ascas. f1. Ascas enteras. f2. Ápice de las ascas. f3. Base de las ascas. g. Paráfisis. h. Ascosporas. Escala: $5 \mathrm{~mm}=\mathrm{a} ; 500 \mu \mathrm{m}=\mathrm{b} ; 200 \mu \mathrm{m}=\mathrm{c}-\mathrm{f1}$; $20 \mu \mathrm{m}=\mathrm{f} 2$-h. Medio de montaje: $\mathrm{H}_{2} \mathrm{O}=\mathrm{b}-\mathrm{f} 1, \mathrm{f} 3$, g, h1; IKI = f2, h3; CRB = h2. Fotos: todas a partir de JACA-MICO-01117.

Figure 7: Morphological characters of Plicariella scabrosa. a. Fresh apothecia. b. Apothecial cross section. c. Cross section of the subhimenium and medullary excipulum. $\boldsymbol{d}$. Ectal excipulum cross section. d1. Medullary to ectal excipulum transition.

d2. Triangular protuberances. d3. Last layer of cells before the triangular protuberances. e. Margin. f. Asci. f1. Full asci. f2. Ascus tip. f3. Ascus base. g. Paraphyses. h. Ascospores. Bar: $5 \mathrm{~mm}=a$; $500 \mu \mathrm{m}=b ; 200 \mu \mathrm{m}=c-f 1 ; 20 \mu \mathrm{m}=f 2-h$. Mounting media: $\mathrm{H}_{2} \mathrm{O}=b-f 1, f 3, \mathrm{~g}, \mathrm{h1} ; \mathrm{IKI}=f 2, h 3 ; \mathrm{CRB}=\mathrm{h} 2$. Photos: all from JACA-MICO-01117. 
Pulvinula convexella (P. Karst.) Pfister (Fig. 8).

E Peziza convexella P. Karst.

$\equiv$ Barlaea convexella (P. Karst.) Sacc.

$\equiv$ Barlaeina convexella (P. Karst.) Sacc.

三 Humaria convexella (P. Karst.) Quél.

$\equiv$ Leucoloma convexellum (P. Karst.) Rehm.

= Pulvinula constellatio (Berk. \& Broome) Boud.

Material estudiado: Zona 5.3, en un talud de tierra, dentro de un bosque de Fagus sylvatica y Abies alba, 28-VIII2015, leg. J. Hernanz, M.A. Ribes, JACA-MICO-01017.

Apotecios de 1-3 mm de anchura, discoides a pulvinados, sésiles, con el himenio cóncavo a casi plano, liso, de color naranja pálido, exterior de color más claro, glabro, margen destacado, ligeramente convoluto y festoneado.

Ascas cilíndricas, operculadas, octospóricas, uniseriadas, con el ápice redondeado, inamiloides, estrechándose hacia una base bifurcada, de (246-)251-289(-311) $\times$ $(16,5-) 17,5-21,3(-22,8) \mu \mathrm{m}, \mathrm{N}=33, \mathrm{Me}=266 \times 19,7 \mu \mathrm{m}$. Ascosporas esféricas, lisas, hialinas, completamente llenas de LBs, de (16,8-)17,3-18,4(-19) × (16,6-)17,1-18,3($18,8) \mu \mathrm{m}, \mathrm{Q}=1(-1,1), \mathrm{N}=80, \mathrm{Me}=17,9 \times 17,6 \mu \mathrm{m}$, $\mathrm{Qe}=1$. Paráfisis filiformes, septadas, bifurcadas, curvadas en el ápice, con gútulas de color naranja, que exceden de la altura de las ascas, de (15,8-)20,2-46,2(-54,3) $\mu \mathrm{m}$, $\mathrm{N}=55, \mathrm{Me}=32 \mu \mathrm{m}$. Excípulo medular con textura intrica$t a$, compuesto por células hialinas de (2,3-)2,9-4,7(-5,6) $\mu \mathrm{m}$, $\mathrm{N}=88, \mathrm{Me}=3,7 \mu \mathrm{m}$ de anchura. Excípulo ectal más oscuro que el medular, con textura globulosa-angularis, con células de (10,5-)12,4-17,4(-19,3) × (9,2-)11,2-14,1(17,6) $\mu \mathrm{m}, \mathrm{N}=51, \mathrm{Me}=14,4 \times 12,6 \mu \mathrm{m}$.

Observaciones: En un trabajo relativamente reciente, Peric (2008) hace una interesante discusión acerca de las consideraciones taxonómicas de la especie, señalando lo siguiente: Pfister (1976) considera Pulvinula constellatio (Berk. \& Broome) Boud como sinónimo de P. convexella, siendo Korf (1988) de la misma opinión. Schumacher (1979), basándose en el examen de 34 colecciones de 30 localidades, incluyendo 15 colecciones de zonas aluviales de río, llega a la conclusión de que el material denominado $P$. convexella puede dividirse en dos grupos en función de las diferencias morfológicas y ecológicas, de forma que cuando crecen en suelos ricos son por lo general más pequeños y con un tinte mate rosado en el himenio, mientras que las muestras que crecen en suelos arenosos son más grandes, irregularmente pulvinados y con un color naranja brillante, que implica diferencias cualitativas en los pigmentos carotenoides; Yao \& Spooner (1996) aceptan el nombre de $P$. constellatio, al considerar que es la base del material tipo y de algunas colecciones británicas, mientras que el nombre de $P$. convexella se introdujo en la literatura británica después de la sinonimia de $P$. constellatio (Cannon et al., 1985). Algunos autores continúan con la tendencia de diferenciar las dos especies, y de esta forma Dissing et al. (2000) y Medardi (2006) basan la diferencia entre ambas en el tamaño, la forma y el color de los apotecios y las dimensiones de las esporas. Por tanto vemos que de acuerdo con las contradicciones e incertidumbres citadas, se hace necesaria la revisión de nuevas colecciones y de exámenes empíricos. Es una especie que se diferencia de Pulvinula carbonaria (Fuckel) Boud., en que esta última aparece en zonas quemadas, sus paráfisis no suelen estar bifurcadas y las esporas son menores de $16 \mu \mathrm{m}$. En España está citada al menos en Álava (Aborníkano, Urkabustaiz, 11-VIII-2005, Bitoriano, Zuia, 12VIII-2006) (Fernandez-Vicente \& Undagoitia, 2009), Asturias (Tineo, Valle de Tablado, 10-VIII-2004) (Rubio et al., 2006), Jaén (Iznatoraf, Sierra de las Villas, 15-VIII2014) (Tello, 2015), Málaga (El Burgo, Arroyo de la Fuensanta, 8-I-2004) (Moreno-Arroyo, 2004) y Navarra (Lumbier, 24-VIII-2014) (Mikel Tapia, com. personal).

\section{Phylum Basidiomycota}

Artomyces cristatus (Kauffman) Jülich (Fig. 9).

ECraterellus cristatus Kauffman.

EClavicorona cristata Doty (Kauffman) Doty.

Material estudiado: Zona 5.1, sobre ramas decorticadas de Abies alba, 13-X-2012, leg. M.A. Ribes, J.C. Campos, I. Olariaga, ARAN-Fungi 00993. Zona 2.4 sobre tronco caído y decorticado de Pinus sylvestris, 13-X-2015, leg. A. Hereza, J.F. Mateo, J. Cuesta, J. Hernanz, I. Olariaga, JACA-MICO-00753, duplo en ARAN-Fungi 05252. Zona 2.16, sobre madera descortezada de Pinus sylvestris, 13-X-2016, leg. J.F. Mateo, JACA-MICO-00996.

Material adicional estudiado: Burgos: Huerta de Abajo, cerca de Tolbaños de Abajo, 30TVM8959, sobre madera de pino, en bosque mixto con Quercus pyrenaica, Fagus sylvatica y Pinus sylvestris, 14-X-1997, leg. C. Lado, Daniëls 167, MA-Fungi 52125.

Basidiomas aislados o creciendo en grandes grupos de basidiomas gregarios, de 4-10 $\mathrm{mm}$ de altura, simple o ramificado una vez, sin pie bien delimitado. Ramas cilíndricas o de forma estrechamente obcónica, en ocasiones surcadas longitudinalmente, macizas, de color rosa grisáceo, en ocasiones con reflejos púrpuras, de color blanco rosáceo en basidiomas muy jóvenes, de color pardo oscuro en seco, de 1-1,5 mm de diámetro. Ápices obtusos o subagudos en basidiomas muy jóvenes, posteriormente truncados o subcóncavos, con el margen entero o dentado. Ramificación dicótomica, en forma de U o $\mathrm{V}$. Tomento basal ausente. Contexto concolor o un poco más pálido que el exterior, inodoro. Podredumbre blanca.

Basidiosporas elípticas a estrechamente elípticas, de pared delgada, lisas, hialinas, con contenido granular o con 1-2 gútulas grandes, amiloides, $5-7 \times 2-3 \mu \mathrm{m} \mathrm{Q}=$ 2,1-2,3, N $=25, \mathrm{Me}=5,9 \times 2,6 \mu \mathrm{m}, \mathrm{Qe}=2,2$. Basidios claviformes, tetraspóricos, de 18-37 × 3,5-5 $\mu \mathrm{m}$, fibulados. Subhimenio formado por hifas cilíndricas de pared delgada, fibuladas, en ocasiones con incrustaciones. Gleocistidios abundantes, emergentes de la parte basal del subhimenio, claviformes a lageniformes, en ocasiones 


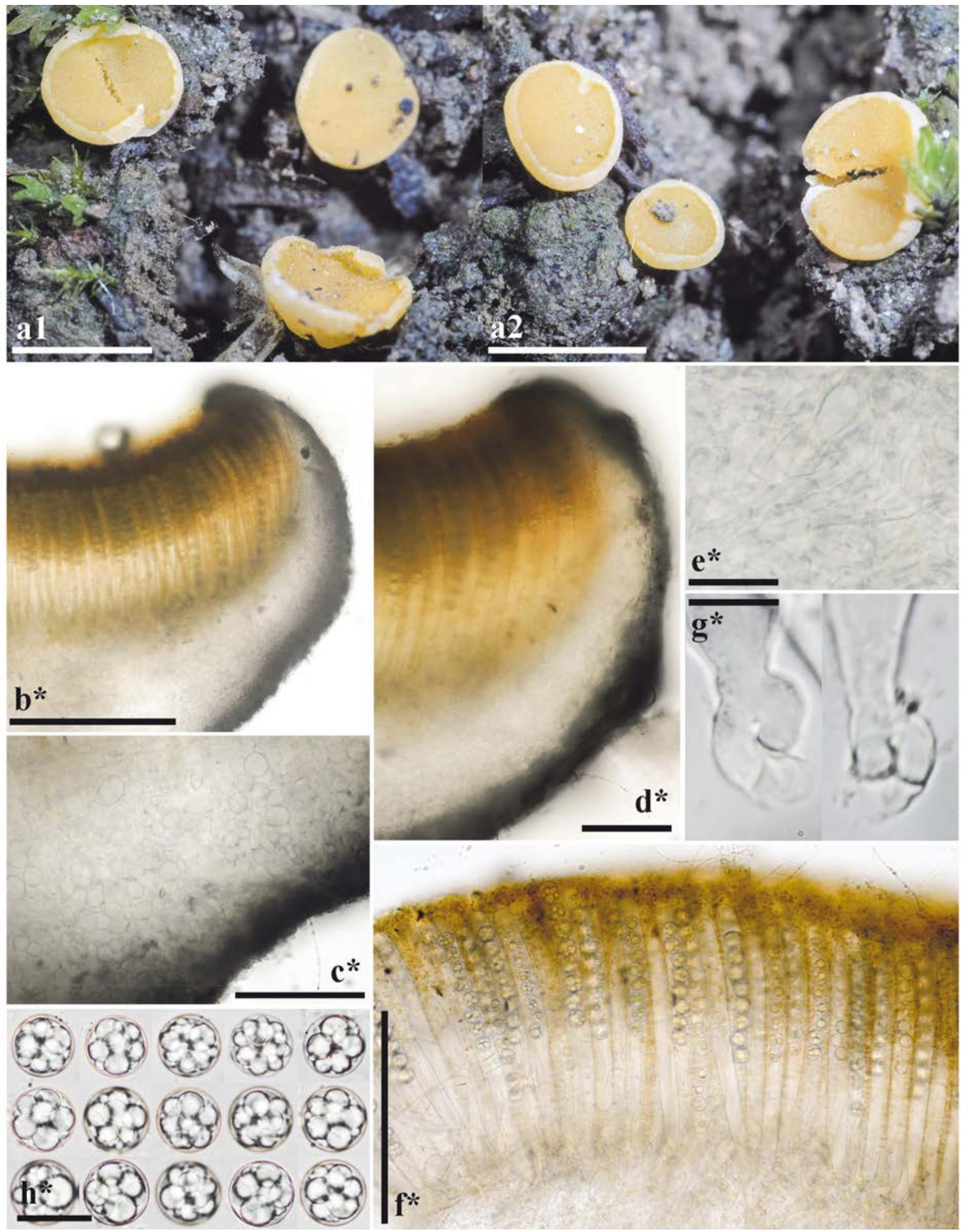

Figura 8: Caracteres morfológicos de Pulvinula convexella. a. Apotecios en fresco. b. Sección transversal del apotecio. c. Excípulo ectal en sección transversal en el flanco. d. Margen en sección transversal e. Excípulo medular. f. Ascas.

g. Base de las ascas. h. Ascosporas. Escala: $3 \mathrm{~mm}=\mathrm{a} ; 300 \mu \mathrm{m}=\mathrm{b} ; 200 \mu \mathrm{m}=\mathrm{f} ; 100 \mu \mathrm{m}=\mathrm{c}-\mathrm{d} ; 20 \mu \mathrm{m}=\mathrm{e}, \mathrm{h} ; 10 \mu \mathrm{m}=\mathrm{g}$. Medio de montaje: $\mathrm{H}_{2} \mathrm{O}=$ b-h. Fotos: todas a partir de JACA-MICO-01017.

Figure 8: Morphological characters of Pulvinula convexella. a. Fresh apothecia. b. Apothecial cross section. c. Ectal excipulum cross section at the flank. d. Margin cross section. e. Medullary excipulum. f. Asci. g. Ascus base. h. Ascospores. Bar: $3 \mathrm{~mm}=a$; $300 \mu \mathrm{m}=$ b; $200 \mu \mathrm{m}=f ; 100 \mu \mathrm{m}=c-d ; 20 \mu \mathrm{m}=e, h ; 10 \mu \mathrm{m}=$ g. Mounting medium: $\mathrm{H}_{2} \mathrm{O}=$ b-h. Photos: all from JACA-MICO-01017. 


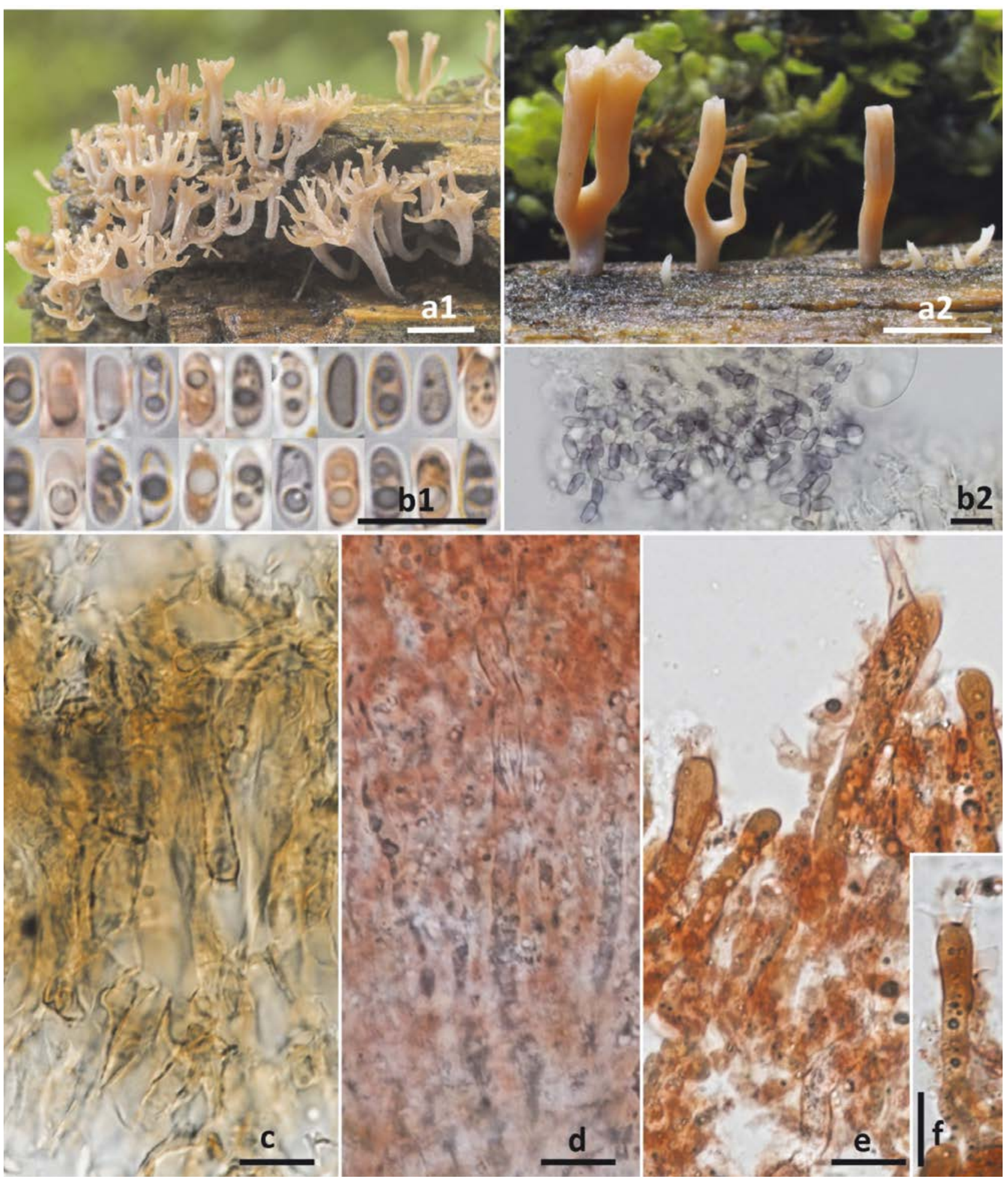

Figura 9: Caracteres morfológicos de Artomyces cristatus. a. Basidiomas in situ. b. Basidiosporas. b1. Basidiosporas en RC. b2. Reacción amiloide de las basidiosporas. c. Hifas del contexto. d. Gleocistidios. e. Himenio. f. Basidio. Escala: $5 \mathrm{~mm}=$ a1, a2; $10 \mu \mathrm{m}=$ b-f. Medio de montaje: Melzer = b2; RC = b1, d-f; KOH 5\% = c. Fotos: JACA-MICO-00996 = a1; ARAN-Fungi 0993=a2; JACA-MICO-00754= b1-f.

Figure 9: Morphological characters of Artomyces cristatus a. Basidiomata in situ. b. Basidiospores. b1. Basidiospores in RC. b2. Amyloid reaction of basidiospores. c. Context hyphae. d. Gleocystidia. e. Hymenium. f. Basidium. Bar: $5 \mathrm{~mm}=a 1, a 2 ; 10 \mu m=b-f$. Mounting media: Melzer $=b 2 ; R C=b 1, d-f ; K O H 5 \%=c$. Photos: JACA-MICO-00996 = a1; ARAN-Fungi 0993 = a2; JACA-MICO-00754 = b1-f. 
lanceolados o con una papila apical, de contenido refringente, de 43-91 × 5-9,5 $\mu \mathrm{m}$. Hifas del contexto dispuestas paralelamente, cilíndricas a fusiformes, de pared ligeramente engrosada, de color pardo rosáceo claro, en ocasiones con pigmento incrustante en forma de bandas anulares, fibuladas, de 4-10 $\mu \mathrm{m}$ de diám. Cristales a veces presentes, amorfos o aciculares.

Observaciones: Artomyces cristatus es una especie fácil de identificar debido a sus ápices truncados y dentados, color rosa violáceo y hábitat sobre madera de coníferas (Corner, 1950). Microscópicamente, las esporas amiloides y la presencia de gleocistidios, característicos en Russulales hericioides (antiguos Hericiales), la distinguen de otros géneros clavarioides. Artomyces pyxidatus (Kauffman) Jülich, la única otra especie del género en Europa, difiere por sus basidiomas de mayor tamaño, mucho más ramificados, de coloración pálida y hábitat sobre madera de angiospermas (Knudsen, 1997). Corner (1950) incluyó ambas especies en Clavicorona Doty, pero éste género corresponde a Clavariaceae Chevall. y comprende especies que poseen esporas no amiloides y que carecen de gleocistidios de contenido refringente.

Artomyces cristatus es originaria del norte de América (Kauffman, 1930) y posee pocos registros en Europa, más concretamente en Suecia, Noruega y Finlandia (GBIF, 2017). Según nuestra búsqueda, nuestras citas corresponderían a las primeras citas en el sur de Europa. Al menos en el norte de Europa, A. cristatus se encuentra restringido a bosques maduros de Pinus que han tenido continuidad ecológica, fructificando típicamente en troncos muertos de gran tamaño que quedan suspendidos y no están en contacto con el suelo (Daun \& Nitare, 2007). Artomyces cristatus está catalogado como amenazado en Suecia y Finlandia (Daun \& Nitare, 2007), probablemente debido a la escasez de bosques de coníferas que han tenido continuidad ecológica. Las localidades ibéricas en las que hemos detectado A. cristatus, destacan también por su buen estado de conservación. Siendo localmente frecuente en el P.N. de Ordesa y sus alrededores, citamos asimismo un espécimen recolectado en Burgos.

Clitocybe houghtonii (W. Phillips) Dennis (Fig. 10).

$\equiv$ Cantharellus houghtonii W. Phillips.

= Omphalia roseotincta A. Pearson.

Material estudiado: Zona 1.1, pradera con Abies alba y Buxus sempervirens, 12-X-2015, leg. M.A. Ribes, G. Sánchez, J.F. Mateo, JACA-MICO-00922. Zona 2.4, bajo Abies alba y Fagus sylvaticus claro herboso de bosque, sobre suelo calizo, 13-X-2015, leg. J. Hernanz, J. Cuesta, J.F. Mateo, A. Hereza, I. Olariaga, JACA-MICO-00757.

Basidiomas creciendo de manera gregaria o fasciculada. Píleo de 15-31 mm de diám., inicialmente convexo, pronto plano y umbilicado en el centro, no mamelonado. Revestimiento pileico seco, ocasionalmente con pequeños fascículos de hifas erizados en el margen, higrófano, de color rosa pálido a rosa ocráceo en estado húmedo, blanquecino al deshidratarse, liso. Margen entero a regularmente lobulado, ini- cialmente involuto, posteriormente incurvado y agudo, estriado por transparencia en basidiomas maduros. Láminas decurrentes, medianamente apretadas, en ocasiones bastante gruesas, a menudo intervenadas, $\mathrm{L}=19-27$, de 1,5-2 $\mathrm{mm}$ de espesor, rectas a ligeramente arqueadas, de color rosa pálido similar al del píleo, de color ocre rosáceo en exsiccatum. Arista laminar lisa, concolor. Estípite de 18-42 × 3-7 mm, generalmente más largo que el píleo, cilíndrico o ligeramente más ancho en la parte inferior, blanco o con tonos rosados muy pálidos, liso, tomentoso en la base. Carne firme, de color blanco, con olor característico a hojas de tomate que se acentúa al frotamiento.

Basidiosporas de (7-)8-10 × 4-6,5 $\mu \mathrm{m}, \mathrm{Me}=8,8 \times$ $5,1 \mu \mathrm{m}, \mathrm{Qe}=1,74$ de forma variable, normalmente elipsoidales, en ocasiones obpiriformes, lisas, de pared delgada, no amiloides, con contenido refringente. Basidios de 27-37 × 4-6,5 $\mu \mathrm{m}$, claviformes, fibulados, con (1-2)4 esterigmas. Trama laminar formada por hifas regulares a ligeramente entrelazadas, cilindricas a estrechamente fusiformes, de pared delgada, fibuladas, de 7-11 $\mu \mathrm{m}$ de diámetro, con pequeños cristales. Cistidios ausentes. Pileipellis de tipo cutis, con un epicutis de unas $100 \mu \mathrm{m}$ de espesor, compuesta por hifas cilíndricas, de pared delgada, hialinas, hasta de $2,5 \mu \mathrm{m}$ de diámetro. Fíbulas presentes en todo el basidioma.

Observaciones: Clitocybe houghtonii es una especie muy bien caracterizada sobre todo debido a los tonos rosados presentes en el píleo y las láminas, además de su olor, que recuerda a hojas de tomate, único entre los Clitocybe europeos. El píleo higrofano, sin pruina y el tamaño de las esporas son también caracteres útiles para identificar C. houghtonii.

La distribución de Clitocybe houghtonii es bastante amplia en Europa ya que al menos es conocido en Alemania, Dinamarca, Italia, Países Bajos, Reino Unido y Suecia (Dennis, 1954; Kuyper, 1995; Consiglio, 1999; Krieglsteiner \& Gminder, 2001; Vesterholt, 2008). No nos consta ninguna cita peninsular previa. A pesar de su distribución relativamente amplia en Europa, C. houghtonii parece una especie rara en toda su área de distribución (Kuyper, 1995). Tal rareza no parece ser debida a una ecología muy específica, ya que existen citas de $C$. houghtonii tanto en bosques de coníferas como de caducifolios (Kuyper, 1995), pero es posible que C. houghtonii se encuentre asociada a masas forestales de alta continuidad ecológica. Nuestras dos recolecciones fueron realizadas en sendos bosques asentados sobre litología calcárea.

\section{Inocybe coelestium Kuyper (Fig. 11).}

Material estudiado: Zona 2.7, en bosque de Fagus sylvatica, 27-VIII-2015, leg. F. Esteve-Raventós, A. Lorenzo, F. Pancorbo, JACA-MICO-00632, duplo en AH47633.

Píleo de 21-35 mm de diám., 7-10 mm de altura, inicialmente cónico-convexo, que posteriormente se expande hasta hacerse convexo o plano-convexo, provisto de un mamelón obtuso; margen inflexo en ejem- 

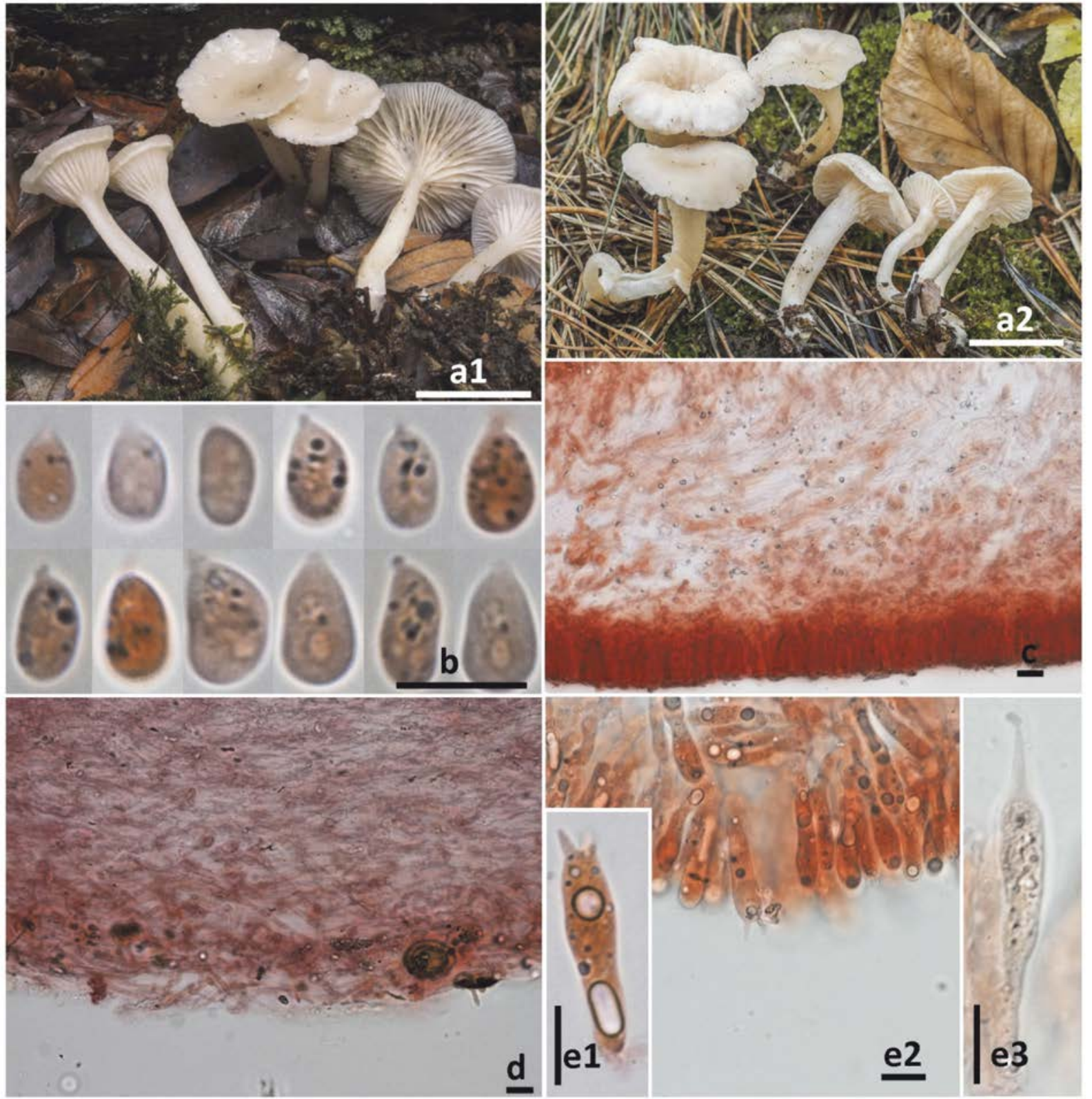

Figura 10: Caracteres morfológicos de Clitocybe houghtonii a. Basidiomas in situ. b. Basidiosporas. c. Trama laminar.

d. Pileipellis. e. Basidios; e1. Basidio tetraspórico; e2. Basidio bispórico; e3. Basidio monospórico. Escala: $10 \mathrm{~mm}=\mathrm{a} 1-2,10 \mu \mathrm{m}=\mathrm{b}-\mathrm{f}$.

Medio de montaje: $\mathrm{RC}=\mathrm{b}$-e. Fotos: JACA-MICO-00757 = a1; JACA-MICO-00922 = a2; JACA-MICO-00757 = b-f.

Figure 10: Morphological characters of Clitocybe houghtonii a. Basidiomata in situ. b. Basidiospores. c. Hymenophoral trama. d. Pileipellis. e. Basidia; e1. Four-spored basidia; e2. Two-spored basidia; e3. Monosporic basidium. Bar: $10 \mathrm{~mm}=a 1-2,10 \mu \mathrm{m}=b-f$.

Mounting media: $R C=b$-e. Photos: JACA-MICO-00757 = a1; JACA-MICO-00922 = a2; JACA-MICO-00757 = b-f.

plares jóvenes, que se expande en ejemplares adultos, dejando en algún caso restos velares, no higrófano; de color ocre a pardusco, con tonos verdosos en el centro, evidentes en fresco, pero volviéndose parduscos tras la desecación; cutícula de aspecto lanoso, con escamas parduscas bien diferenciadas alrededor del disco. Láminas apretadas $(\mathrm{L}=55-60 ; 1=1-3)$, rectas; de color inicial crema, finalmente pardo-ocráceo; arista algo más pálida o casi del mismo color que las caras, práctica- mente entera. Estípite de 25-60 × 4-6 mm, cilíndrico, ensanchado hacia la base, no bulboso, sólido; de color blanquecino a crema en el ápice, pardusco en la zona central y blanquecino con tonos verdosos en la base, que se mantienen en material seco, cubierto con fibrillas que le dan un aspecto estriado, no pruinoso. Carne firme, blanquecina en el píleo, que adquiere un color pardusco en el estípite con tonos verduscos; olor aromático, con matices florales. 


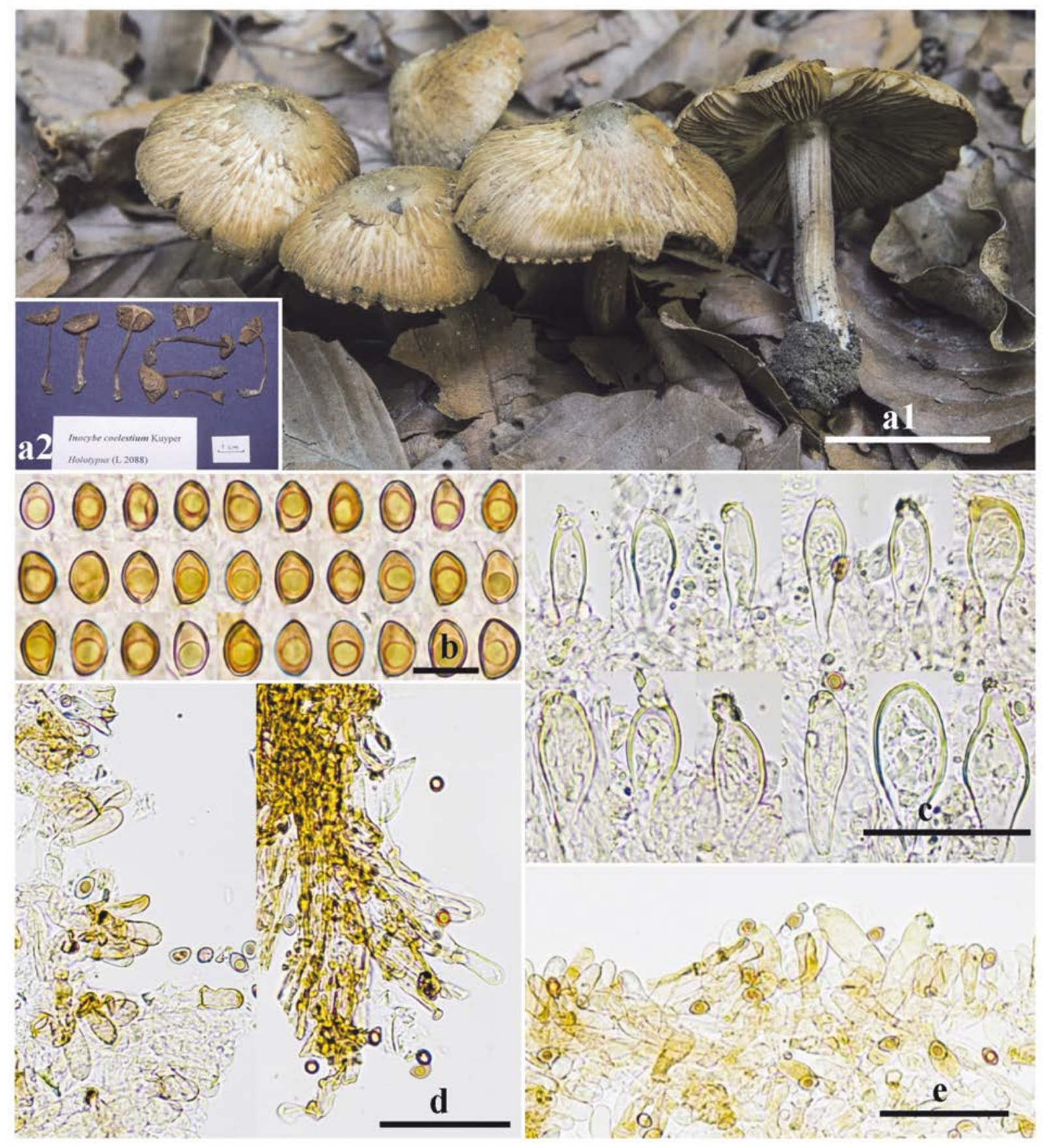

Figura 11: Caracteres morfológicos de Inocybe coelestium. a. Basidiomas. a1. Basidiomas in situ. a2. Basidiomas del holótipo de I. coelestium. b. Basidiosporas. c. Queilocistidios y filo laminar. d. Caulocistidios en el ápice del estípite. e. Pleurocistidios. Escala: $20 \mathrm{~mm}=\mathrm{a} ; 50 \mu \mathrm{m}=\mathrm{c}$-e; $10 \mu \mathrm{m}=$ b. Medio de montaje: $\mathrm{NH}_{4} \mathrm{OH}=$ b-e. Fotos: todas a partir de JACA-MICO-00632. Figure 11: Morphological characters of Inocybe coelestium. a. Basidiomata. a1. Basidiomata in situ. a2. Basidiomata from I. coelestium holotypus. b. Basidiospores. c. Cheilocystidia and lamella edge. d. Caulocystidia in stipe apex. e. Pleurocystidia. Bar: $20 \mathrm{~mm}=a$; $50 \mu \mathrm{m}=c-e ; 10 \mu \mathrm{m}=b$. Mounting media: $\mathrm{NH}_{4} \mathrm{OH}=b$-e. Photos: all from JACA-MICO-00632.

Basidiosporas de $(7,4-) 8,0-9,0(-9,7) \times(5,0-) 5,3-6,2(-$ $6,6) \mu \mathrm{m}, \mathrm{Q}=(1,3-) 1,4-1,6(-1,8), \mathrm{N}=63, \mathrm{Me}=8,5 \times 5,7$ $\mu \mathrm{m}, \mathrm{Qe}=1,5$, ovales en vista frontal, amigdaloides en vista lateral, con el ápice ligeramente apuntado. Basidios claviformes, tetraspóricos. Pleurocistidios metuloides, de $(38,4-) 39,0-54,0(-57,2) \times(10,4-) 10,5-20,5(-22,4) \mu \mathrm{m}$,
$\mathrm{Me}=47,3 \times 15,7 \mu \mathrm{m}$, de cilíndricos a claviformes o subfusiformes, más o menos cristalíferos en el ápice; pared de grosor variable $(1,6-) 1,9-3,1(-3,7) \mu \mathrm{m}, \mathrm{Me}=2,4 \mu \mathrm{m}$, más anchas en el ápice, con reacción amarillenta en soluciones amoniacales. Arista laminar heterogénea, compuesta por queilocistidios escasos, y paracistidios abun- 
dantes, de paredes finas, cilíndricos a subclaviformes, algunos septados, muchos de ellos con contenido intracelular amarillento. Queilocistidios similares a los pleurocistidios. Caulocistidios ausentes, aunque en la zona apical, se observan pelos septados con terminaciones cilíndricas a subclaviformes de paredes ligeramente gruesas. Fíbulas presentes.

Observaciones. Perteneciente a Inocybe sect. Lactiferae R. Heim, grupo donde se encuadran especies con olores aromáticos (fruta madura, floral, balsámicos...), así como la presencia de colores vistosos como los rojizos o verdosos. En esta sección se incluyen especies muy conocidas y citadas como I. fraudans (Britzelm.) Sacc. (=I. pyriodora sensu auct. pl.) e I. corydalina Quél., aunque a la vista de la importancia de los caracteres organolépticos para separar los taxones, es frecuente la confusión generada por la interpretación de los aromas, en muchas ocasiones muy sutiles. En este sentido, quizás los estudios moleculares ayudarían a una mejor interpretación del grupo. En el caso de I. coelestium, son diagnósticos la presencia de tonos verdosos en el píleo (lo que le asemejaría a I. corydalina), el olor floral, el tamaño no muy grande de los basidiomas, las láminas muy apretadas y no ventrudas y el hábitat ligado a bosques continentales con presencia de Fagus sylvatica, en ocasiones mixtos con Abies o Picea. Siendo esporádica en cuanto a su aparición, su distribución en nuestro continente está probablemente relacionada con la presencia de estos bosques húmedos y templados, siempre sobre sustratos calcáreos. Desde la descripción original realizada por Kuyper (1985) con ejemplares recogidos en Alemania, también ha sido mencionada por el mismo autor del Tirol (Austria), y probablemente esté presente en Francia, Italia y otros países centroeuropeos (aunque no conozcamos registros bajo este epíteto). Excelentes representaciones iconográficas han sido aportadas por Stangl (1989) y Enderle (2004). Aparece registrada como una de las especies tóxicas del género, por su contenido en psilocibina y baeocistina, causantes del característico tono verdoso que aparece en las fructificaciones (Stijve et al., 1985). No tenemos constancia de la existencia de un registro previo de esta especie en el territorio ibérico.

\section{Inocybe gymnocarpa Kühner (Fig. 12).}

Material estudiado: Zona 2.4, en bosque de Fagus sylvatica y Abies alba, 30-VIII-2015, leg. G. Sánchez, M.A. Ribes, F. Esteve-Raventós, F. Pancorbo, JACA-MICO-00636, duplo en AH47667.

Píleo de 14-45 mm de diám., de 10-18 mm de altu$\mathrm{ra}$, inicialmente hemisférico, que posteriormente se expande hasta hacerse convexo o plano-convexo, casi aplanado al final; margen incurvado en ejemplares jóvenes, más derecho en los adultos, sin restos velares; no higrófano; de color ocre más o menos uniforme; cutícula tomentosa, lanosa, seca. Láminas medianamente apretadas $(\mathrm{L}=60-65 ; 1=1-3)$, sinuosas, anexas; inicialmente de color crema, finalmente pardo-ocráceas; arista algo más pálida o casi del mismo color que las caras. Estípite de 25-55 × 5-9 mm, cilíndrico, no pruinoso, sólido al principio, hueco en ejemplares maduros; de color ocre amarillento en toda su longitud, cubierto por fibrillas longitudinales que forman una masa algodonosa blanquecina en la base. Carne de color crema, que adquiere unos tonos ocres en el estípite; olor ligeramente terroso, húmedo.

Basidiosporas de $(9,9-) 10,4-11,8(-12,8) \times(5,7-) 5,8-$ $7,0(-7,5) \mu \mathrm{m}, \mathrm{Q}=(1,5-) 1,6-1,9(-2,0), \mathrm{N}=60, \mathrm{Me}=11,0$ $\times 6,4 \mu \mathrm{m}, \mathrm{Qe}=1,7$, ovales en vista frontal, amigdaloides en vista lateral. Basidios claviformes, tetraspóricos. Pleurocistidios no encontrados. Queilocistidios polimórficos, claviformes a piriformes, subcapitados, subfusiformes, algunos con un largo pedicelo basal, de (28,3-)43,5-78,6($93,7) \times(17,3-) 17,7-24,5(-26,7) \mu \mathrm{m}, \mathrm{N}=22, \mathrm{Me}=62,4 \times$ $20,9 \mu \mathrm{m}$. Caulocistidios ausentes, presentando en la parte apical pelos caulocistidiodes formados por varias células encadenadas. Fíbulas presentes.

Observaciones. La distribución de esta especie en el continente europeo parece estar ligada a los bosques montanos de carácter continental-eurosiberiano y a las regiones subboreales, en suelos calcáreos bajo coníferas (abetos o píceas), en ocasiones en mezcla con caducifolios como el haya (en el caso del Pirineo) o en ambiente subalpino con presencia de Dryas (Favre, 1960, en los Alpes suizos). Sin ser muy frecuente entre las especies de I. subg. Mallocybe Kuyper, es de fácil reconocimiento por sus característicos y voluminosos queilocistidios, su porte robusto y píleo convexo, habitualmente roto en pequeñas escamas adpresas y concoloras, que le dan un aspecto lanoso-escamoso; el velo no se observa en los ejemplares desarrollados, de ahí el epíteto "gymnocarpa", que hace referencia a fructificaciones "expuestas" o "desnudas". Nuestra colección constituye el primer registro en la Comunidad de Aragón; previamente solo había sido citada del Pirineo catalán (Lérida) por Ballarà (1997) y posteriormente, acompañada de una excelente fotografía del mismo autor, en la colección "Bolets de Catalunya" (2000, vol. XIX, Lám. 925). Los registros referidos a esta especie por Malençon (Malençon \& Bertault, 1970) de Marruecos, probablemente corresponden a otro taxón, si nos atenemos a su localización tan meridional y hábitat bajo Pinus pinea. Los registros europeos, sin ser numerosos, provienen de las regiones montañosas eurosiberianas alcanzando los niveles subalpinos (Pirineos, Alpes), así como de la región sub-boreal (Kühner, 1955b; Favre, loc. cit.; Stangl, 1989; Breitenbach \& Kränzlin, 2000; Jacobson \& Larsson, 2012).

\section{Inocybe leucoblema Kühner (Fig. 13).}

Material estudiado: Zona 2.4, en bosque de Fagus sylvatica y Abies alba, 30-VIII-2015, leg. G. Sánchez, M.A. Ribes, F. Esteve-Raventós, F. Pancorbo, JACA-MICO 01184, duplo en AH47665.

Píleo de 22-40 mm de diám., 9-15 mm de altura, al principio convexo, plano-convexo en la madurez, con un amplio mamelón obtuso, la superficie cubierta por un 


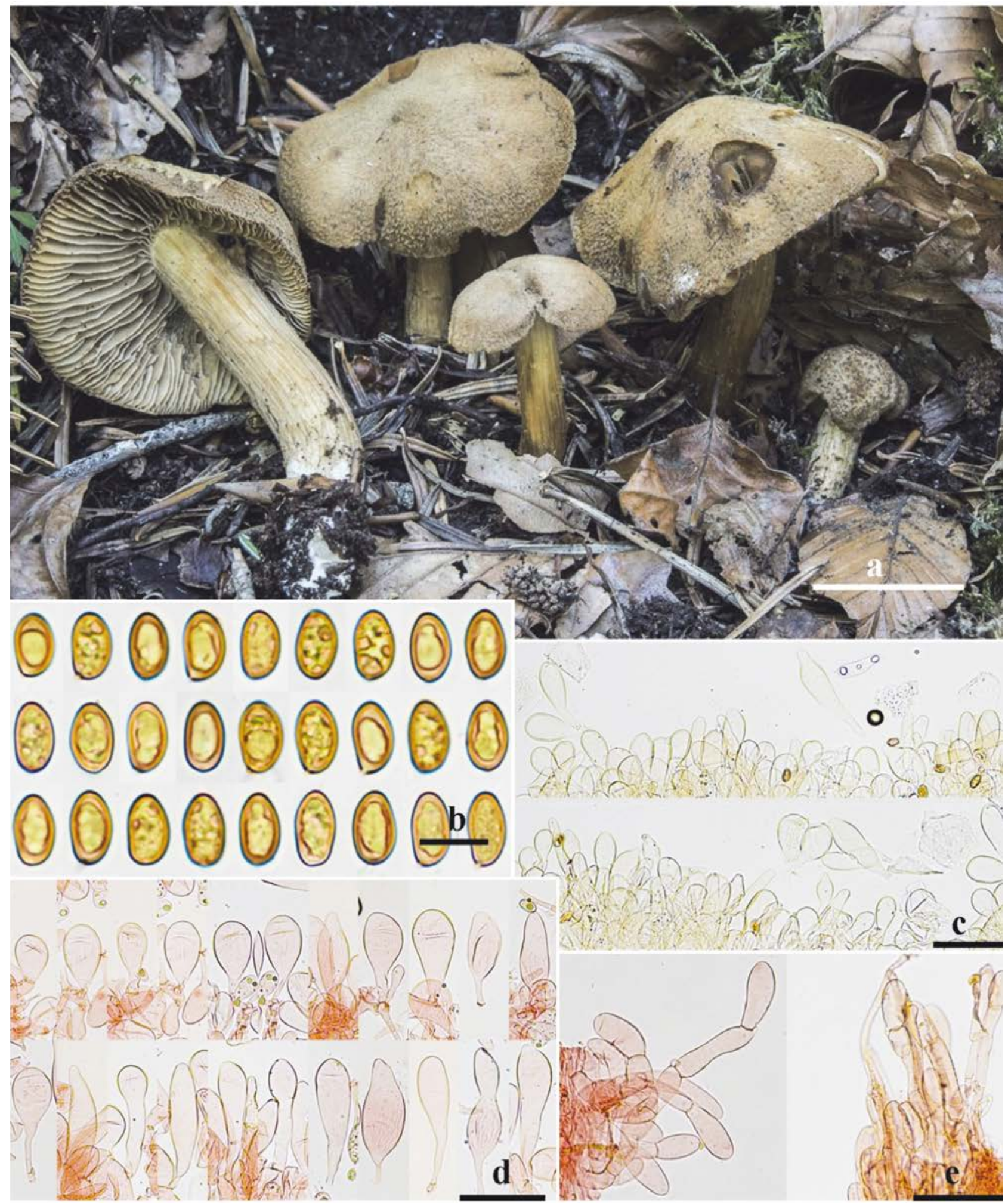

Figure 12: Caracteres morfológicos de Inocybe gymnocarpa. a. Basidiomas in situ. b. Basidiosporas. c. Queilocistidios y filo laminar. d. Queilocistidios. e. Caulocistidios en el ápice del estípite. Escala: $20 \mathrm{~mm}=\mathrm{a} ; 50 \mu \mathrm{m}=\mathrm{c}-\mathrm{e} ; 10 \mu \mathrm{m}=\mathrm{b}$.

Medio de montaje: $\mathrm{NH}_{4} \mathrm{OH}=\mathrm{b}, \mathrm{c} ; \mathrm{RC}=\mathrm{d}$, e. Fotos: todas a partir de JACA-MICO-00636.

Figure 12: Morphological characters of Inocybe gymnocarpa. a. Basidiomata in situ. b. Basidiospores. c. Cheilocystidia and lamella edge. d. Cheilocystidia. e. Caulocystidia in stipe apex. Bar: $20 \mathrm{~mm}=a ; 50 \mu \mathrm{m}=c-e ; 10 \mu \mathrm{m}=b$. Mounting media: $\mathrm{NH}_{4} \mathrm{OH}=b, c ; R C=d$, e. Photos: all from JACA-MICO-00636. 


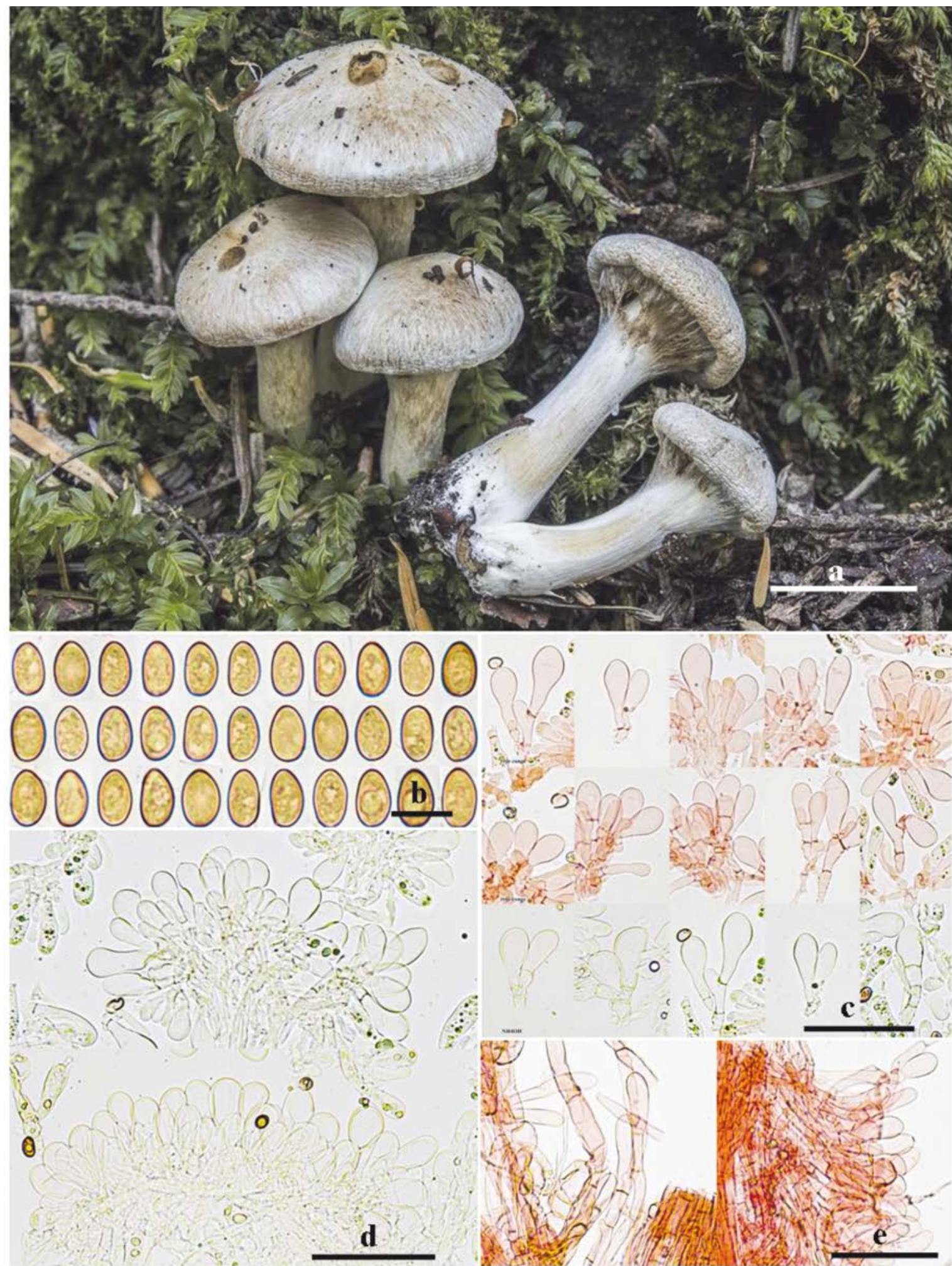

Figura 13: Caracteres morfológicos de Inocybe leucoblema. a. Basidiomas in situ. b. Basidiosporas. c. Queilocistidios, d. Queilocistidios y filo laminar. e. Caulocistidios en el ápice del estípite. Escala: $20 \mathrm{~mm}=\mathrm{a} ; 50 \mu \mathrm{m}=\mathrm{c}-\mathrm{e} ; 10 \mu \mathrm{m}=\mathrm{b}$. Medio de montaje: $\mathrm{NH}_{4} \mathrm{OH}=\mathrm{b}-\mathrm{d}$; $\mathrm{RC}=\mathrm{c}$, e. Fotos: todas a partir de JACA-MICO-01184.

Figure. 13: Morphological characters of Inocybe leucoblema. a. Basidiomata in situ. b. Basidiospores. c. Cheilocystidia d. Cheilocystidia and lamella edge. e. Caulocystidia in stipe apex. Bar: $20 \mathrm{~mm}=a ; 50 \mu \mathrm{m}=c, d, e ; 10 \mu \mathrm{m}=b$. Mounting media: $\mathrm{NH}_{4} \mathrm{OH}=b-d ; \mathrm{RC}=c$, e. Photos: all from JACA-MICO-01184. 
velo blanco abundante, que le da un aspecto seríceo plateado y que se mantiene en gran parte de su superficie; margen incurvado durante bastante tiempo, más derecho en los adultos, en los que se aprecian también abundantes restos velares; no higrófano; de color ocre o corteza de pan; cutícula radialmente fibrilosa, lisa o ligeramente tomentosa. Láminas medianamente apretadas $(\mathrm{L}=50-60$; $\mathrm{l}=1-3)$, estrechas $( \pm 2 \mathrm{~mm})$, adnadas; de color beige al principio, finalmente pardas; arista uniforme a ligeramente ondulada, blanquecina. Estípite de 35-48 × 7-8 mm, cilíndrico, ensanchándose hacia la base, sólido al principio, hueco en ejemplares maduros; de color pardusco, cubierto completamente por fibrillas longitudinales, que son una prolongación del velo. Carne de color amarillo pajizo tanto en el píleo como en el estípite; olor débil, ligeramente fúngico.

Basidiosporas de (7,6-)8,4-9,5(-10) $\times(5-) 5,3-6(-6,5)$ $\mu \mathrm{m}, \mathrm{Q}=(1,3-) 1,5-1,7(-1,8), \mathrm{N}=80, \mathrm{Me}=9 \times 5,7 \mu \mathrm{m}, \mathrm{Qe}$ $=1,6$, ovales en vista frontal, con una ligera depresión suprahilar en vista lateral. Basidios claviformes, tetraspóricos. Pleurocistidios no encontrados. Queilocistidios hialinos, claviformes a subpiriformes, formando en algún caso un grupo de 2-3 células catenuladas con el elemento terminal más o menos claviforme, de (20,3-)25,3-41,8($66,8) \times(7,5-) 8,4-14,2(-18) \mu \mathrm{m}, \mathrm{N}=41, \mathrm{Me}=32,4 \times 11,5$ $\mu \mathrm{m}$. Caulocistidios ausentes, presentando en la parte apical pelos caulocistidiodes formados por varias células encadenadas. Fíbulas presentes.

Observaciones. Esporádica, aunque se trata de una especie de I. subg. Mallocybe característica de los bosques de coníferas montanos y subalpinos de la Europa continental y boreal, alcanzando también los niveles alpinos asociada a Dryas octopetala y Salix spp., siempre sobre suelos calcáreos (Kühner, 1955b; Favre, 1955, 1960; Vauras \& Huhtinen, 1986; Stangl, 1989; Bizio, 1995; Jacobson \& Larsson, 2012). También presente en Norteamérica en cotas altas de carácter alpino (Cripps et al., 2010). Aunque la presencia de un abundante velo blanquecino es carácter diagnóstico, se han descrito otras especies relacionadas que habitan sólo las áreas alpinas hasta la fecha y que manifiestan también este carácter: Inocybe leucoloma Kühner difiere por su aspecto más frágil y píleo aplanado de adulto, aunque las diferencias microscópicas son poco notables; I. hebelomoides Kühner es una especie silicícola, asociada a Salix herbacea, que difiere además por sus esporas más ovoides y cortas y unos cistidios netamente catenulados.

En la península ibérica existen registros del Pirineo catalán en nivel alpino junto a Dryas octopetala y $S a-$ lix retusa en suelo calcáreo en Nùria, Gerona (Vila et al., 2001), aunque anteriormente aparece un registro procedente de las dunas de Castelldefels (Rivas-Martínez \& Losa-Quintana, 1969), que probablemente corresponda a I. heimii Bon; asimismo existen varias citas procedentes de la región del Maestrazgo (Castellón, Tarragona y Teruel) en áreas más bajas y con mayor influencia mediterránea, bajo Pinus sylvestris, $P$. nigra y $P$. halepensis en suelo calcáreo (Sánchez et al., 1995); estas últimas deberían ser revisadas y en lo posible analizadas molecularmente, para aclarar la exis- tencia probable de otra especie diferente o confirmar su identificación.

Inocybe nitidiuscula f. epixantha (Kühner) Stangl (Fig. 14). $\equiv$ Inocybe friesii f. epixantha Kühner.

- Inocybe friesii var. epixantha (Kühner) Cetto nom. inval. -Art. 33.3-.

Material estudiado: Zona 2.11, bajo Pinus uncinata y Betula pendula, 7-X-2014, leg. F. Pancorbo, J. Cuesta, J. Hernanz, JACA-MICO-00640, duplo en AH44485. Idem, bajo Pinus uncinata, JACA-MICO-01189, duplo en AH44486. Idem, bajo Pinus uncinata, JACA-MICO-01190, duplo en AH44488.

Píleo de 8-39 mm de diám., 4-20 mm de altura, inicialmente cónico-campanulado a cónico-convexo, posteriormente se expande hasta plano-convexo, provisto de un mamelón más o menos agudo, obtuso en los ejemplares de mayor porte; de color ocre amarillento; cutícula lisa, fibrilosa en ejemplares adultos, margen apenas incurvado, pronto recto, un poco excedente, a veces ligeramente festoneado por los restos del velo. Láminas espaciadas ( $\mathrm{L}=26-32 ; 1=1-3)$, anchas a ventrudas, casi libres a marginadas, con un diente decurrente; de color inicial crema, finalmente pardo-ocráceo; arista inicialmente casi del mismo color que las caras, luego algo más pálida, blanquecina. Estípite de 23-70 × 2-4 mm, uniformemente cilíndrico, ligeramente ensanchado hacia la base, no bulboso; inicialmente blanquecino $u$ ocráceo, con tonos rosados tenues en el tercio superior, con la edad ocráceo-amarillento o grisáceo-amarillento, semejante al píleo, que se va haciendo más pálido hasta casi blanquecino hacia la base; claramente pruinoso en el tercio superior, el resto de aspecto fibriloso por restos del velo, con numerosas fibrillas blanquecinas. Carne delgada, blanquecina con esfumaciones rosáceas bajo la superficie pileica; olor ligeramente espermático al corte.

Basidiosporas de (8,3-)9,1-10,7(-11,5) × (5-)5,3-6,3($6,5) \mu \mathrm{m}, \mathrm{Q}=(1,4-) 1,6-1,8(-2), \mathrm{N}=57, \mathrm{Me}=9,8 \times 5,8 \mu \mathrm{m}$, $\mathrm{Qe}=1,7$, lisas, amigdaliformes, con el ápice ligeramente estirado. Pleurocistidios metuloides de (54,7-)60,1-75,6($83,9) \times(16,2-) 18-21,8(-23,6) \mu \mathrm{m}, \mathrm{N}=23, \mathrm{Me}=66,6 \times 20,1$ $\mu \mathrm{m}$, en general fusiformes a sublageniformes con el cuello más o menos alargado, poco cristalíferos en el ápice, de paredes gruesas de $1-1,3 \mu \mathrm{m}$ en la parte media y 3,3-3,7 $\mu \mathrm{m}$ en el ápice, con reacción amarillenta casi nula en las soluciones amoniacales. Queilocistidios polimórficos, más cortos y ventrudos que los queilocistidios, de (30,8-)34,6-51,8(-57,2) $\times(15,1-) 16-21,4(-22,2) \mu \mathrm{m}, \mathrm{N}=38, \mathrm{Me}=42,9 \times 18,8 \mu \mathrm{m}$ de subfusiformes a utriformes, subglobosos a piriformes, mezclados con paracistidios claviformes a subglobosos. Caulocistidios presentes en el tercio superior del estípite, metuloides, similares a los queilocistidios y agrupados en haces con abundantes cauloparacistidios. Fíbulas presentes.

Observaciones. Las colecciones estudiadas, recogidas en la misma fecha, proceden de localidades muy próximas en los mismos ambientes, y están constituidas por numerosos ejemplares en distintos estadios de desa- 
rrollo. La clara presencia de caulocistidios y tonalidades o reflejos rojizos en el tercio superior del pie, hacen referencia a su inclusión en Inocybe sect. Tardae Bon, y en concreto en $I$. subsect. Tardinae Bon. Nuestra determinación está basada en el estudio comparativo que hemos realizado del material holotípico de Kühner (1955a). Originalmente considerado por su autor como una forma de Inocybe friesii R. Heim [= I. nitidiuscula (Britzelm) Sacc.], nuestro parecer es de que probablemente se trate de una especie independiente, aunque no se puede afirmar esta suposición por el momento, al no haberse realizado estudios con técnicas moleculares. Asimismo, la iconografía y descripción aportada por Favre (1955) se ajusta muy bien a la de nuestras muestras; no obstante, es improbable que la referencia que hacen de esta forma Bon \& Chevassut (1989), de material recogido en áreas mediterráneas francesas, corresponda al mismo taxón.

Inocybe nitidiuscula $\mathrm{f}$. epixantha prospera en ambientes montanos y altimontanos de la Europa continental, tanto en los bosques de coníferas subalpinos como en niveles alpinos asociado a Dryas, en suelos calcáreos. Difiere de I. nitidiuscula por el color del píleo con matices

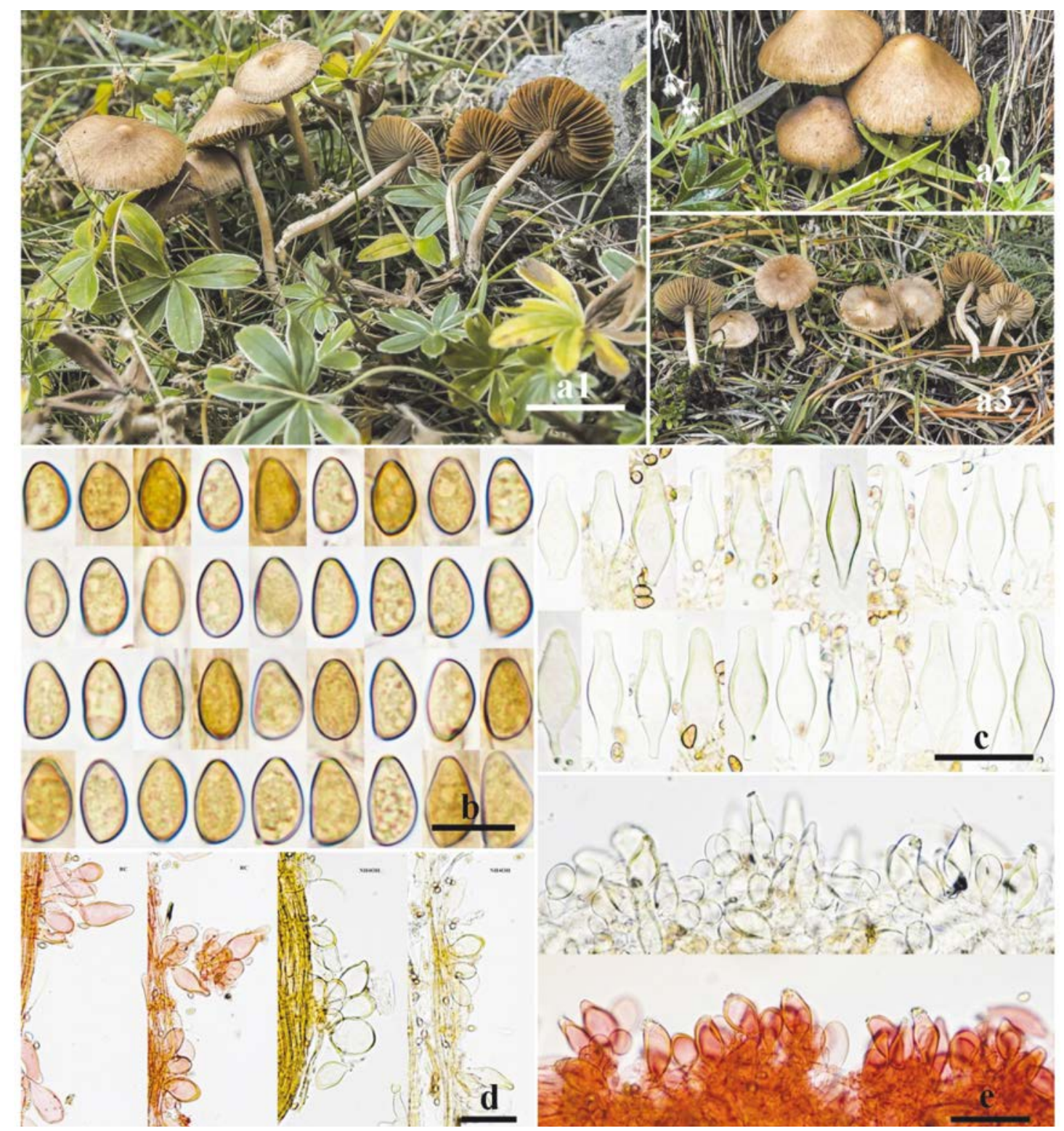

Figura 14: Caracteres morfológicos de Inocybe nitidiuscula f. epixantha. a. Basidiomas in situ. b. Basidiosporas. c. Pleurocistidios. d. Caulocistidios en el ápice del estípite. e. Queilocistidios y filo laminar. Escala: $20 \mathrm{~mm}=\mathrm{a} 1 ; 50 \mu \mathrm{m}=\mathrm{c}-\mathrm{e} ; 10 \mu \mathrm{m}=\mathrm{b}$. Medio de montaje: $\mathrm{NH}_{4} \mathrm{OH}=\mathrm{b}-\mathrm{e} ; \mathrm{RC}=\mathrm{d}$, e. Fotos: todas a partir de JACA-MICO-00640.

Figure 14: Morphological characters of Inocybe nitidiuscula f. epixantha. a. Basidiomata in situ. b. Basidiospores.

c. Pleurocystidia. d. Caulocystidia in stipe apex. $\boldsymbol{e}$. Cheilocystidia and lamella edge. Bar: $20 \mathrm{~mm}=a 1 ; 50 \mu \mathrm{m}=c-e ; 10 \mu \mathrm{m}=b$. Mounting media: $\mathrm{NH}_{4} \mathrm{OH}=b-e ; \mathrm{RC}=d$, e. Photos: all from JACA-MICO-00640. 
gris-leonados o amarillentos y el aspecto fibriloso del mismo. En la península ibérica no se ha hecho ninguna referencia al mismo hasta la fecha.

Inocybe occulta Esteve-Rav., Bandini, B. Oertel \& G. Moreno (Fig. 15).

Material estudiado: Zona 2.15, en bosque de Pinus uncinata, 27-VIII-2015, leg. M.A. Ribes, J. Hernanz, G. Sánchez, F. Esteve-Raventós, A. Lorenzo, F. Pancorbo, JACA-MICO-00642, duplo en AH47628.
Píleo de 22-35 mm de diám., 10-15 mm de altura, inicialmente cónico-campanulado a cónico-convexo, posteriormente se expande hasta convexo a aplanado, provisto de un mamelón obtuso; margen involuto en ejemlares jóvenes, luego regular u ondulado, ligeramente higrófano en el disco central; de color ocráceo a ocráceo-amarillento, más anaranjado en el disco; cutícula glabra, ligeramente viscosa con la humedad, fibrosa radialmente, margen radialmente fibroso, aunque nada o apenas rimoso en ejemplares adultos; no se aprecian restos de velo en el margen del píleo. Láminas medianamente apretadas $(\mathrm{L}=48-58 ; \mathrm{l}=1-3)$, li-

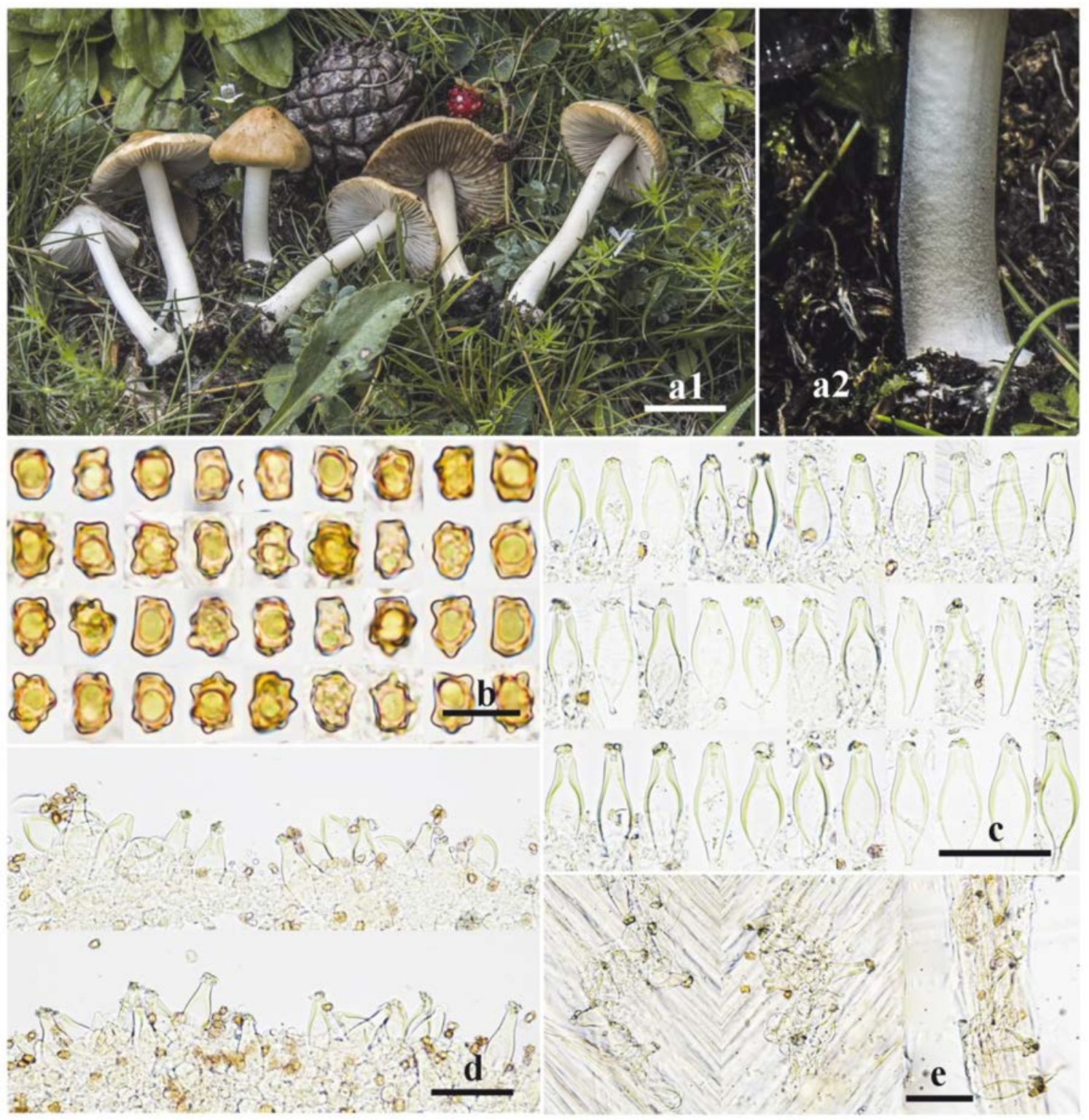

Figura 15: Caracteres morfológicos de Inocybe occulta. a. Basidiomas in situ. a2. Detalle de la base del estípite. b. Basidiosporas. c. Pleurocistidios. d. Queilocistidios y filo laminar. e. Caulocistidios en la base del estípite. Escala: $20 \mathrm{~mm}=\mathrm{a} 1 ; 50 \mu \mathrm{m}=\mathrm{c}-\mathrm{e}$; $10 \mu \mathrm{m}=$ b. Medio de montaje: $\mathrm{NH}_{4} \mathrm{OH}=$ b-e. Fotos: todas a partir de JACA-MICO-00642.

Figure 15: Morphological characters of Inocybe occulta. a. Basidiomata in situ. a2. Stipe base detail. b. Basidiospores. c. Pleurocystidia. d. Cheilocystidia and lamella edge. $\boldsymbol{e}$. Caulocystidia in stipe apex. Bar: $20 \mathrm{~mm}=a 1 ; 50 \mu \mathrm{m}=c-e ; 10 \mu \mathrm{m}=b$. Mounting media: $\mathrm{NH}_{4} \mathrm{OH}=$ b-e. Photos: all from JACA-MICO-00642 
bres, ventrudas; de color inicial blanquecino, en ocasiones con ligero reflejo lilacino-violáceo, luego beige, finalmente pardo-ocráceo; arista algo más pálida o casi del mismo color que las caras, finamente crenuladas. Estípite de 32-50 $\times$ 4-6 mm, cilíndrico con la base bulbosa y marginada, sólido; de color blanco que apenas oscurece o se torna beigeocráceo o amarillento pálido con la edad, manteniendo su color en exsiccatum; superficie cubierta enteramente por una fina y densa pruina blanquecina que alcanza claramente el bulbo. Carne firme, blanquecina que no se oscurece; olor herbáceo o subespermático.

Basidiosporas de $(6,7-) 7,3-8,7(-9,2) \times(5,1-) 5,4-6,6(-$ $7,2) \mu \mathrm{m}, \mathrm{Q}=(1,1-) 1,2-1,48(-1,5), \mathrm{N}=80, \mathrm{Me}=8 \times 6 \mu \mathrm{m}$, $\mathrm{Qe}=1,3$, con nódulos poco prominentes, subisodiamétricas a ligeremante heterodiamétricas. Basidios claviformes, tetraspóricos. Pleurocistidios metuloides, de (46,5-)48,8$56,4(-64,4) \times(14,4-) 15,7-19,3(-20,6) \mu \mathrm{m}, \mathrm{N}=36, \mathrm{Me}=$ $53,3 \times 17,4 \mu \mathrm{m}$, fusiformes con el cuello más o menos alargado, con ápice cristalífero, presentando algunos un pedicelo basal, con paredes gruesas de (1,3-)1,9-3,9(-4,3) $\mu \mathrm{m}$, $\mathrm{N}=20, \mathrm{Me}=2,8 \mu \mathrm{m}$, con reacción más o menos amarillenta con las soluciones amoniacales. Arista laminar heterogénea, compuesta por queilocistidios y paracistidios claviformes de paredes finas. Queilocistidios similares a los pleurocistidios. Caulocistidios muy abundantes a lo largo de todo el estípite, metuloides, similares a los cistidios laminares y agrupados en haces con abundantes cauloparacistidios claviformes a piriformes. Fíbulas presentes.

Observaciones. En un reciente artículo que se encuentra actualmente en fase de publicación, Esteve-Raventós et al. (2017-2018, en revisión) han realizado un amplio estudio morfológico y molecular del llamado "complejo Mixtilis". A Inocybe mixtilis (Britzelm.) Sacc. se la ha considerado tradicionalmente una especie "goniosporada" muy común y fácil de reconocer, a lo largo de sus amplias áreas de distribución en el hemisferio boreal. No obstante, los resultados obtenidos en este estudio, realizado sobre la base de un amplísimo número de colecciones, demuestran que en realidad I. mixtilis es un complejo de varias especies, algunas de las cuales apenas muestran diferencias a nivel morfológico, aunque parecen constituir entidades bien definidas a nivel genético. Una de ellas es I. occulta, que ha sido determinada con el nombre de Inocybe mixtilis en amplias áreas de Europa y Norteamérica; ambas constituyen diferentes especies genéticas cuya separación resulta muy compleja morfológicamente ("criptoespecies"). Según los resultados de estos estudios, I. occulta parece ser la especie de mayor distribución y la más frecuente del "complejo Mixtilis". Las diferencias entre I. mixtilis e I. occulta a nivel macroscópico son muy tenues, aunque en I. occulta el píleo es algo menos viscoso y ligeramente higrófano en tiempo húmedo; también las esporas parecen tener una tendencia algo más heterodiamétrica cuando se realizan estudios biométricos con numerosas mediciones (Qe ligeramente más alto). Los análisis moleculares realizados a la colección de Ordesa han confirmado que se trata de I. occulta, especie cuya validación se realizará próximamente por los autores mencionados.

\section{Inocybe tricolor Kühner (Fig. 16).}

Material estudiado: Zona 5.7, en pradera alpina con Dryas octopetala, 29-VIII-2015, leg. J. Hernanz, M.A. Ribes, F. Esteve-Raventós, F. Pancorbo, JACA-MICO-00635, duplo en AH47658.

Píleo de 20-26 mm de diám., 10-15 mm de altura, inicialmente cónico-campanulado a cónico-convexo, que posteriormente se expande hasta convexo o plano-convexo, provisto de un mamelón obtuso; margen inflexo, incluso en ejemplares adultos, no higrófano, decorado con escamas aplicadas concéntricas más o menos recurvadas; de color pardo a pardo-rojizo, vinoso; cutícula de aspecto lanoso, con escamas bien contrastadas sobre un fondo ligeramente más pálido, margen con aspecto lanoso; no se aprecian restos de velo en el margen del píleo. Láminas medianamente apretadas $(\mathrm{L}=48-58 ; \mathrm{l}=1-3)$, arqueadas a subdecurrentes; de color inicial grisáceo o crema, luego beige, finalmente pardo-ocráceo; arista algo más pálida o casi del mismo color que las caras, prácticamente entera. Estípite de 30-35 × 5-7 mm, en ocasiones casi cilíndrico, pero a menudo progresivamente ensanchado hacia la base, no bulboso, sólido; color blanco en el ápice, el resto pardusco con tonos vinosos, cubierto con fibrillas blanquecinas que forman una masa algodonosa en la base. Carne firme, blanquecina que adquiere unos tonos rojizos-vinosos en los ejemplares más maduros; olor aromático, complejo.

Basidiosporas de $(7,7-) 8,3-9,5(-10,2) \times(5,1-) 5,3-$ $6,0(-6,2) \mu \mathrm{m}, \mathrm{Q}=(1,4-) 1,5-1,7(-1,9), \mathrm{N}=42, \mathrm{Me}=8,9 \times$ $5,6 \mu \mathrm{m}, \mathrm{Qe}=1,6$, ovales en vista frontal, amigdaliformes en vista lateral con el ápice ligeramente apuntado en algún caso. Basidios claviformes, tetraspóricos. Pleurocistidios metuloides no muy abundantes, de (44,9-)46,7$59,2(-69,2) \times(11,7-) 12,6-17,3(-20,4) \mu \mathrm{m}, \mathrm{N}=19, \mathrm{Me}=$ $54,6 \times 14,7 \mu \mathrm{m}$, desde estrechamente utriformes a claviformes o subfusiformes, netamente cristalíferos en el ápice y con contenido intracelular amarillento, pared de grosor variable $(0,9-) 1,0-1,7(-1,9) \mu \mathrm{m}, \mathrm{Me}=1,3 \mu \mathrm{m}$, con reacción débil en las soluciones amoniacales. Arista laminar heterogénea, compuesta por queilocistidios en general escasos, paracistidios no muy numerosos y algunas formas de tránsito entre queilocistidios y basidios. Queilocistidios similares a los pleurocistidios, con contenido intracelular amarillento. Caulocistidios presentes y escasos en la zona apical, (1/6-1/10 superior), nada o apenas cristalíferos, con paredes a menudo estrechas, cilíndricos a sublageniformes; aparecen mezclados con formas de transición semejantes a pelos o simples terminaciones hifales; pigmento intracelular pardo-rojizo. Fíbulas presentes.

Observaciones. Se trata de una especie originalmente descrita por Kühner (1955a) de la región de la Vanoise (St. Bon y estación invernal de Courchevel), lo que refleja las apetencias por las zonas montanas de esta especie, probablemente recolectada en los bosques de coníferas de la región. Posteriormente ha sido registrada en diversos países de la Europa continental y subboreal (Stangl \& Ve- 


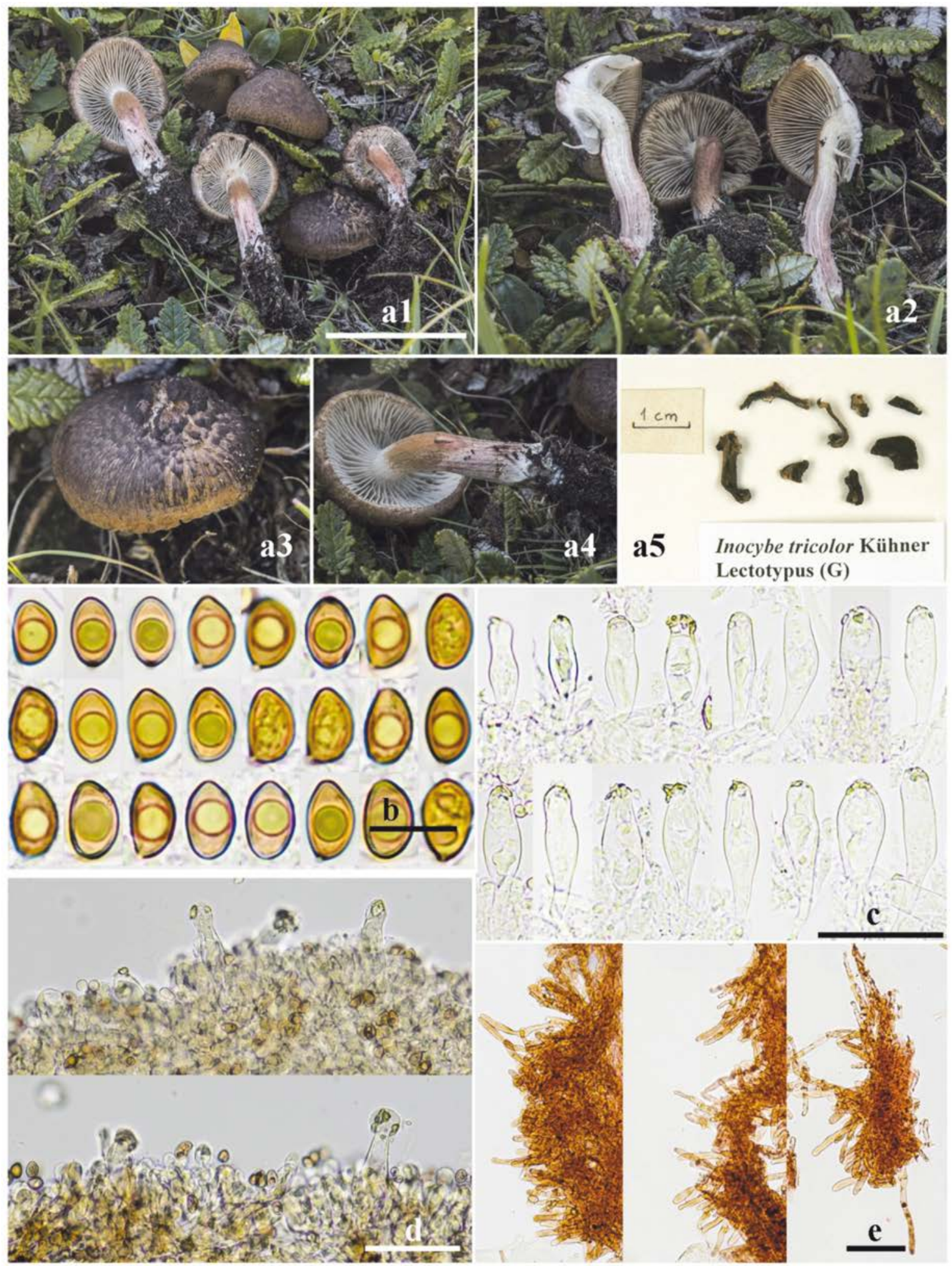

Figura 16: Caracteres morfológicos de Inocybe tricolor. a. Basidiomas in situ. a5. Basidiomas del lectótipo de I. tricolor. b. Basidiosporas. c. Pleurocistidios. d. Queilocistidios y filo laminar. e. Caulocistidios en el ápice del estípite. Escala: $20 \mathrm{~mm}=$ a1; $50 \mu \mathrm{m}=\mathrm{c}-\mathrm{e} ; 10 \mu \mathrm{m}=\mathrm{b}$. Medio de montaje: $\mathrm{NH}_{4} \mathrm{OH}=\mathrm{b}-\mathrm{d}$; $\mathrm{RC}=$ e. Fotos: todas a partir de JACA-MICO-00635.

Figure 16: Morphological characters of Inocybe tricolor. a. Basidiomata in situ. a5. Basidiomata from I. tricolor lectotypus. b. Basidiospores. c. Pleurocystidia. d. Cheilocystidia and lamella edge. e. Caulocystidia in stipe apex. Bar: $20 \mathrm{~mm}=a 1$; $50 \mu \mathrm{m}=c-e ; 10 \mu \mathrm{m}=b$. Mounting media: $\mathrm{NH}_{4} \mathrm{OH}=b-d ; \mathrm{RC}=e$. Photos: all from JACA-MICO-00635. 
selsky, 1979; Alessio, 1984; Kuyper, 1986; Breitenbach \& Kränzlin, 2000) en estos mismos ambientes. Parece asimismo alcanzar los niveles subalpinos e incluso alpinos, como así lo certifican los registros de Kühner \& Lamoure (1989), Stridvall et al. (1989); Bon (1997) y Jacobson \& Larsson (2012), creciendo en presencia de Dryas octopetala y Salix spp., en sustrato calcáreo. Por tanto, la colección de la Pala de Montinier (Tella), aparte de constituir el primer registro a nivel nacional, confirma la presencia de esta especie en las zonas altas de los Pirineos.

Existe una cita de la Italia mediterránea (Salento, Apulia) por Giliberto \& Costiniti (2013), cuyo hábitat bajo Quercus coccifera y $Q$. macrolepis a $90 \mathrm{msnm}$ nos sugeriría la conveniencia de realizar un estudio comparativo a nivel molecular para confirmar la identidad del taxón italiano y la probable existencia de especies "gemelas" ligadas a diferentes ámbitos ecológicos o biogeográficos; el pequeño tamaño y el estípite radicante bulboso son algunos de los aspectos interesantes señalados por estos autores italianos.

Inocybe tricolor es una especie muy esporádica, poco frecuente, pero muy atractiva por su vistosa coloración y característico olor; por esta razón es incluida en $I$. sect. Lactiferae R. Heim, siendo diagnósticos el fuerte enrojecimiento de los carpóforos, el olor complejo afrutado y el píleo decorado con escamas bien diferenciadas y aplicadas que le dan un aspecto floconoso-atigrado. El estudio del material tipo (lectótipo) procedente de $(\mathrm{G})$, nos mostró caracteres que se ajustan muy bien a los de nuestra colección.

\section{Inocybe xanthomelas Boursier \& Kühner (Fig. 17).}

Material estudiado: Zona 5.2, en bosque de Fagus sylvatica, 27-VIII-2015, leg. M.A. Ribes, J. Hernanz, F. Esteve-Raventós, F. Pancorbo, JACA-MICO-00643, duplo en AH47646.

Material adicional estudiado: FRANCIA, Aquitania, Osse-en Aspe, Forêt d'Issaux, 30TXN8463, 917 m, bajo Corylus avellana en bosque de Fagus sylvatica, 9-X2016, leg. M.A. Ribes, J. Cuesta, J.F. Mateo, F. Pancorbo, AH47714. Ibidem, 30TXN8663, 924 m, 11-X-2016, leg. M.A. Ribes, J. Cuesta, J.F. Mateo, F. Pancorbo, AH48140.

Píleo de 20-30 mm de diám., 8-22 mm de altura, inicialmente acampanado cónico, que rápidamente con el desarrollo se expande hasta plano-convexo, provisto de un mamelón obtuso no demasiado marcado; margen inflexo en ejemplares jóvenes, que se expande pronto, no higrófano; de color amarillo pálido a ocre amarillento; cutícula glabra, fibrilosa, ligeramente viscosa con la humedad, con el margen ampliamente fibriloso llegando a rimoso; la superficie en los ejemplares jóvenes aparece revestida de un velo más o menos fugaz blanquecino. Láminas medianamente apretadas $(\mathrm{L}=38-42 ; 1=1-3)$, libres o anexas; de color inicial blanquecino o crema, finalmente pardo-ocráceo; arista más pálida, prácticamente entera. Estípite de 58-68 × 3-6 mm, cilíndrico con la base bulbo- so-marginada, sólido, cubierto completamente por una pruina blanca; blanquecino grisáceo en los ejemplares jóvenes, que con el desarrollo van tomando una coloración más oscura en la parte inferior, llegando a ennegrecer cuando están secos. Carne blanquecina que con el tiempo se va oscureciendo, sobre todo en el estípite; olor herbáceo o subespermático. Fíbulas presentes.

Basidiosporas nodulosas, subisodiamétricas de $(7,2-$ ) $7,5-10,5(-11,3) \times(4,8-) 5,5-8,2(-8,8) \mu \mathrm{m}, \mathrm{Q}=(1,1-) 1,2-$ $1,5(-1,6), \mathrm{N}=54, \mathrm{Me}=8,6 \times 6,5 \mu \mathrm{m}, \mathrm{Qe}=1,3$, con nódulos prominentes. Basidios claviformes, tetraspóricos. Pleurocistidios metuloides, de (53,3-)55,1-66,4(-67,5) $\times$ (14-)14,5-19(-19,9) $\mu \mathrm{m}, \mathrm{N}=18, \mathrm{Me}=60,1 \times 16,7 \mu \mathrm{m}$, de paredes gruesas de $0,7-1,1 \mu \mathrm{m}$ en la parte media y $3,1-$ 3,5 $\mu \mathrm{m}$ en el ápice, con reacción débilmente amarillenta en las soluciones amoniacales; en ocasiones muestran un contenido oleaginoso de color amarillento-pardusco, sobre todo en los ejemplares más adultos o maduros. Queilocistidios similares a los pleurocistidios, presentando algunos de ellos un contenido amarillento, mezclados con paracistidios claviformes. Caulocistidios presentes a todo lo largo del estípite, llegando hasta la base, metuloides, similares a los cistidios laminares y agrupados en haces con abundantes cauloparacistidios claviformes.

Observaciones. La interpretación de Inocybe xanthomelas (Kühner, 1933) ha sido compleja y ha dado lugar a numerosas confusiones con otras especies a lo largo del tiempo (p. ej. con Inocybe krieglsteineri Fdez.-Sasia). Ello es debido a la existencia de otras especies que comparten caracteres tan llamativos como las esporas asteriformes y el oscurecimiento o incluso ennegrecimiento de los carpóforos. Los registros de I. xanthomelas de Esteve-Raventós et al. (2015) no corresponden a esta especie, que según nuestros análisis moleculares más recientes (Larsson et al., en preparación), certifican que el lectótipo de I. xanthomelas corresponde a un taxón diferente, con el píleo más amarillento pálido, propio de los hayedos templados (probablemente asociado también con otras Fagáceas de ambientes húmedos), con un ennegrecimiento patente y cistidios lageniformes. Tales características corresponden perfectamente a la muestra que hemos recogido en el Valle de Pineta bajo las hayas, y que además muestran en los primeros estadios de desarrollo, un velo blanquecino fibriloso-algodonoso en los primordios, aunque luego es efímero en tiempo húmedo y aparentemente ausente.

Hemos recolectado también dos colecciones provenientes de la vertiente norte (Pirineo francés) en hayedos, que parecen corresponder también al concepto original de esta especie. Existen colecciones de ambientes mediterráneos que fueron determinadas originalmente como I. xanthomelas y que parecen corresponder a dos especies que han sido descritas recientemente como nuevas en la península ibérica, e.g. I. flavobrunnescens Esteve-Rav., G. Moreno \& Bizio (Esteve-Raventós et al., 2015) e I. praetervisoides Esteve-Rav., G. Moreno \& Olariaga (Esteve-Raventós et al., 2016), propias de suelos arenosos de naturaleza ácida en presencia de Quercus esclerófilos, y que además difieren por el aspecto no estrellado de sus esporas. 

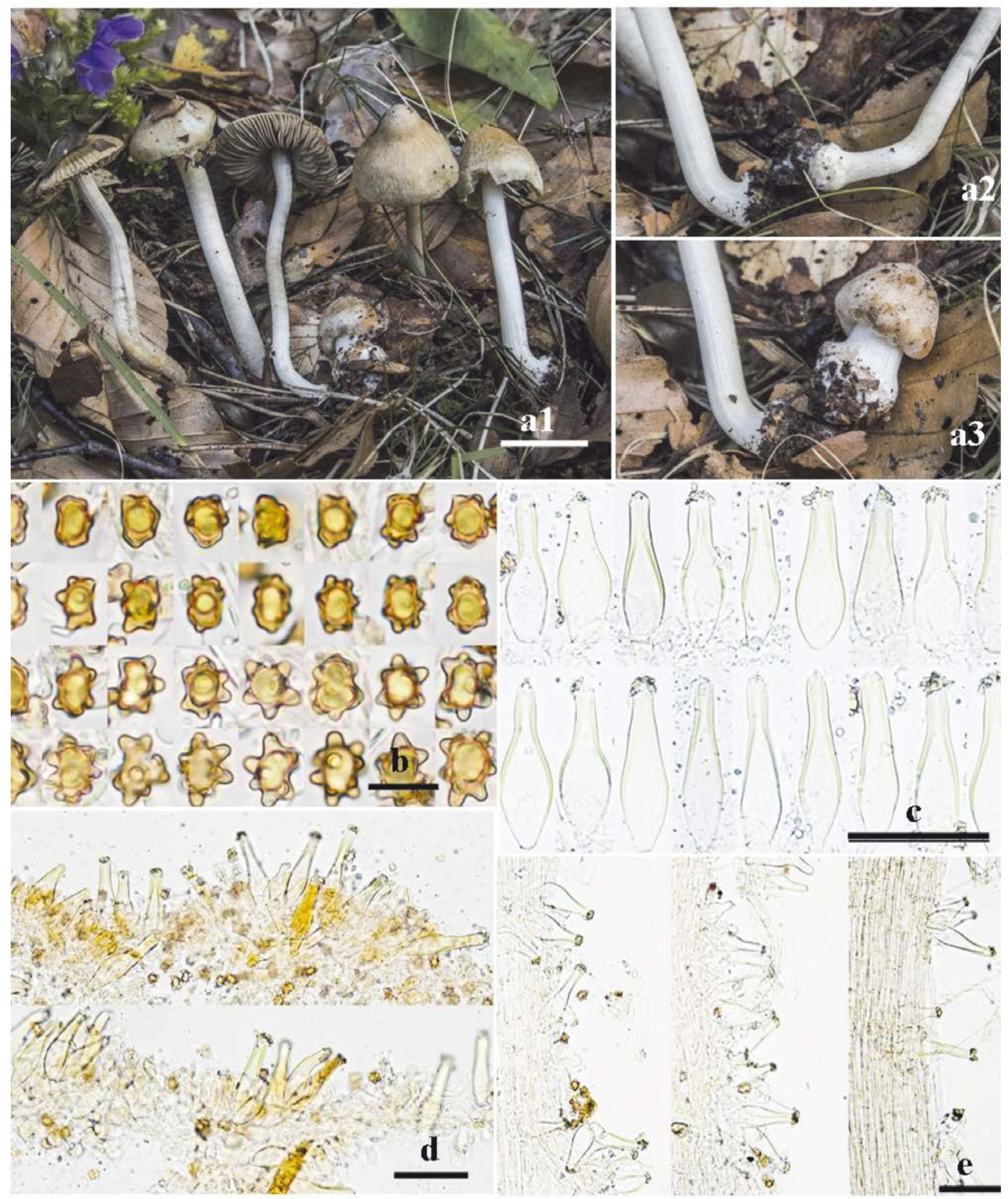

Figura 17: Caracteres morfológicos de Inocybe xanthomelas. a. Basidiomas in situ. b. Basidiosporas. c. Pleurocistidios. d. Queilocistidios y filo laminar. e. Caulocistidios en la base del estípite. Escala: $20 \mathrm{~mm}=\mathrm{a} ; 50 \mu \mathrm{m}=\mathrm{c}-\mathrm{e} ; 10 \mu \mathrm{m}=\mathrm{b}$. Medio de montaje: $\mathrm{NH}_{4} \mathrm{OH}=$ b-e. Fotos: todas a partir de JACA-MICO-00643.

Figure 17: Morphological characters of Inocybe xanthomelas. a. Basidiomata in situ. b. Basidiospores. c. Pleurocystidia. d. Cheilocystidia and lamella edge. $\boldsymbol{e}$. Caulocystidia in stipe base. Bar: $20 \mathrm{~mm}=a 1 ; 50 \mu \mathrm{m}=c-e ; 10 \mu \mathrm{m}=b$. Mounting media: $\mathrm{NH}_{4} \mathrm{OH}=$ b-e. Photos: all from JACA-MICO-00643. 


\section{Lactarius fraxineus Romagn. (Fig. 18).}

Material estudiado: Zona 4.2, en bosque de Quercus sp. y Corylus avellana, 28-VIII-2015, leg. A. Hereza, G. Sánchez, S. Serrano, J. F. Mateo, JACA-MICO-00546.

Píleo de 60-100 mm de diám., inicialmente convexo, que posteriormente se expande hasta convexo o planoconvexo, con una depresión central más menos acentuada; margen inflexo en ejemplares jóvenes, que en ejemplares adultos se torna ligeramente ondulado, no higrófano; de color pardo rojizo en el centro, aclarándose hacia el margen, mostrando en algún caso unas zonaciones concéntricas; superficie pileica untuosa, ligeramente rugosa. Láminas apretadas, con abundantes lamélulas, adnadas, decurrentes, anastomosadas cerca de la unión con el estípite; de color crema; arista algo más pálida o casi del mismo color que las caras, prácticamente entera. Estípite de 30-70 × 10-15 mm, cilíndrico, que en algunos casos se ensancha y en otros se atenúa hacia la base, sólido en ejemplares jóvenes, hueco en los maduros; de color pardo rojizo, similar al del píleo, que se hace blanquecino en el ápice. Carne firme, frágil, de color rojizo; olor agradable, débil. Látex abundante, de color blanco, inmutable aislado, picante. Al secarse sobre las láminas o el estípite, vira a gris-verdoso al cabo de un tiempo. Presenta reacción nula al $\mathrm{KOH}(40 \%)$ tanto en el látex como en la carne.

Basidiosporas de (5,9-)6,2-7,6(-7,8) × (5,3-)5,6-6,5($6,9) \mu \mathrm{m}, \mathrm{Q}=1-1,3(-1,4), \mathrm{N}=45, \mathrm{Me}=7,1 \times 6 \mu \mathrm{m}, \mathrm{Qe}=$ 1,2 , (medidas sobre material rehidratado procedente de herbario); subglobosas a ovales, ornamentadas por pequeñas crestas conectadas que dan la apariencia de un falso retículo. Basidios de 35-45 × 9-11 $\mu \mathrm{m}$, subclaviformes, en su mayoría tetraspóricos, aunque se observan también bispóricos y monospóricos. Macrocistidios fusiformes, con el ápice atenuado y habitualmente estrangulado. Macroqueilocistidios de 48,0-50,9 x 8,3-10,2 $\mu \mathrm{m}$, macropleurocistidios de morfología similar, de 49,9-57,9 x 8,4 - 11,3 $\mu \mathrm{m}$. Pileipellis de tipo ixocutis, débilmente gelificada. Hifas filamentosas e intrincadas, de forma cilíndrica con el ápice ligeramente engrosado con una anchura media a este nivel de 2,5-4,7 $\mu \mathrm{m}$.

Observaciones. Perteneciente a la Lactarius subsect. Pyrogalini Singer, grupo donde se encuadran especies en las que el látex al secarse vira a verde-grisáceo, así como esporas a menudo cebradas y revestimiento pileico untuoso a viscoso; en esta sección se incluyen especies muy conocidas y citadas como Lactarius blennius (Fr.) Fr. típica de hayedos o Lactarius pyrogalus (Bull.) Fr., típica de avellanos, que también la encontramos junto a nuestra recolecta. En el caso de L. fraxineus son diagnósticos el olor agradable, ligeramente afrutado, el revestimiento pileico untuoso y el sabor acre del látex, que lo separan de Lactarius quietus (Fr.) Fr., de color algo más claro, con el que presenta una gran similitud macroscópica. Tiene una cierta afinidad con Lactarius hysginus (Fr.) Fr. por su superficie pileica untuosa y su morfología esporal, pero tanto el hábitat como el olor y las tonalidades violáceas de éste último, separan bien ambos taxones. Aunque Rogmanesi (1963) lo encuentra bajo Fraxinus excelsior, su hábitat no está restringido a esta oleácea; en Europa se ha encontrado bajo carpes y robles (Basso, 1999), robles, avellanos y arces y otros planifolios como hayas, abedules, álamos en suelos húmedos (Lecomte \& Legros, 2011). En España ha sido citado por Llistosella (1991) bajo alisos y cerezo silvestre en el Baix Empordà. Tenemos constancia de otras recolectas no publicadas todavía en Gerona, tanto en bosque mediterráneo como en ambiente montano (Pérez de Gregorio, com. personal) así como en Guadalajara en la ribera del Jarama bajo avellanos, robles y sauces (J.C. Campos, com. personal).

Pholiota squarrosoides (Peck) Sacc. (Fig. 19).

Material estudiado: Zona 2.8. Bosque de Fagus sylvatica, 13-IX-2014, leg. F. Serrano, S. Tello, JACA-MICO-00132. Secuencia ITS GenBank MF345957. Ibidem, 21-IX-2015, leg. A. Lorenzo, J. Hernanz. JACA-MICO-01074. Ibidem, 20-IX-2016, leg. J. Hernanz. JACAMICO-0682. Ibidem. 4-X-2016, leg. F. Serrano, F. Cervera, JACA-MICO-00691.

Material adicional estudiado: FRANCIA, Aquitania, Arette, Col de Labays, 30TXN8463, 1350 m, en bosque de Fagus sylvatica, 2-IX-2006, leg. F. Serrano, J. Hernanz. No se conserva material de herbario. Ibidem, 12IX-2009, leg. J. Hernanz. AH48185. Ibidem, 27-IX-2009, leg. J. Hernanz. AH48186. Ibidem, 28-IX-2013, leg. A. Palazón, J. Hernanz. AH48187.

Basidiomas con crecimiento cespitoso. Píleo de 30$120 \mathrm{~mm}$, no higrófano, al principio convexo, después más aplanado, manteniendo un umbón en el centro; superficie pileica algo viscosa en tiempo húmedo, blanquecina crema, cubierta por escamas entre cónicas y piramidales, con la base fibrilosa y el ápice más compacto, de color marrón tostado a marrón rosado, que se distancian al desarrollarse el píleo, siendo absorbidas por la superficie pileica para quedar sus ápices como pequeñas escamas cónicas compactas, no fibrillosas; margen afilado, de color pálido amarillento; Láminas abundantes, más bien gruesas, de adnadas a subdecurrentes, pálido amarillentas, después, al madurar las esporas, toman un color marrón amarillento y en estado muy maduro se vuelven de color marrón más oscuro y ligeramente rojizo. Esporada pardo rojiza. Estípite de 40-130 × 6-14 mm, cilíndrico, seco, con una zona anular fibrillosa poco notable, con colores parecidos a los del píleo, densamente fibriloso-escuamuloso bajo la zona anular. Carne con ligero olor aromático.

Basidiosporas de $(4,4-) 4,8-5,8(-6,8) \times(2,7-) 2,9-$ $3,5(-3,6) \mu \mathrm{m}, \mathrm{Q}=1,5-1,8, \mathrm{~N}=84, \mathrm{Me}=5,3 \times 3,3 \mu \mathrm{m}$, $\mathrm{Qe}=1,6$, subfaseoliformes en vista lateral, de elipsoidales a ovoides en vista frontal, bastante pálidas, con paredes delgadas, sin poro germinativo, lisas al microscopio óptico. Basidios de $\mathrm{Me}=26 \times 5,6 \mu \mathrm{m}$, tetraspóricos, con fíbulas basales. Arista de la lámina estéril. Queilocistidios de 32,4-48,5 × 6,2-11 $\mu \mathrm{m}$, cilíndricos a subla- 

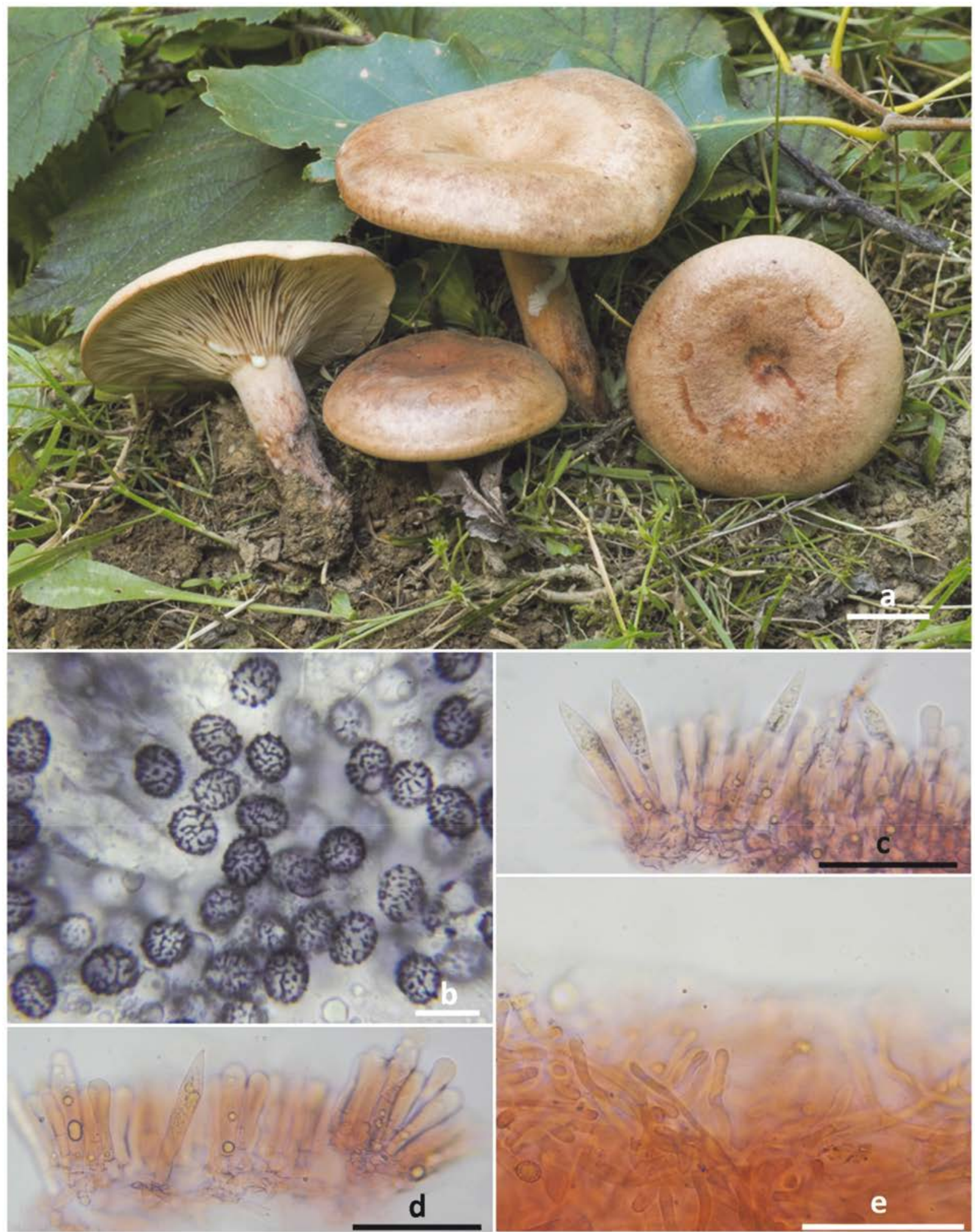

Figura 18: Caracteres morfológicos de Lactarius fraxineus. a. Basidiomas in situ. b. Basidiosporas. c. Pleurocistidios. d. Queilocistidios. e. Pileipellis. Escala: $20 \mathrm{~mm}=\mathrm{a} ; 50 \mu \mathrm{m}=\mathrm{c}$-e; $10 \mu \mathrm{m}=\mathrm{b}$. Medio de montaje: Melzer $=\mathrm{b}$; $\mathrm{RC}=\mathrm{c}$-e Fotos: todas a partir de JACA-MICO-00546.

Figure 18: Morphological characters of Lactarius fraxineus. a. Basidiomata in situ. b. Basidiospores. c. Pleurocystidia. d. Cheilocystidia. e. Pileipellis. Bar: $20 \mathrm{~mm}=a$; $50 \mu \mathrm{m}=c-e ; 10 \mu \mathrm{m}=b$. Mounting media: Melzer $=b ; R C=c-e$. Photos: all from JACA-MICO-00546. 


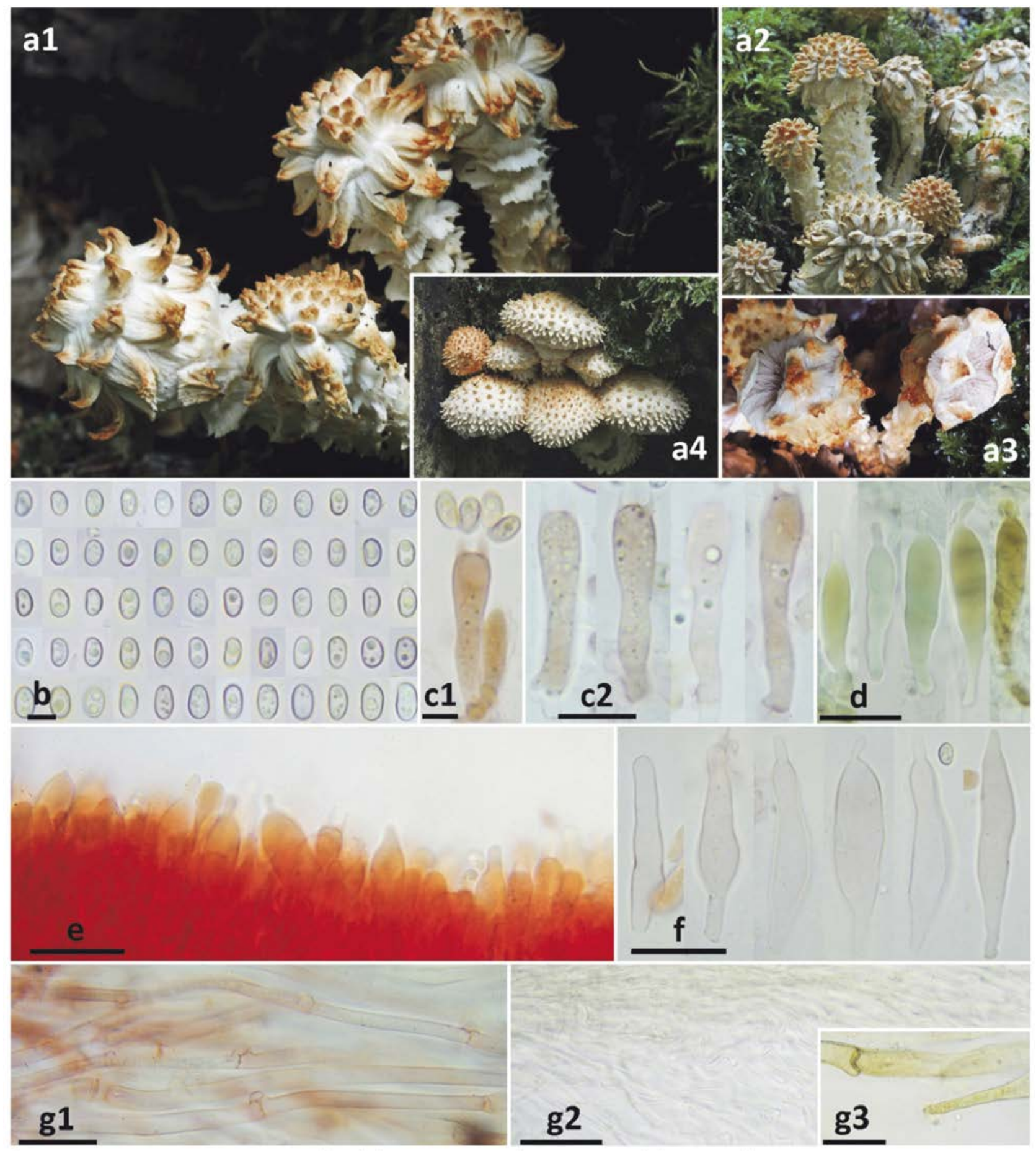

Figura 19: Caracteres morfológicos de Pholiota squarrosoides. a1, a2. Basidiomas maduros (JACA-MICO-00132). a3. Detalle del himenio (JACA-MICO-00132). a4. Basidiomas maduros (AH48185). b. Esporas. c. Basidios. c1. Basidios tetraspóricos. c2. Basidios fibulados. d. Pleurocistidios. e. Arista laminar. f. Queilocistidios. g. Pileipellis. g1. Hifas fibuladas. g2. Ixocutis. g3. Pigmentación de las hifas. Escala: $5 \mu \mathrm{m}=\mathrm{b}, \mathrm{c} 1 ; 20 \mu \mathrm{m}=\mathrm{d}, \mathrm{f}, \mathrm{g} 2$, g3; $10 \mu \mathrm{m}=\mathrm{c} 2$, g1.

Medio de montaje: $\mathrm{RC}=\mathrm{b}, \mathrm{c} 1, \mathrm{c} 2$, e, f, g1; Azul patente $\mathrm{V}+\mathrm{KOH} 5 \%=\mathrm{d} ; \mathrm{H}_{2} \mathrm{O}=\mathrm{g} 2$, g3. Fotos micro: Todas a partir de JACA-MICO-00132.

Figure 19: Morphological characters of Pholiota squarrosoides. a1, a2. Mature basidiomata (JACA-MICO-00132). a3. Hymenium detail (JACA-MICO-00132). a4. Mature basidiomata (AH48185). b. Spores. c. Basidia. c1. Four-spored basidia.

c2. Clamp-connection in basidia. d. Pleurocystidia. e. Arista laminar. $\boldsymbol{f}$. Cheilocystidia. g. Pileipellis. g1. Clamp-connecition hyphae. g2. Ixocutis. g3. Hyphae pigmentation. Bar: $5 \mu \mathrm{m}=b, c 1 ; 20 \mu \mathrm{m}=d, f, g 2, g 3 ; 10 \mu \mathrm{m}=c 2$, g1. Mounting media: $R C=b, c 1, c 2$, e, f, g1; Patent blue $\mathrm{V}+\mathrm{KOH} 5 \%=d ; \mathrm{H}_{2} \mathrm{O}=\mathrm{g} 2$, g3. Micro photos: All from JACA-MICO-00132. 
geniformes, algunos mucronados, de paredes delgadas, hialinos. Pleurocistidios de 35,5-55,1 × 6,7-9,2 $\mu \mathrm{m}$, fusiformes a lageniformes, mucronados, que presentan un contenido intracelular amarillento en $\mathrm{KOH}$. Crisocistidios no observados. Pileipellis en ixocutis de hifas de 4-8 $\mu \mathrm{m}$ de diám., inmersas en una capa gelatinosa. Subpellis constituida por hifas hinchadas, con incrustaciones marrones. Fíbulas presentes.

Observaciones. Pholiota squarrosoides es una especie saprobia poco citada en España, que nace principalmente en grandes troncos caídos, en bosques maduros con escasa intervención humana, la mayoría de las veces de haya (Fagus sylvatica), pero también de otras especies de hoja caduca (Holec, 2001). En nuestro caso la hemos recolectado siempre en Fagus sylvatica. A pesar de que por su nicho ecológico es un taxón raro, su distribución en la Europa Continental es amplia, siendo conocida en Francia, Alemania, Austria, Polonia, República Checa, Eslovaquia, Rumanía, Ucrania, Suecia y Finlandia. Sin embargo en Norteamérica es bastante común y ampliamente distribuida (Holec, 2001; Kuo, 2007). En España ha sido citada en la Reserva de Lizardoia y en la Reserva de Aztaparreta, ambas de la Comunidad Foral de Navarra (Heilmann-Clausen \& Walleyn, 2007). P. squarrosoides está considerada como buen indicador utilizable en las prioridades de conservación de los bosques de hayas europeos (Christensen et al., 2004). En los dos bosques donde la hemos recolectado, abundan los troncos de gran tamaño y han estado muchos años sin explotar. En el caso de Col de Labays (Arette, Francia), vuelve a explotarse forestalmente en la actualidad. Los ejemplares del Valle de Ordesa (Huesca, España) han fructificado en los tres años observados: 2014, 2015 y 2016. En ese mismo periodo los especímenes han madurado sin llegar a abrir el píleo, rompiéndolo en su parte superior, lo que le da un aspecto secotioide. Desconocemos los motivos de ese extraño desarrollo, ya que no sabemos si tiene que ver con el hecho de crecer en una rama muerta de haya que se ha desprendido de un gran tronco mucho más voluminoso, aunque sí parece probado que la cantidad de alimento disponible puede condicionar el tamaño de los basidiomas (Smith \& Hesler, 1968).

A veces ha sido confundida con Pholiota squarrosa (Oeder) P. Kumm., de la cual se diferencia macroscópicamente por tener las escamas mucho más marcadas, compactas y de colores más tostados, por su color de fondo crema blanquecino, más claro hacia el borde, y con mucho menor componente amarillo que $P$. squarrosa y además por tener la superficie pileica algo viscosa en tiempo húmedo. Microscópicamente se diferencia principalmente por tener las esporas mucho más pequeñas, mucho más pálidas, más faseoliformes y sin poro apical. La especie más parecida microscópicamente es Pholiota jahnii Tjall.-Beuk. \& Bas, que tiene esporas diminutas pero algo mayores, también ligeramente faseoliformes, con un pequeño poro apical no muy visible, del que carece $P$. squarrosoides. Sin embargo, las diferencias macroscópicas con P.jahnii son evidentes, ya que esta última tiene la su- perficie pileica mucho más viscosa, mucho más amarillenta y con escamas muy oscuras. Por otro lado P. squarrosoides rara vez crece en la base de troncos vivos, como ocurre en numerosas ocasiones con las otras dos especies.

En la Tabla 4 se resumen las principales diferencias entre las tres especies citadas:

Filogenéticamente, del análisis de nuestras colecciones de Pholiota squarrosoides, P. jahnii y P. squarrosa se observa que se agrupan claramente en cada uno de sus clados, reforzando así la independencia de cada especie. No obstante, se observa una ligera distancia entre los ejemplares de P.squarrosoides europeos y los asiáticos y americanos, que en principio no parece una distancia significativa, pero podría resultar de interés realizar el análisis de un número mayor de secuencias procedentes de diversos continentes para estimar su relevancia (Fig. 20).

Ramaria largentii Marr \& D.E.Stuntz ss. auct. eur. (Fig. 21).

Material estudiado: Zona 2.1, en bosque de Abies alba, 30-VIII-2014, leg. F. Serrano, JACA-MICO-00567.

Observaciones: Tomamos la especie americana en un sentido amplio por los autores europeos, pues hay varias especies involucradas bajo este nombre; los análisis moleculares de algunas muestras de Ramaria largentii en los países nórdicos indican que se corresponde en realidad con $R$. brunneicontusa R.H. Petersen (Bendiksen \& al., 2013). Queda por ver a qué corresponde el material español de esta especie.

Ramaria ochrochlora Furrer-Ziogas \& Schild (Fig. 22).

Material estudiado: Zona 1.1, en borde de bosque de Abies alba con Buxus sempervirens, 12-X-2015, leg. M.A. Ribes, G. Sánchez, F. Mateo, Daniëls 3376, JACAMICO 621.

Basidioma arborescente hasta de $11 \times 9 \mathrm{~cm}$ con base tomentosa y fasciculada, blanca, cambiando a un color azulado como en las ramas; sin pie definido y con cordones miceliales blancos (Fig. 22). Ramificación dicótoma a policótoma, en $\mathrm{U}$, rango de ramificación de 4-7; ramas cilíndricas, densamente agrupadas, de 1-3 mm de diámetro; de color amarillo o amarillo anaranjado (67.brill.OY, 83.brill.Y, 86.1.Y) en la juventud, luego más oscuro o amarillo grisáceo (70.1.OY, 84.s.Y, 90.gy.Y); que cambian de color al corte y roce, siendo al principio de color verde azulado o azul verdoso (145.m.G, 162.v.l.b.G, 164.m.b G, 172.v.g B) y al final negruzco (152.blackish G). Himenóforo unilateral, con la esporada de color amarillo anaranjado (68.s.OY, 69.deep OY). Ápices agudos, bífidos a crestados; del color de las ramas o más pálidos y con los mismos cambios que éstas. Carne correosa; de color blanco o gris amarillento (93.y Gray); sabor y olor no probados. 
Tabla 4: Comparación entre Pholiota squarrosoides, $P$. jahnii y $P$. squarrosa.

Table 4: Comparison among Pholiota squarrosoides, P. jahnii and P. squarrosa.

\begin{tabular}{|c|c|c|c|}
\hline & P. squarrosoides & P. jahnii & P. squarrosa \\
\hline \multicolumn{4}{|l|}{ Píleo } \\
\hline Escamas & $\begin{array}{l}\text { Entre cónicas y piramidales, con base } \\
\text { fibrilosa y ápice más compacto. De } \\
\text { adultas escamas cónicas, compactas y no } \\
\text { fibrilosas }\end{array}$ & $\begin{array}{l}\text { Pequeñas espinas sobre grandes } \\
\text { verrugas bastante densas }\end{array}$ & Triangulares, erectas y fibrilosas \\
\hline Colores & $\begin{array}{l}\text { De joven la base de las escamas } \\
\text { blanquecino-crema con las puntas de } \\
\text { marrón tostado a marrón rosado. De } \\
\text { adultas con fondo blanquecino crema, } \\
\text { más claro hacia el borde y escamas de } \\
\text { ocre tostado a marrón tostado o color } \\
\text { ladrillo. }\end{array}$ & $\begin{array}{l}\text { Marrón muy oscuro con fondo } \\
\text { amarillento o anaranjado. }\end{array}$ & $\begin{array}{l}\text { Ocre tostado con notables tonos } \\
\text { amarillentos }\end{array}$ \\
\hline $\begin{array}{l}\text { Viscosidad en } \\
\text { tiempo húmedo }\end{array}$ & Un poco viscoso & Netamente viscoso & Seco \\
\hline $\begin{array}{l}\text { Esporas } \\
(\text { Escala }=10 \mu \mathrm{m})\end{array}$ & & & \\
\hline $\begin{array}{l}\text { Tamaño } \\
\text { (HOLEC 2001) }\end{array}$ & $\begin{array}{l}\text { Muy pequeñas } \\
(4,0-) 4,5-6,0(-6,5) \times(2,5-) 2,7-3,5(-4,0)\end{array}$ & $\begin{array}{l}\text { Pequeñas } \\
(4,5-) 5,0-7,0(-7,5) \times 3,0-4,0(-4,5)\end{array}$ & $\begin{array}{l}\text { Medianas } \\
(5,8-) 6,2-8,2(-9) \times 3,7-5,0\end{array}$ \\
\hline Color & Muy pálidas & Pálidas & Bien coloreadas \\
\hline Poro apical & Sin poro & Muy pequeño & Bien diferenciado \\
\hline
\end{tabular}

Basidiosporas amigdaloides, de (9-)9,5-11(-12) $\times$ $(3,5-) 4-4,5(-5) \mu \mathrm{m} \mathrm{Q}=2,2-2,7, \mathrm{~N}=28, \mathrm{Me}=10,2 \times 4,2$ $\mu \mathrm{m}, \mathrm{Qe}=2,4$, pared esporal delgada, amarillo-olivácea, ornamentada con verrugas troncocónicas abundantes hasta de $1 \mu \mathrm{m}$ de altura. Basidios claviformes, con fíbula basal, de (44-)50-60(-68) × 7-8,5 $\mu \mathrm{m}$, con 4 esterigmas. Hifidios filiformes, con fíbula basal, de unos $2 \mu \mathrm{m}$ de anchura, a veces con ápice noduloso. Hifas generativas fibuladas, con septos parcialmente ampuliformes y no ornamentados de 8-13 $\mu \mathrm{m}$ de anchura. En la trama, hifas de (2-)4-11 $\mu \mathrm{m}$ de anchura, con las paredes generalmente delgadas, y en los cordones miceliales de 1,5-3 $\mu \mathrm{m}$ de anchura, delgadas, con incrustaciones cristalinas estrelladas en la zona más externa. Hifas secretoras en la trama y en el micelio, de 1-4 $\mu \mathrm{m}$ de anchura, que pueden terminar en una vesícula ampuliforme hasta de $11 \mu \mathrm{m}$ de anchura.

Observaciones: El color oliváceo y el cambio de color azul verdoso al roce, unido a la presencia de cristales estrellados y esporas espinosas, nos recuerda mucho a Ramaria abietina (Pers.: Fr) Quél. Sin embargo, Ramaria ochrochlora tiene las esporas de mayor tamaño, con un valor de $\mathrm{Lm}>10 \mu \mathrm{m}$, mientras que $R$. abietina tiene esporas con un valor de $\mathrm{Lm}<7,5 \mu \mathrm{m}$. Una 

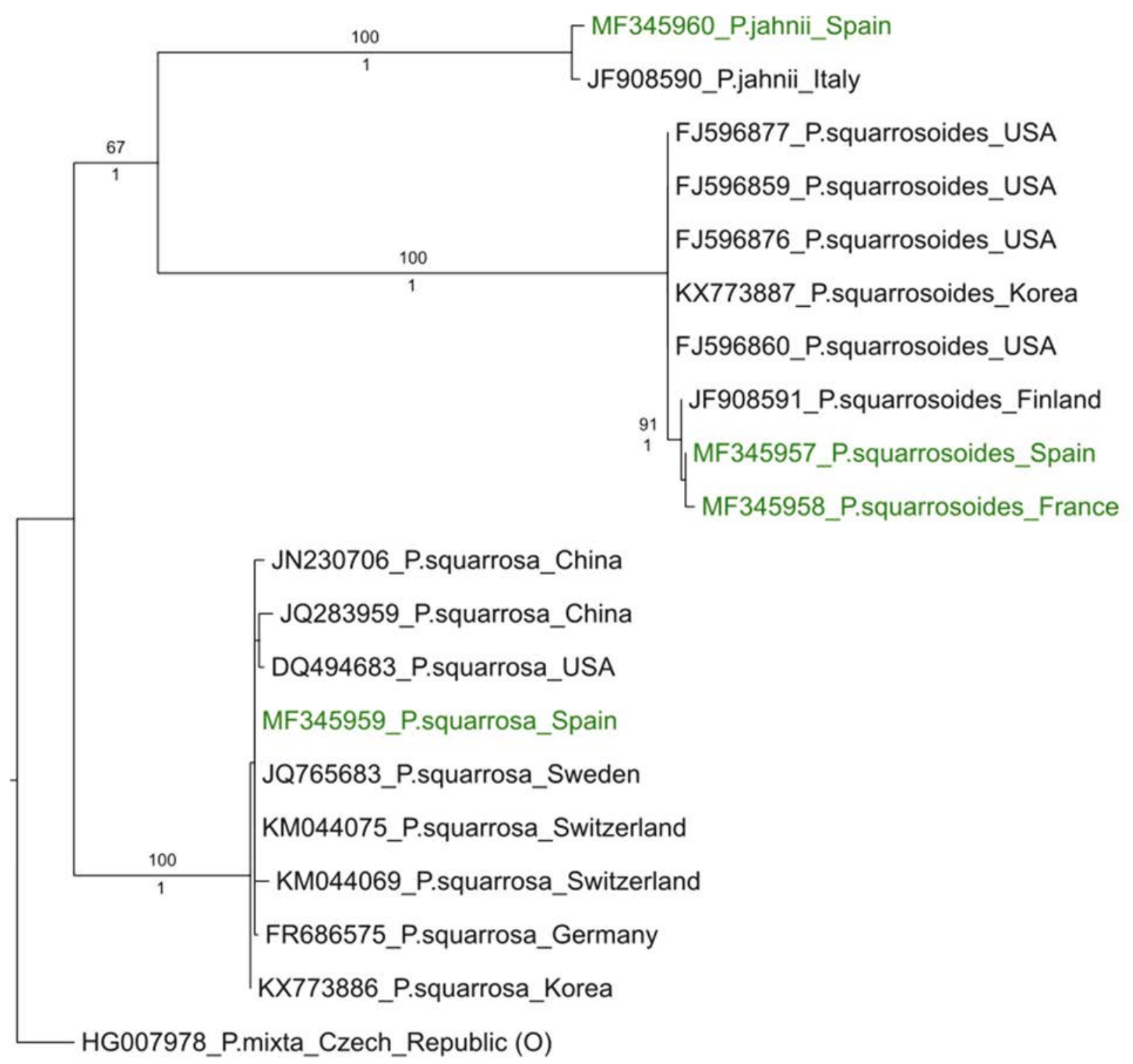

$$
0.03
$$

Figura 20: Filograma obtenido como mejor árbol del análisis de máxima verosimilitud, resultado del análisis de una matriz que contiene las regiones ITS1, 5,8S e ITS2. Los valores situados encima de las ramas corresponden al bootstrap del análisis de máxima verosimilitud y los situados debajo corresponden a los valores de probabilidad posterior del análisis bayesiano. Las secuencias obtenidas en el presente estudio se dibujan en color verde y las procedentes de GenBank en color negro. La secuencia elegida como outgroup se indica con $(\mathrm{O})$.

Figure 20: Phylogram obtained as best tree from maximum likelihood analysis, from the combined analyses of ITS1, 5.8S and ITS2, datasets. Bootstrap values obtained in the maximum likelihood analysis are added over the branches, and Bayesian Posterior Probability values are indicated below the branches. The sequences obtained in the present study are drawn in green colour, and those from GenBank in black colour. The selected specimen as outgroup is indicated with $(O)$.

tercera especie es Ramaria ochraceovirens (Jungh.) Donk; sin embargo su identidad aún está discutida (Christan, 2008).

Es una especie europea, que se describió en Suiza creciendo en bosque montano con Larix y Picea (Schild,
1971). Existen muestras adicionales bajo el nombre de Ramaria ochrochlora, en material depositado en herbarios y procedentes de Austria, Suecia e Islandia (GBIF, 2017). La muestra estudiada es la primera cita para la península ibérica. 


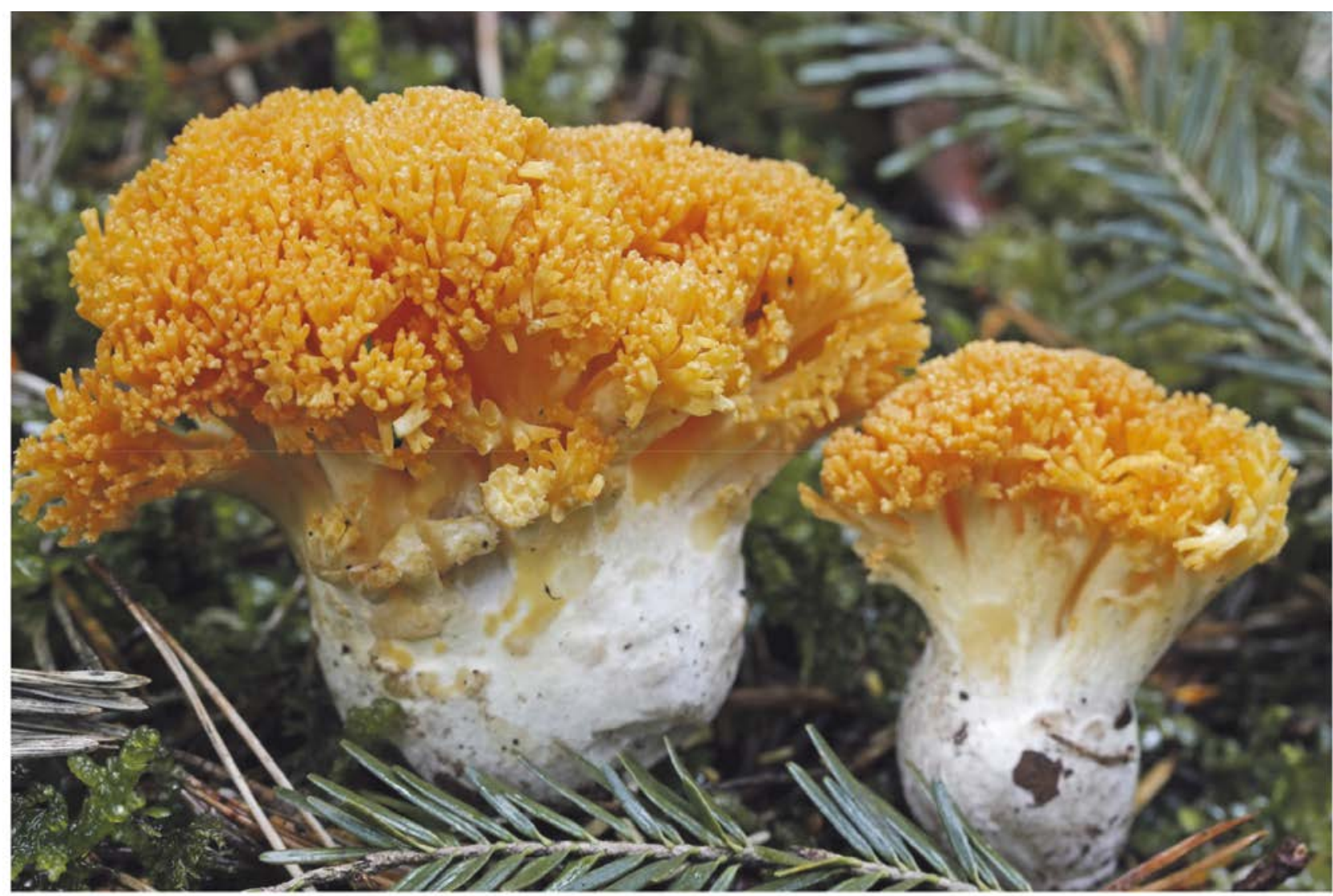

Figura 21: Caracteres morfológicos de Ramaria largentii. JACA-MICO-567.

Figure 21: Morphological characters of Ramaria largentii. JACA-MICO-567.

Tricholoma ilkkae Mort. Chr., Heilm.-Claus., Ryman \& Niclas Bergius (Fig. 23).

Material estudiado: Zona 2.4. Bosque de Fagus sylvatica, Abies alba y Pinus sylvestris, 07-X-2014, leg. F. Serrano, JACA-MICO 00219. Secuencia ITS GenBank MF345963.

Basidiomas de tamaño mediano. Píleo de 30-52 mm de diám., al principio de hemisférico a convexo, después convexo a aplanado, que, a menudo, presenta un umbón en la parte central. Superficie pileica con escamas lanosas de color pardo rojizo a pardo oscuro, casi negro, sobre un fondo de color crema o blanquecino, distribuidas de forma irregular. Margen pardo grisáceo claro o amarillo pajizo, con restos de velo, afieltrado o incluso lanoso en los ejemplares jóvenes. Láminas numerosas, emarginadas, blanquecinas, con la arista irregular. Estípite de 46-107 × 10-12 mm, fibroso, rígido, cilíndrico, con anillo blanquecino algodonoso bien definido y persistente, cubierto en la parte inferior por una armilla cubierta de escamas pardo anaranjadas sobre un fondo blanquecino. Carne blanquecina, olor dulce, afrutado.

Basidiosporas de (5,4-)5,6-6,5(-6,8) $\times(4,3-) 4,4-4,9$ (5,3) $\mu \mathrm{m}, \mathrm{Q}=1,2 \times 1,4(-1,5), \mathrm{N}=60, \mathrm{Me}=6,1 \times 4,7 \mu \mathrm{m}$, $\mathrm{Qe}=1,3$, anchamente elipsoidales. Basidios de 30,2-38,9 $\times 6,2-7,4 \mu \mathrm{m}, \mathrm{Me}=33,6 \times 6,7 \mu \mathrm{m}$, tetraspóricos. Queilo- cistidios no observados. Pileipellis en forma de cutis, con hifas cilíndricas con pigmentos marrones no incrustantes. No se han encontrado fíbulas.

Observaciones. Tricholoma ilkkae es una especie recientemente descrita por Christensen \& Heilmann-Clausen (2013) inicialmente como Tricholoma ilkkaii, nom. prov. y posteriormente por Heilmann-Clausen et al. (2017) con material tipo procedente de la isla de Gotland en Suecia y material adicional de Noruega, Turquía y España. El material español proviene de dos recolecciones en bosques de Abies alba en el pirineo catalán, ambas del 29-IX-2002, y que fueron determinadas en principio como Tricholoma caligatum (Viv.) Ricken (SCM B-4205 en Mata de Valencia d'Aneu, leg. \& det. A. Rocabruna y SCM B-4346 en el Parque Nacional de Aigües Tortes, leg. \& det. A. Rocabruna y M. Tabares).

Posteriormente, Murata et al. (2013) la habían dejado indicada como especie nueva nombrada como "Tricholoma sp. from Spain" sobre la base del material procedente del Pirineo catalán anteriormente citado. Y ya en España, se han conocido algunas colecciones en abetales pirenaicos que muy probablemente correspondan con esta especie. Así, Campos et al. (2013) la citan como Tricholoma matsutake (S. Ito \& S. Imai) Singer, en dos localizaciones de la provincia de Huesca: El Cornato, Valle de Pineta (Bielsa) y Lierde (Villanúa de Jaca). 

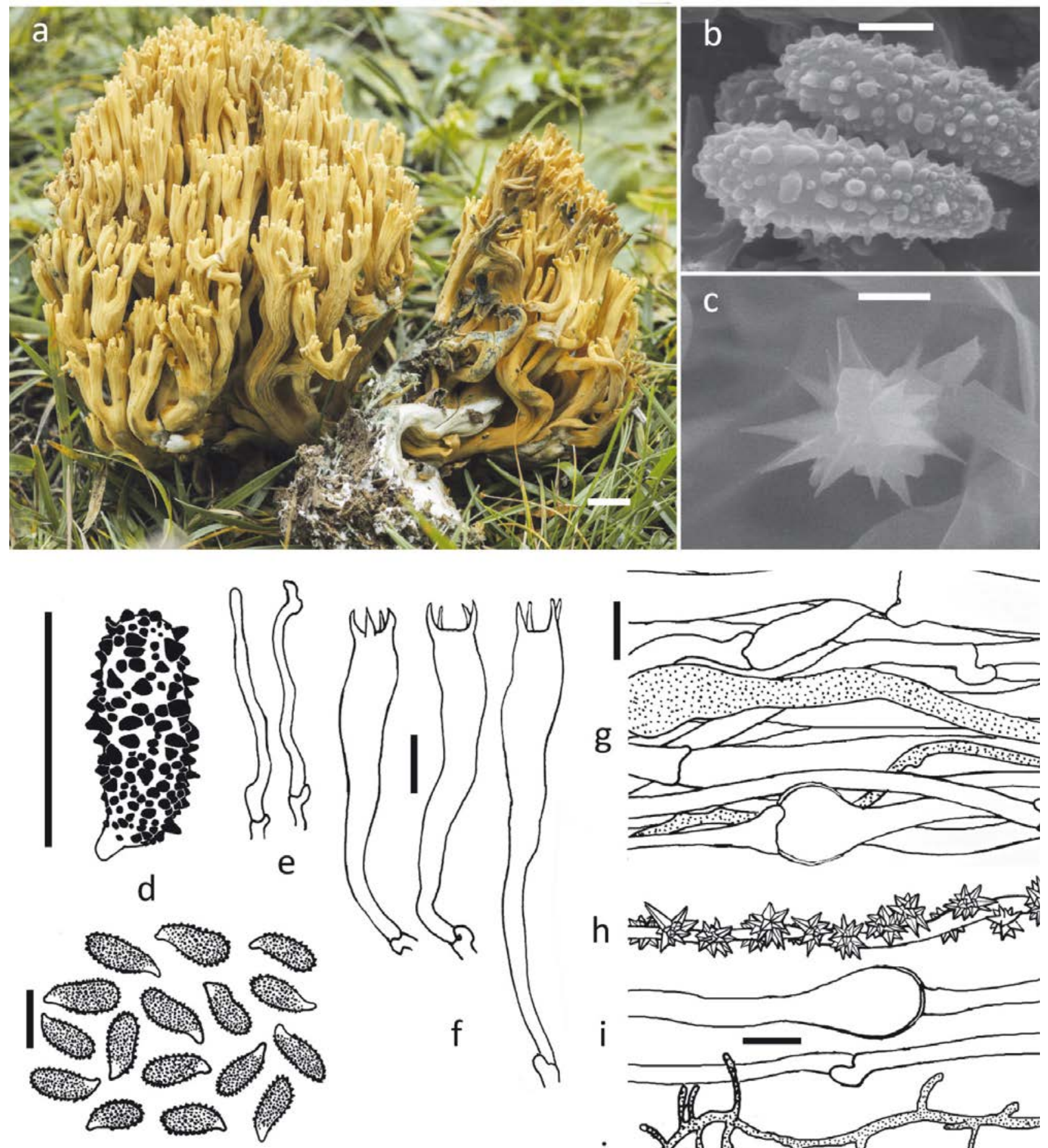

P.Daniëls 2016

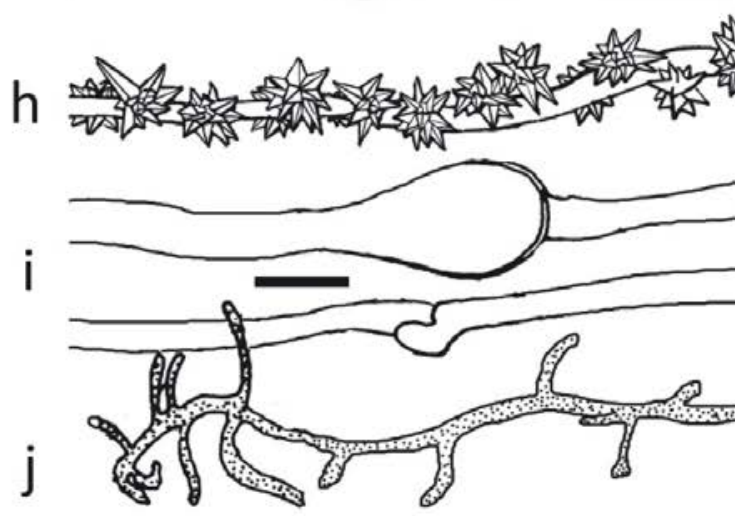

Figura 22: Caracteres morfológicos de Ramaria ochrochlora . a. Basidiomas in situ. b. Basidiosporas en MEB. c. Cristal de cordon micelial en MEB. d. Basidiosporas. e. Hifidios. f. Basidios. g. Hifas de la trama.

h. Hifas con cristales estrellados de los cordones miceliales. i. Hifas de los cordones miceliales. j. Hifa secretora de los cordones miceliales. Escala: $1 \mathrm{~cm}=\mathrm{a} ; 10 \mu \mathrm{m}=\mathrm{d}-\mathrm{j} ; 5 \mu \mathrm{m}=\mathrm{c} ; 2 \mu \mathrm{m}=\mathrm{b}$. Fotos y dibujos: todas a partir de JACA-MICO-621. Figure 22: Morphological characters of Ramaria ochrochlora . a. Basidiomata in situ. b. Basidiospores at SEM. c. Mycelial strands crystal at SEM. d. Basidiospores. e. Hiphidia. f. Basidia. g. Trama hyphae. h. Hyphae whith star crystals from mycelial strands. i. Mycelial strands hyphae. j. Mycelial strands secretory hypha. Bar: $1 \mathrm{~cm}=a ; 10 \mu \mathrm{m}=d-j ; 5 \mu \mathrm{m}=c ; 2 \mu \mathrm{m}=b$. Photo and drawings: all from JACA-MICO-621. 


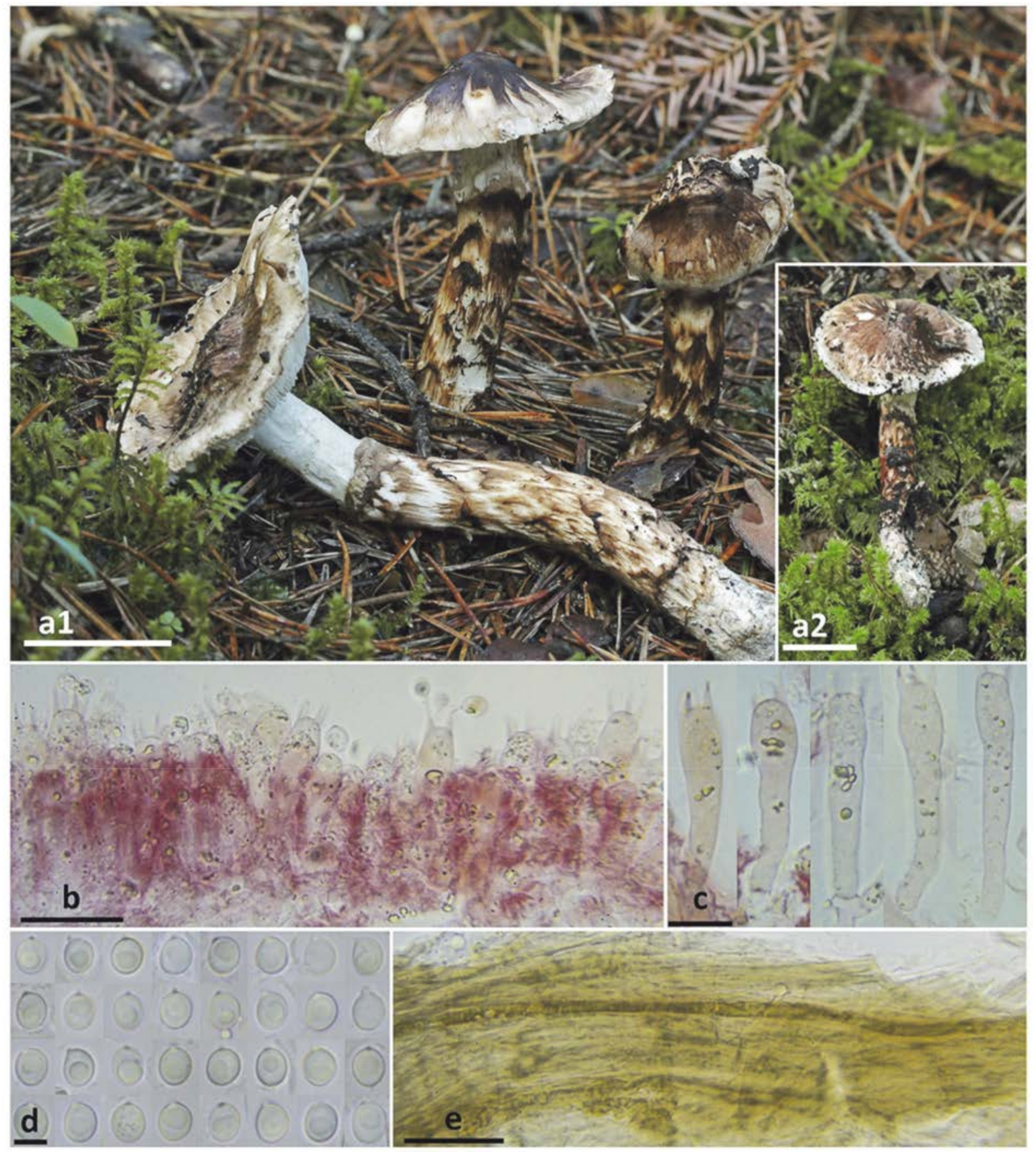

Figura 23: Caracteres morfológicos de Tricholoma ilkkae. a. Basidiomas maduros. b. Arista laminar. c. Basidios tetraspóricos. d. Esporas. e. Pileipellis. Escala: $20 \mathrm{~mm}=\mathrm{a} 1$, a2; $20 \mu \mathrm{m}=\mathrm{b}, \mathrm{e} ; 10 \mu \mathrm{m}=\mathrm{c} ; 5 \mu \mathrm{m}=\mathrm{d}$. Medio de montaje: $\mathrm{RC}=\mathrm{b}, \mathrm{c} ; \mathrm{H}_{2} \mathrm{O}=\mathrm{d}$, e.

Fotos: Todas a partir de JACA-MICO-00219.

Figure 23: Morphological characters of Tricholoma ilkkae. a. Mature basidiomata. b. Lamella edge. c. 4-spore basidia. d. Spores. e. Pileipellis. Bar: $20 \mathrm{~mm}=a 1, a 2 ; 20 \mu \mathrm{m}=b, e ; 10 \mu \mathrm{m}=c ; 5 \mu \mathrm{m}=d$. Mounting media: $R C=b, c ; \mathrm{H}_{2} \mathrm{O}=d$, $e$.

Photos: All from JACA-MICO-00219.

Las características de la recolecta estudiada del Valle de Ordesa (JACA-MICO-00219) encaja perfectamente con la descripción original de la especie, también los resultados de la secuenciación de la región ITS coincide muy bien con las secuencias aportadas en la descripción original, tanto del holotipo y recolectas suecas, como de las recolectas del pirineo catalán.

Según los análisis filogenéticos, Tricholoma ilkkae está próximo a T. dulciolens Kytöv. (Fig. 24). Ambas especies comparten esporas pequeñas, pero 


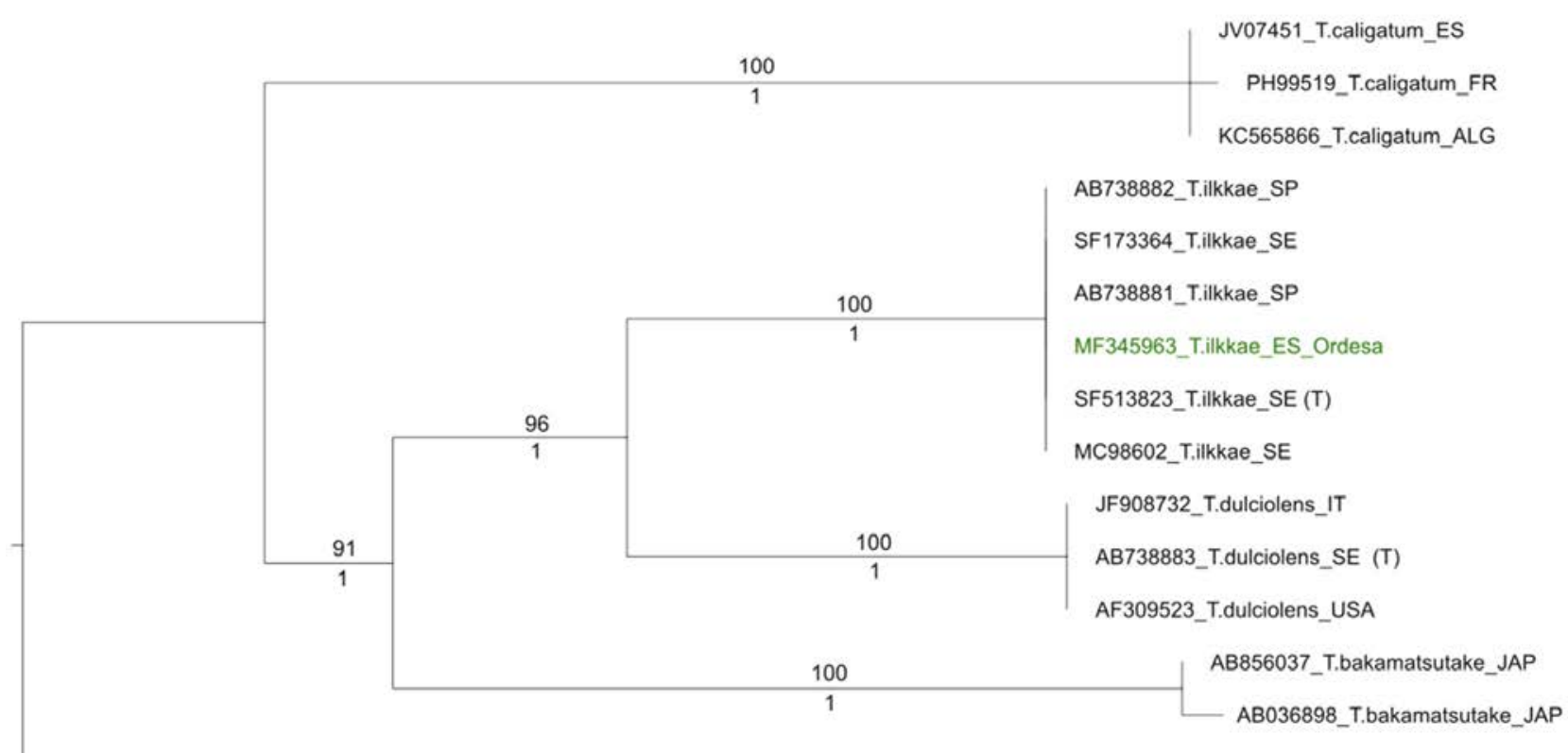

TMU62964_T.matsutake_S_KOR (O)

Figure 24: Filograma obtenido como mejor árbol del análisis de Máxima verosimilitud, resultado del análisis de una matriz que contiene las regiones ITS1, 5.8S e ITS2. Los valores situados encima de las ramas corresponden al bootstrap del análisis de máxima verosimilitud y los situados debajo corresponden a los valores de probabilidad posterior del análisis bayesiano. La secuencia obtenida en el presente estudio se dibuja en color verde y las procedentes de GenBank en color negro. Las secuencias correspondientes a los tipos de las especies se indican con $(\mathrm{T})$ y la secuencia elegida como outgroup se indica con $(\mathrm{O})$.

Figure 24: Phylogram obtained as best tree from maximum likelihood analysis, from the combined analyses of ITS1, 5.8 S and ITS2, datasets. Bootstrap values obtained in the maximum likelihood analysis are added over the branches, and Bayesian Posterior Probability values are indicated below the branches. The sequence obtained in the present study is drawn in green colour, and those from GenBank in black colour. The type specimens are indicated with (T) and the selected specimen as outgroup is indicated with $(O)$.

Tricholoma ilkkae se puede distinguir de T. dulciolens por tener el estípite más corto y por presentar escamas más oscuras en el píleo y en la armilla del estípite.

La especie se podría confundir con Tricholoma dulciolens, T. caligatum y T. matsutake. Tricholoma dulciolens tiene un color mucho más claro y menos contrastado en las escamas y el pie más largo. Tricholoma caligatum tiene las esporas más pequeñas y su distribución parece ser estrictamente mediterránea, mientras que T. ilkkae es de ambientes más fríos. Tricholoma matsutake difiere por presentar colores menos definidos, por sus cuerpos fructíferos más grandes y por tener las esporas también más grandes (Heilmann-Clausen et al., 2017).

Parece ser que Tricholoma ilkkae es una especie asociada a bosques maduros de coníferas asentados sobre sustratos calizos, estableciendo ectomicorrizas con Pinus ssp. y posiblemente con Picea abies (Heilmann-Clausen et al., 2017), pero todas las recolecciones pirenaicas que conocemos se han dado en bosques dominados por Abies alba, por lo que muy probablemente también establezca micorrizas con este árbol. No conocemos recolectas en España en bosques de $P i$ nus ssp.

\section{Discusión}

En esta segunda campaña se han determinado 409 taxones, de los cuales 74 pertenecen a la campaña anterior. El 76\% corresponde al phylum Basidiomycota, el 22,2\% al Ascomycota, el 1,5\% al Myxomycota y el 0,2\% al Zygomycota, siendo los órdenes más representativos los Agaricales con el 43,3\% de todas las especies reconocidas en este trabajo, los Russulales con un 11,2\%, Pezizales con un $8,6 \%$, Polyporales con un 7,6\%, Helotiales con un 4,2\%, Gomphales con un 3,7\%, Cantharellales con un 2,4\% e Hypocreales con un 2,2\%. En la Tabla 5 se refleja el detalle. En la Fig. 25 se puede ver la distribución de los taxones agrupados por órdenes de los phyla Ascomycota y Basidiomycota. 
Tabla 5: Detalle de taxones recolectados por órdenes.

Table 5: Detailed taxa by order.

\begin{tabular}{|c|c|c|c|c|c|c|c|}
\hline \multicolumn{2}{|c|}{ Ascomycota } & \multicolumn{2}{|c|}{ Basidiomycota } & \multicolumn{2}{|c|}{ Myxomycota } & \multicolumn{2}{|c|}{ Zygomycota } \\
\hline Orden & Ctd & Orden & Ctd & Orden & Ctd & Orden & Ctd \\
\hline Diaporthales & 2 & Agaricales & 177 & Liceales & 2 & Endogonales & 1 \\
\hline Dothideales & 1 & Atheliales & 1 & Physarales & 4 & & \\
\hline Elaphomycetales & 2 & Auriculariales & 7 & & & & \\
\hline Geoglossales & 4 & Boletales & 7 & & & & \\
\hline Helotiales & 17 & Cantharellales & 10 & & & & \\
\hline Hypocreales & 9 & Dacrymycetales & 3 & & & & \\
\hline Incertae sedis & 1 & Geastrales & 2 & & & & \\
\hline Leotiales & 1 & Gloeophyllales & 1 & & & & \\
\hline Orbiliales & 1 & Gomphales & 15 & & & & \\
\hline Ophiostomatales & 1 & Hymenochaetales & 6 & & & & \\
\hline Pezizales & 35 & Polyporales & 31 & & & & \\
\hline Pleosporales & 1 & Russulales & 46 & & & & \\
\hline Rhytismatales & 2 & Thelephorales & 4 & & & & \\
\hline Sordariales & 3 & Tremellales & 1 & & & & \\
\hline Trichosphaeriales & 1 & & & & & & \\
\hline Xylariales & 10 & & & & & & \\
\hline Total Ascomycota & 91 & Total Basidiomycota & 311 & Total Myxomycota & 6 & Total Zygomycota & 1 \\
\hline
\end{tabular}

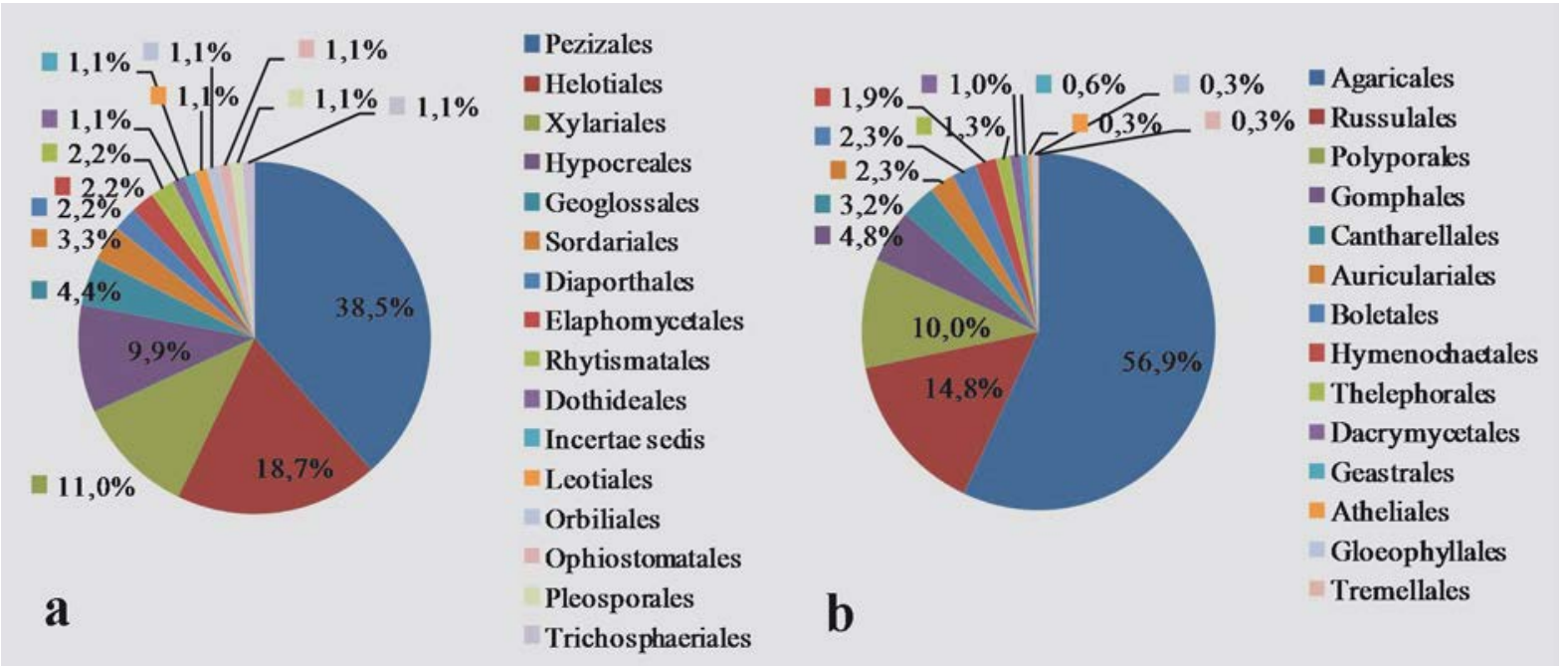

Figura 25: Distribución de taxones recolectados por órdenes. a. Ascomycota, b. Basidiomycota.

Figure 25: Distribution of taxa collected by orders. a. Ascomycota, b. Basidiomycota.

De las especies recolectadas en esta segunda campaña, seis de ellas están incluidas en alguna de las listas rojas especificadas en Ribes et al. (2016) y corresponden a los siguientes taxones:

- Caloscypha fulgens (Pers.) Boud.

- Coprinopsis martinii (P.D. Orton) Redhead, Vilgalys \& Moncalvo
- Craterellus melanoxeros (Desm.) Pérez-De-Greg.

- Gomphus clavatus (Pers.) Gray

- Ramaria botrytis (Pers.) Ricken

- Ramariopsis crocea (Pers.) Corner

Por otro lado, aunque dentro de los objetivos de este proyecto no se propuso la evaluación de determinados bosques en cuanto a especies indicadoras de su grado de con- 
servación, el elevado número de especies recolectadas sí que nos sirve como una aproximación y como una línea a seguir en futuros trabajos del valor de conservación de algunos hayedos dentro del Parque. Christensen et al. (2004) proponen una lista de veintiuna especies fúngicas indicadoras que se pueden tener en cuenta para las prioridades de conservación de hayedos europeos, apoyadas por un análisis de 106 reservas forestales de hayas en Europa. Por otro lado, Heilmann-Clausen \& Walleyn (2007) visitan algunos hayedos españoles de Asturias y de Navarra en noviembre de 2005 e identifican 153 especies de hongos que crecen sobre madera y elaboran una lista de 27 especies indicadoras en base a las propuestas de la lista anteriormente citada y las propuestas por Ainsworth $(2004,2005)$ y HeilmannClausen \& Christensen (2003). Tomando como referencia estas diferentes propuestas, mostramos en la Tabla 6 los resultados obtenidos. Es interesante observar, a pesar de que no se ha prospectado ninguna área con este objetivo, que la zona donde más especies indicadoras se han encontrado, es el bosque de Turieto alto, una zona que ha estado cerrada al paso hasta hace muy poco.

\section{Agradecimientos}

Queremos agradecer a D. Manuel Montes, Director del Parque, a Elena Villagrasa, responsable de Conservación y a Ramon Castillo y a los demás Agentes de la Guardería, por las autorizaciones concedidas y ayuda en la logística. También a D. Pablo Munilla, que desde la Dirección General de Medio Ambiente de D.G.A. apoyó la concesión de este proyecto y nos dio su confianza.

A Nicolas Van Vooren y Gilbert Moyne por la ayuda en la identificación de Boudiera tracheia. A Hans-Otto Baral por la confirmación y a Jens H. Petersen por la información sobre las citas de Calycellina chlorinella. A Javier Mateos, Raúl Tena, Borja Rodríguez y Mikel Tapia por la información sobre las citas de Chlorencoelia versiformis. A Marcel Vega y Nicolas Van Vooren por la información sobre las recolectas y la secuencia ITS de Cupulina montana. A Raúl Tena, Miquel Àngel Pérezde-Gregorio, Manuel Becerra, Carlos M. Pérez del Amo y Pedro Arrillaga por la información sobre las citas de Peziza gerardii. A Rubén Martínez por facilitarnos los

Tabla 6: Especies indicadoras del valor de conservación en hayedos de Ordesa.

Table 6: Indicator species of conservation value of Ordesa beech forests.

\begin{tabular}{|c|c|c|c|c|c|c|c|c|c|c|c|c|}
\hline Especie & 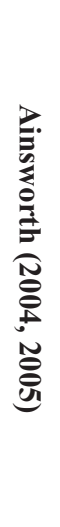 & 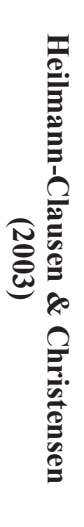 & 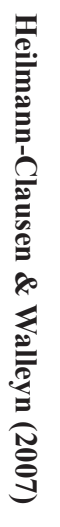 & 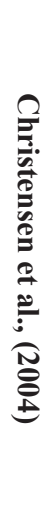 & 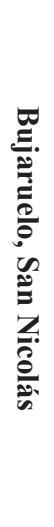 & 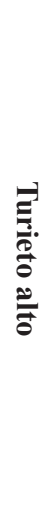 & 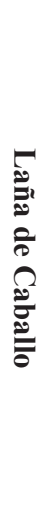 & 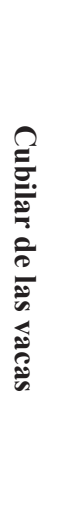 & 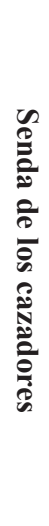 & 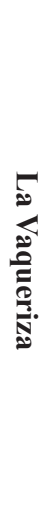 & 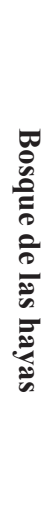 & 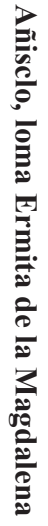 \\
\hline Annulohypoxylon cohaerens & & & $\checkmark$ & & & & $\checkmark$ & & & & $\checkmark$ & \\
\hline Dentipellis fragilis & & & & $\checkmark$ & & $\checkmark$ & $\checkmark$ & & & & & \\
\hline Eutypa spinosa & $\checkmark$ & $\checkmark$ & $\checkmark$ & & & $\checkmark$ & & & & & & \\
\hline Flammulaster limulatus & $\checkmark$ & & & $\checkmark$ & & & $\checkmark$ & $\checkmark$ & $\checkmark$ & & & $\checkmark$ \\
\hline Ischnoderma resinosum & & & $\checkmark$ & $\checkmark$ & & & & & & $\checkmark$ & & \\
\hline Lentinellus ursinus & $\checkmark$ & & $\checkmark$ & $\checkmark$ & $\checkmark$ & $\checkmark$ & & & & & & \\
\hline Mycoacia nothofagi & $\checkmark$ & & $\checkmark$ & $\checkmark$ & & $\checkmark$ & & $\checkmark^{1}$ & & & $\sqrt{ }^{2}$ & \\
\hline Pholiota squarrosoides & & & $\checkmark$ & $\checkmark$ & & & & $\checkmark$ & & & & \\
\hline Phyllotopsis nidulans & $\checkmark$ & & $\checkmark$ & & & $\checkmark$ & & & & $\checkmark$ & & \\
\hline Stereum subtomentosum & & & $\checkmark$ & & & $\checkmark$ & $\checkmark$ & & & & & \\
\hline Total especies indicadoras & & & & & 1 & 6 & 4 & 3 & 1 & 2 & 2 & 1 \\
\hline
\end{tabular}

\footnotetext{
1 Material no recolectado.

2 Material no recolectado.
} 
datos de su recolecta de Plicariella scabrosa. A Plácido Iglesias, Alberto Lorenzo y Carlos M. Pérez del Amo por la información sobre las citas de Pulvinula convexella. A Miquel Àngel Pérez de Gregorio por la información y datos aportados sobre Lactarius fraxineus. También queremos agradecer a Gabriel Moreno Horcajada la realización de las fotografías al microscopio electrónico de barrido de Ramaria ochrochlora. A Félix Infante García-Pantaleón por la cesión del microscopio con cámara clara con el que se ha realizado los dibujos de microscopía. A Juan Carlos Zamora por sus valiosos consejos y sugerencias respecto a la elaboración de los análisis filogenéticos.

A José Cuesta Cuesta, Gonzalo Sánchez Dueñas, Miguel Ángel Gonzalo Muñoz, Manuel Luque Víboras, Santiago Serrano Junquera, Nino Santamaría Rodriguez, Demetrio Merino Alcántara, Dianora Estrada Aristimuño, Salvador Tello Mora, Francisco J. Figueroa Garrido, Juan Carlos Campos Casabón, Claude Lavoise, Ita Paz, Francisco Barrajon Ibáñez, Francisco Cervera Sáez, Raul Mairal Arroyo, Alberto Lorenzo Ferrer, Eduardo Benguria Inchaurtieta, compañeros del Equipo Ordesa 2014 por su importante aportación al catalogo de especies y su ayuda y compañía en las prospecciones de estos años.

\section{Referencias}

Ainsworth, M. 2004. Developing tools for assessing fungal interest in habitats I: beech woodland saprotrophs. English Nature Research Reports 597, 75 p.

Ainsworth, M. 2005. Identifying important sites for beech deadwood fungi. Field Mycology 6: 41-61. https:/doi. org/10.1016/S1468-1641(10)60303-9

Alessio, C. L. 1984. Complemento allo studio del genere Inocybe: $4^{\circ}$ contributo. Bollettino del Grupo Micologico G. Bresadola 27(1-2): 21-34.

Alonso, J. L., Fernández Vicente, J., Pérez Butrón, J. L. \& Pérez Puente, A. 2001. Setas de los eucaliptales de la cornisa Cantábrica (III) y catálogo micológico de los eucaliptales (II). Yesca 13: 18-38.

Aranzadi, Sociedad De Ciencias. 1993. Peziza gerardii. [http:// www.aranzadi.eus/ficha-de-recogida-micologia?kod=2/1/0 54.05.15.00.03.00\&zbk $=5042235 \&$ origen $=$ ci\& clase $1=\&$ or $\operatorname{den} 1=\&$ familia $1=\&$ genero $1=\&$ especie $1=$ gerardii\&nomb re popular $1=\& \operatorname{sinonimia} 1=]$

Aranzadi, Sociedad De Ciencias. 2013. Peziza gerardii. [http:// www.aranzadi.eus/ficha-de-recogida-micologia?kod=2/1/0 54.05.15.00.03.00\&zbk $=3033895$ \&origen $=$ ci\&clase $1=\&$ or $\operatorname{den} 1=\&$ familia $1=\&$ genero $1=\&$ especie $1=$ gerardii $\&$ nomb re_popular $1=\&$ sinonimia $1=]$

Arauzo, S., Fernández Vicente, J. \& Iglesias, P. 2007. Boudiera tracheia y Scleromitrula candolleana, dos ascomicetos poco comunes encontrados en el P. N. de Urkiola. Errotari 4: 57-66.

Ballarà, J. 1997. Nou estudi d'espècies interessants dels estatges alpí I subalpí dels Pirineus Catalans. Revista Catalana de Micología 20: 1-24.

Baral, H.-O. \& Marson, G. 2005. In vivo veritas. Over 10000 Images of fungi and plants (microscopical drawings, water colour plates, photo macro- \& micrographs), with materials on vital taxonomy and xerotolerance. DVD, $3^{\text {rd }}$ edition.

Basso, M. T. 1999. Lactarius Pers. Fungi Europaei, vol. 7: 103107. Mykoflora, Alassio
Becerra, M. 2014. Peziza gerardii. Bolets de Catalunya, de la península ibérica y de les Illes Balears XXXIII. Lámina 1635.

Beltrán Tejera, E. 2010. Fungi. In: Arechavaleta M., S. Rodríguez, N. Zurita \& A. García (Coord.). Lista de especies silvestres de Canarias. Hongos, plantas y animales terrestres. 2009. Gobierno de Canarias. pp. 25-105.

Bendiksen, E., Bendiksen, K., Brandrud, T. E. Kytövuori, I. \& Toivonen, M. 2013. Ektomykorrhiza dannende korallsopper (Ramaria p.p.) i rik barskog i Norge. Agarica 33: 3-26

Benson, D. A., Cavanaugh, M., Clark, K., Karsch-Mizrachi, I., Lipman, D. J., Ostell, J., \& Sayers, E. W. 2013. GenBank. Nucleic Acids Research, 41(D1): D36-D42. https://www. ncbi.nlm.nih.gov/genbank/, https://doi.org/10.1093/nar/ gks1195

Berger, M. P. \& Munson, P. J. 1991 A novel randomized iterative strategy for aligning multiple protein sequences, Bioinformatics, 7(4): 479-484. https://www.ncbi.nlm.nih.gov/pubmed/1747779, https://doi.org/10.1093/bioinformatics/7.4.479

Bizio, E. 1995. Alcune Inocybe più frequenti della Zona Alpina delle Dolomiti. Rivista di Micologia 38(2):3-60.

Bon, M. \& Chevassut, G. 1989. Agaricomycètes de la Région Languedoc-Cevennes (4ème partie). Documents Mycologiques XIX (75):25-46.

Bon, M. 1997. Clé monographique des Inocybes alpins. Bulletin trimestriel de la Fédération Mycologique Dauphiné-Savoie 144:71-109.

Breitenbach, J. \& Kränzlin, F. 2000. Champignons de Suisse, Vol. 5. Mykologia, Luzern.

Caballero Moreno, A. \& Palacios Remondo, J. 2003. Aportación al catálogo micológico de La Rioja (España): el género Peziza Linneo ex Amans. Zubía 21: 9-27.

Calonge, F. D., García, A., Sanz, M. \& Bastardo, J. 2003. Some interesting fungi found in Spain, with special reference to the province of Valladolid. Micologia italiana 2: 45-52.

Campos, J. C., Mateo, J. F., Muñoz, G., Olariaga, I., Pancorbo, F., Parra, L. A., Pérez de Gregorio, M. A., Pérez-Gorjón, S., Ribes, M. A., Rodríguez, B., Rojo, C., Sánchez, G, \& Zamora, J. C. 2013. IV Congreso Pirenaico de Micología: Catálogo de táxones y estudio de los más interesantes. Boletín de la Sociedad Micológica de Madrid 37: 203-223.

Cannon, P. F., Hawksworth, D. L. \& Sherwood-Pike, M. A. 1985. The British Ascomycotina, an Annotated Checklist. Slough, Commonwealth Agricultural, 302 pp.

Chaillet, P., Moingeon, J. M. \& Moyne. G. 2005. Contribution à la connaissance des Ascomycètes de Franche-Comté: quelques espèces récoltèes en 2005. Bulletin de la Fédération mycologique de l'Est 4: 29-36.

Christan, J. 2008. Die Gattung Ramaria in Deutschland. IHW Verlag Eching. 352 pp.

Christensen, M., \& Heilmann-Clausen, J. 2013. The genus Tricholoma. Fungi of Northern Europe, vol. 4. Svampetryk, Denmark

Christensen, M., Heilmann-Clausen, J., Walleyn, R., \& Adamcik, S. 2004. Wood-inhabiting fungi as indicators of nature value in European beech forests. In: Marchetti, M. (ed.), "Monitoring and Indicators of Forest Biodiversity in Europe, from ideas to operationality". Proceedings European Forestry Institute 51: 229-237.

Consiglio, G. 1999. Contributo alla conoscenza dei macromiceti della regione Emilia-Romagna. XVI. Genere Clitocybe Parte Seconda. Rivista di Micologia 42(3): 195-210.

Corner, E. J. H. 1950. Clavaria and allied genera. Ann. Bot. Mem. 1: 1-740.

Cripps, C. L., Larsson, E. \& Horak, E. 2010. Subgenus Mallocybe (Inocybe) in the Rocky Mountains alpine zone with molecular reference to European arctic-alpine material. North American Fungi 5: 97-126. 
Daniëls, P. P. \& Moreno-Arroyo, B. 2006. Contribución al estudio de la diversidad fúngica andaluza. Boletín de la Sociedad Micológica de Madrid 30: 271-279.

Daun, R. \& Nitare, J. 2007. Artomyces cristatus. Liten kandelabersvamp. En línea en: [http://artfakta.artdatabanken. se/taxon/1975]

Dennis, R. W. G. 1954. A forgotten British fungus. Kew Bulletin 9(3): 423-425. https://doi.org/10.2307/4108814

Dennis, R. W. G. 1974. New or interesting British Microfungi, III. Kew Bulletin 30(2): 345-365. https://doi.org/10.2307/4103162

Dissing, H. \& Schumacher, T. 1979. Preliminary studies in the genus Boudiera, taxonomy and ecology. Norwegian journal of botany 26: 99-109.

Dissing, H., Eckblad, F.-E. \& Lange, M. 2000. Pezizales Bessy. In: Hansen, L. \& H. Knudsen. Nordic Macromycetes. Vol. 1, Ascomycetes. Copenhagen Nordsvamp, 309 pp.

Dixon, J. R. 1975. Chlorosplenium and its segregates. II. The genera Chlorociboria and Chlorencoelia. Mycotaxon 1(3): 193-237.

Donadini, J.-C. 1980. Le genre Peziza. III. Sous-genre Galactinia. Bulletin de la Société Mycologique de France 96 (3): 239-246.

Donadini, J.-C. 1981. Le genre Peziza dans le sud-est de la France, avec clef du genre pour la France. Thèse de l'Université de Provence, Marseille, $131 \mathrm{p}$.

Dougoud, R. 2012. Plicariella scabrosa (Pezizales), une discale aux caractères singuliers, dont certains demeuraient encore inconnus. Ascomycete.org 4(1): 5-9.

Dougoud, R., Van Vooren, N. \& Vega, M. 2015. Cupulina montana (Pezizales, Pyronemataceae), un nouveau genre et une nouvelle espèce des montagnes d'Europe. Ascomycete.org 7(2): 39-44

Enderle, M. 2004. Die Pilzflora des Ulmer Raumes. Süddeutsche Verlagsgesellschaft Ulm.

Errotari, Asociación Micológica de Durango. 2007. Peziza gerardii Cooke. [http://www.errotari.com/Micologia/ fotos/5998a.jpg]

Errotari, Asociación Micológica de Durango. 2008. Peziza gerardii Cooke. [http://www.errotari.com/Micologia/especie.php?5998]

Esteve-Raventós, F., Bandini, D., Oërtel, B., González, V., Moreno, G. \& Olariaga, I. 2017-2018. Advances in the knowledge of the Inocybe mixtilis group (Inocybaceae, $\mathrm{Ag}$ aricomycetes), through molecular and morphological studies. Persoonia (en revisión).

Esteve-Raventós, F., Moreno, G., Alvarado, P. \& Olariaga, I. 2016. Unraveling the Inocybe praetervisa group through type studies and ITS data: Inocybe praetervisoides sp. nov. from the Mediterranean region. Mycologia 108: 123-134. http://doi.org/10.3852/15-053

Esteve-Raventós, F., Moreno, G., Bizio, E. \& Alvarado, P. 2015. Inocybe flavobrunnescens (Inocybaceae, Agaricales), a new species in section Marginatae. Mycological Progress 14: 14 https://doi.org/10.1007/s11557-015-1036-0

Favre, J. 1955. Les champignons supérieurs de la Zone Alpine du Parc National Suisse. Resultats des recherches scientifiques entreprises au Parc National Suisse 5: 1-212.

Favre, J. 1960. Catalogue descriptive des champignons supérieurs de la zone subalpine du Parc National Suisse. Resultats des recherches scientifiques entreprises au Parc National Suisse VI: 323-610

Fernández-Vicente, J. \& Undagoitia, J. 2009. Adiciones al catálogo del Parque Natural del Gorbeia y aledaños, y listado de Ascomicetos (Ascomycota) (III). Errotari 6: 118-149.

Fernández-Vicente, J., Undagoitia, J. \& Hidalgo, F. 2007. Algunos ascomicetes interesantes del Parque Natural de Valderejo de Araba, País Vasco (Ascomycota). Yesca 19: 18-34.
Gardes, M. \& Bruns, T. D. 1993. ITS primers with enhanced specificity for basidiomycetes: Application to the identification of mycorrhizae and rusts. Molec. Ecol. 2: 113-118. https://doi.org/10.1111/j.1365-294X.1993.tb00005.x

GBIF Secretariat: GBIF Backbone Taxonomy. doi:10.15468/39omei. (Acceso junio 2017). http://www.gbif. org/species/2550499 y http://www.gbif.org/species/5238503

Gelpi, C. 2016. Peziza succosa / Peziza gerardii. Sociedad Micológica Extremeña. Micoex. [http://micoex.org/2016/09/17/ peziza-succosa/]

Giliberto, M. \& Costiniti, G. 2013. Inocybe tricolor, una rara specie psicotropa, trovata nel Salento. Rivista di Micologia 46(3): 227-231.

Güngör, H., Alli, H. \& Işiloğlu, M. 2013. Three new macrofungi records for Turkey. Turkish Journal of Botany 37: 411-413.

Hansen, K., Læssøe, T. \& Pfister, D. H. 2001. Phylogenetics of the Pezizaceae, with an emphasis on Peziza. Mycologia 93(5): 958-990. https://doi.org/10.2307/3761760

Hansen, K., Sandal, S. K. \& Dissing, H. 1998. New and rare species of Pezizales from calcareous woodlands in Denmark. Nordic Journal of Botany 18(5): 611-626. https://doi. org/10.1111/j.1756-1051.1998.tb01544.x

Heilmann-Clausen, J. \& Christensen, M. 2003. Fungal diversity on decaying beech logs - implications for sustainable forestry. Biodiversity \& Conservation 12: 953-973. https://doi. org/10.1023/A:1022825809503

Heilmann-Clausen, J., Christensen, M. \& Frøslev, T.G., Kjøller, R. 2017. Taxonomy of Tricholoma in northern Europe based on ITS sequence data and morphological characters. Persoonia 38: 38-57. https://doi.org/10.3767/003158517X693174

Heilmann-Clausen, J. \& Walleyn, R . 2007. Some records of wood-inhabiting fungi on Fagus sylvatica in northern Spain. Revista Catalana de Micología 29: 67-80

Helleman, S., Lindemann, U., Baral, H.-O. \& Yates, C. 2013. Micropeziza filicina sp. nov. (Helotiales), a fern inhabiting species of intermediate generic position, with an emendation of the genus Micropeziza Fuckel. Ascomycete.org 5(4): 129-136.

Hirsch, G. 1980. Beiträge zur Kenntnis der Gattung Boudiera Cke. (Pezizales, Ascomycetes) I. Einige Boudiera-Kollection aus der DDR und ihre Stellung zu den bisher bekannten Arten. Wissenschaftliche Zeitschrift der Friedrich-SchillerUniversität Jena/Thüringen 29(4): 640-655.

Holec, J. 2001. The genus Pholiota in central and western Europe. Libri Botanici. Vol. 20. IHW-Verlag. 220pp.

ISCC-NBS 1964. Centroid Color Charts. U.S. Department of Commerce. National Bureau of Standards. Washington D.C.

Jacobson, S. \& Larsson, E. 2012. Inocybe (Fr.) Fr. In: Knudsen, H., Vesterholt, J. (eds.), Funga Nordica. Nordsvamp, Copenhagen, pp. 981-1021.

Katoh, K., Misawa, K., Kuma, K. \& Miyata, T. 2002. MAFFT: A novel method for rapid multiple sequence alignment based on fast Fourier transform. Nucleic Acids Research 30: 3059-3066. https://doi.org/10.1093/nar/gkf436

Kauffman, C. H. 1930. The fungus flora of the Siskiyou mountains in southern Oregon. Papers of the Michigan Academy of Science, Arts and Letters 11: 151-210.

Kearse, M., Moir, R., Wilson, A., Stones-Havas, S., Cheung, M., Sturrock, S., Buxton, S., Cooper, A., Markowitz, S., Duran, C., Thierer, T., Ashton, B., Mentjies, P., \& Drummond, A. 2012. Geneious Basic: an integrated and extendable desktop software platform for the organization and analysis of sequence data. Bioinformatics, 28(12): 1647-1649. http://www.geneious.com/ https://doi.org/10.1093/bioinformatics/bts 199

Knudsen, H. 1997. Clavicoronaceae Corner. In: Hansen, L. \& H. Knudsen (ed.), Nordic Macromycetes vol. 3: 281-282. Nordsvamp. Copenhaguen. 
Korf, R. P. 1988. A compendium of currently valid names for species illustrated in volumes 2 and 3 of Boudier's Icones Mycologicae. Annotated: errata, some necessary changes in citations, and suggested changes based on recent taxonomic information. 48 pp., Ithaca: Privately printed.

Krieglsteiner, G. J. \& Gminder, A. 2001. Die Grosspilze BadenWürttembergs, Bd. 3, Ständerpilze: Blätterpilze I. Ulmer, Germany. $634 \mathrm{pp}$.

Kühner, R. \& Lamoure, D. 1989. Fac-simile du catalogue des Agaricales de la zone alpine du Parc National de la Vanoise et des régions limitrophes (Extrait des travaux scientifiques du P.N. de la Vanoise) Tome XV, abril 1986 - genre Inocybe (Fr.) Fr. p.p. 145-163. Documents Mycologiques 19(76): 31-40.

Kühner, R. 1933. Notes sur le genre Inocybe. 1) Les Inocybe goniosporés (fin). Bulletin trimestriel de la Société Mycologique de France 49: 81-121.

Kühner, R. 1955a. Compléments à la "Flore Analytique". V) Inocybe léiosporés cystidiés. Espèces nouvelles ou critiques. Bulletin de la Société des Naturalistes d'Oyonnax 9 (Mém. Hors-sér. 1): 3-95.

Kühner, R. 1955b. Compléments à la "Flore Analytique". VI) Inocybe goniosporés et Inocybe acystidiés. Espèces nouvelles ou critiques. Bulletin trimestriel de la Société Mycologique de France 71(3): 169-201.

Kuo, M. 2007, November. Pholiota squarrosoides. MushroomExpert.com (Acceso Junio 2017): [http://www.mushroomexpert.com/pholiota squarrosoides.html]

Kuyper, T. W. 1995. Clitocybe (Fr.) Staude, Schwämme Mitteldeustchl.: XXVIII, 122. 1857. In: Bas, C.; Kuyper, T. W. \& Noordeloos, M. E. (eds.): Flora Agaricina Neerlandica. Vol. 3. CRC press. pp. 42-62

Kuyper, T. W. 1985. Studies in Inocybe - II. Persoonia 12(4): 479-482.

Kuyper, T. W. 1986. A revision of the genus Inocybe in Europe I. Subgenus Inosperma and the smooth-spores species of subgenus Inocybe. Persoonia Supplement 3(1): 1-247.

Lecomte, M. \& Legros, J. P. 2011. Lactarius fraxineus Romagnesi une espèce moins rare qu'on ne le suppose! Bulletin de l'Association des Mycologues Francophones de Belgique. 4: 34-39

Llistosella, J. 1991. Russulaceae, notes florístiques. Butlletí Societat Catalana de Micologia 14-15: 67-76.

Lowen, R. \& Dumont, K. P. 1984. Taxonomy and nomenclature in the genus Calycellina (Hyaloscyphaceae). Mycologia 76(6): 1003-1023. https://doi.org/10.2307/3793016

Lutzoni, F., Kauff, F., Cox, C. J., McLaughlin, D., Celio, G., Dentinger, B., Padamsee, M., Hibbett, D., James, T. Y., Baloch, E., Grube, M., Reeb, V., Hofstetter, V., Schoch, C., Arnold, E., Miadlikowska, J., Spatafora, J., Johnson, D., Hambleton, S., Crockett, M., Shoemaker, R., Sung, G.-H., Lücking, R., Lumbsch, T., O’Donnell, K., Binder, M., Diederich, P., Ertz, D., Gueidan, C., Hansen, K., Harris, R. C., Hosaka, K., Lim, Y.-W., Matheny, B., Nishida, H., Pfister, D., Rogers, J., Rossman, A., Schmitt, I., Sipman, H., Stone, J., Sugiyama, J., Yahr, R. \& Vilgalys, R. 2004. Assembling the fungal Tree of Life: Progress, classification, and evolution of subcellular traits. American Journal of Botany 91: 1446-1480. https://doi.org/10.3732/ajb.91.10.1446

Malençon, G. \& Bertault, R. 1970. Flore des champignons supérieurs du Maroc. Vol. 1. Institut Scientifique Chérifien et Faculté des Sciences, Rabat.

Medardi, G. 2006. Atlante fotografico degli Ascomiceti d'Italia. Trento. A.M.B. Fondazione Centro Studi Micologici, $454 \mathrm{pp}$.

Medardi, G. 2007. Boudiera dennisii, Discinella boudieri and Rutstroemia microsperma found in Austria. Österreichische Zeitschrift für Pilzkunde 16: 5-10.
Miller, M. A., Pfeiffer, W., Schwartz, T. 2010. Creating the CIPRES Science Gateway for inference of large phylogenetic trees. In: Proceedings of the Gateway Computing Environments Workshop (GCE), 14 Nov.: 1-8. New Orleans, LA, USA. https://www.phylo.org/. https://doi.org/10.1109/ GCE.2010.5676129

Moreno-Arroyo, B. (Coordinador). 2004. Inventario Micológico Básico de Andalucía. Consejería de Medio Ambiente, Junta de Andalucía, 678 pp. Córdoba.

Morozova, I. I. 2014. New records of discomycetous fungi from Ukraine. Turkish Journal of Botany 38: 398-405. https://doi. org/10.3906/bot-1301-14

Murata, H., Ota, Y., Yamada, A., Ohta, A., Yamanaka, T. \& Hitoshi, N. 2013. Phylogenetic position of the ectomycorrhizal basidiomycete Tricholoma dulciolens in relation to species of Tricholoma that produce "matsutake" mushrooms. Mycoscience 54(6): 438-443. https://doi.org/10.1016/ j.myc.2013.02.003

Pärtel, K., Baral, H.-O., Tamm, H. \& Põldmaa, K. 2017. Evidence for the polyphyly of Encoelia and Encoelioideae with reconsideration of respective families in Leotiomycetes. Fungal Diversity 82: 183-219. https://doi.org/10.1007/ s13225-016-0370-0

Peric, B. 2008. Pulvinula convexella, espèce nouvelle pour la flore mycologique du Monténégro. Bulletin trimestriel de la Fédération Mycologique Dauphiné-Savoie 188: 23-30.

Petersen, J. H. 2017. Calycellina chlorinella (Ces.) Dennis. Svampeatlas 2.0. [https://svampe.databasen.org/taxon/11269]

Pfister, D. H. 1976. A synopsis of the genus Pulvinula. Occasional papers of the Farlow Herbarium of cryptogamic botany $9: 1-19$

Polhorský, A. 2016. Plicariella scabrosa (Cooke) Spooner. Nahuby.sk. http://www.nahuby.sk/atlas-hub/Plicariella-scabrosa/drsnociaska/kustrebka/ID14158.

Rambaut, A. 2007. FigTree, version 1.4.3. Available from $\mathrm{http} / /$ tree.bio.ed.ac.uk/software/figtree/

Rambaut, A., Suchard, M. A., Xie, D., \& Drummond, A. J., 2014. Tracer v1.6.

Ribes, M. A., Hernanz, J., Tello, S., Campos, J. C., Paz, I., Sánchez, G., Pancorbo, F. y Serrano, F. 2016. Contribución al conocimiento de la biodiversidad fúngica del Parque Nacional de Ordesa y Monte Perdido I. Pirineos. 171. e021. doi: https://doi.org/10.3989/Pirineos.2016.171005

Ribollet, P. 2008. Récoltes intéressantes. Cahiers mycologiques Nantais 20: 37.

Rivas-Martínez, S. \& Losa-Quintana, J. M. 1969. Comportement sociologique des champignons des dunes littorales du fleuve Llobregat (Barcelone). Bulletin trimestriel de la Société Mycologique de France 85(2): 235-244.

Rocabruna, A. \& Tabarés. M. 2001. Aportación al conocimiento del los hongos del macizo montañoso del Montseny (Cataluña). III. Revista Catalana de Micología 23: 25-36.

Rogmanesi, H. 1963. Une espèce nouvelle de lactaire: Lactarius fraxineus. Bulletin trimestriel de la Société Mycologique de France 79(4): 471-475.

Ronquist, F., Teslenko, M., Van der Mark, P., Ayres, D. L., Darling, A., Höhna, S., Larget, B., Liu, L., Suchard, M. A. \& Huelsenbeck, J. P. 2012. MrBayes 3.2: Efficient Bayesian Phylogenetic Inference and Model Choice Across a Large Model Space. Systematic Biology, 61(3): 539-542. https:// doi.org/10.1093/sysbio/sys029

Rubio, E. 2007. Peziza gerardii Cooke. [https://www.asturnatura.com/fotografia/setas-hongos/peziza-gerardiicooke-1/2799.html]

Rubio, E. 2009. Boudiera tracheia (Rehm ex Gamundí) Dissing \& T. Schumach. [https://www.asturnatura.com/fotografia/ setas-hongos/boudiera-tracheia-rehm-ex-gamundi-dissingt-schumach-2/7558.html] 
Rubio, E., Suárez, A., Miranda, M. A. \& Linde, J. 2006. Catálogo provisional de los macromicetos (setas) de Asturias. RIDEA. 210 pp. [https://www.asturnatura.com/articulos/revista/catalogohongosast.pdf]

Sánchez, F., Esteve-Raventós, F., Honrubia, M. \& Torres, P. 1995. Hongos ectomicorrícicos en el Maestrazgo. III. Inocybe (Fr.) Fr. Cryptogamie. Mycologie 16(4): 321-335.

Santamaría Rodríguez, N. 2009. Peziza moseri, Peziza bovina, Peziza gerardii, Octospora roxheimii, Geopyxis carbonaria y Geopyxis majalis, seis ascomycetes primaverales recolectados en la Sierra de Neila (Burgos). Errotari 6: 73-90.

Schild, E. (1971). Clavariales. Fungorum rariorum Icones Coloratae, $5: 1-144$

Schumacher, T. 1979. Notes on taxonomy, ecology, and distribution of operculate discomycetes (Pezizales) from river banks in Norway. Norwegian journal of botany 26: 53-83.

Smith, A. H. \& Hesler, L. R. (1968). The North American species of Pholiota. Web site: [http://quod.lib.umich.edu/f/ fung 1 tc/agj9559.0001.001/207? didno=AGJ9559.0001.001; page $=$ root; rgn $=$ full + text; ;ize $=100 ;$ view $=$ image $]$

Stangl, J. \& Veselsky, J. 1979. Inocybe pyriodora (Pers. ex Fr.) Kummer und die Verwandten (Beiträge zur Kenntnis seltenerer Inocyben. Nr. 14). Ceská Mykologie 33(2): 68-80.

Stangl, J. 1989. Die Gattung Inocybe in Bayern. Hoppea 46: 5-388.

Stijve, T., Klán, J., \& Kuyper, T. W. 1985. Occurrence of psilocybin and baeoscystin in the genus Inocybe (Fr.) Fr. Persoonia 12(4): 469-473.

Stridvall, L., Stridvall, A., \& Jacobson, S. 1989. Släktet Inocybe I Sverige. En preliminary översikt. Jordstjärnan 10(2): 29-76.

Sukumaran, J., \& Holder, M. T. 2010. DendroPy: a Python library for phylogenetic computing. Bioinformatics 26:1569$1571 \mathrm{https} / / /$ doi.org/10.1093/bioinformatics/btq228

Tello, S. 2015. Aportaciones micológicas 22. Pulvinula convexella. Micobotánica-Jaén 10(1): 161-198.
Van Vooren, N. \& Moyne, G. 2012. Plicariella flavovirens comb. nov. (Ascomycota, Pezizales), une pézize remarquable. Ascomycete.org 4(1): 11-14.

Van Vooren, N. 2006. Ascomycètes, saison 2005. Bulletin trimestriel de la Fédération Mycologique Dauphiné-Savoie 183: 11-24.

Van Vooren, N. 2010. Description de Peziza gerardii (Ascomycota, Pezizales) et présentation d'une récolté à petites spores. Mycologia Montenegrina 12: 33-40.

Van Vooren, N. 2015. Plicariella scabrosa. 2000 Pezizales. En línea en [http://www.ascomycete.org/2000Pezizales/TaxonView/tabid/129/ArticleId/785/language/en-US/Plicariella-scabrosa. aspx?mapid=398]

Vauras, J. \& Huhtinen, S. 1986. Finnish records on the genus Inocybe. Ecology and distribution of four calciphilous species. Karstenia 26: 65-72.

Vesterholt, J. 2008. Clitocybe. - In: Knudsen, H. \& Vesterholt, J. (eds.): Funga Nordica, 392-403. Nordsvamp, Copenhagen.

Vila, J., Esteve-Raventós, F., Llistosella, J. \& Llimona, X. 2001. Contribución al conocimiento de los hongos del piso alpino de los Pirineos de Cataluña. III. Revista Catalana de Micología 23: $51-65$

White, T. J., Bruns, T., Lee, S. \& Taylor, J. 1990. Amplification and direct sequencing of fungal ribosomal RNA genes for phylogenetics. In: Innis, M., Gelfand, J., Sninsky, J. \& White, T. (eds.), PCR protocols: A guide to methods and applications. Orlando: Academic Press. pp. 315-322. https://doi. org/10.1016/B978-0-12-372180-8.50042-1

Yao, Y.-J. \& Spooner, B. M. 1996. Notes on British species of Pulvinula, with two newly recorded species. Mycological Research 100(7): 883-884. https://doi.org/10.1016/ S0953-7562(96)80040-2

Zwick1, D. J. 2006. Genetic algorithm approaches for the phylogenetic analysis of large biological sequence datasets under the maximum likelihood criterion. Ph.D. dissertation, The University of Texas at Austin. 